\begin{abstract}
Title of Document:

EMOTION REGULATION MEDIATES THE RELATIONSHIP BETWEEN ADHD AND DEPRESSIVE SYMPTOMS IN YOUTH.
\end{abstract}

Karen E. Seymour, Ph.D., 2010

Directed By:

Associate Professor Andrea M. ChronisTuscano, Ph.D., Department of Psychology

A significant body of longitudinal research suggests increased rates of mood disorders as well as depressive symptoms in youth diagnosed with attentiondeficit/hyperactivity disorder (ADHD) in contrast to non-ADHD comparison youth. Furthermore, individuals with co-occurring ADHD and mood disorders experience more serious impairments and worse outcomes than those with either disorder alone. However, few studies have examined the underlying mechanisms which may better elucidate the relationship between ADHD and depression in youth. The present study examined emotion regulation as a mediator in the relationship between ADHD and depressive symptoms in youth. Moreover, effortful control was examined as a mediator in the relationship between ADHD and emotion regulation. Participants included 69 youth between the ages of 10 and 14 with $(n=37)$ and without $(n=32)$ DSM-IV ADHD. Parent and youth ratings of depressive symptoms and emotion regulation were collected, and youth completed computerized measures of effortful 
control. Results demonstrated significant differences between youth with and without ADHD on depressive symptoms and emotion regulation ability, but not effortful control. Furthermore, emotion regulation fully mediated the relationship between ADHD and depressive symptoms. Clinical implications and limitations are discussed. Keywords: Attention-deficit/hyperactivity disorder, emotion regulation, depression, distress tolerance 


\title{
EMOTION REGULATION MEDIATES THE RELATIONSHIP BETWEEN ADHD AND DEPRESSIVE SYMPTOMS IN YOUTH.
}

\author{
By \\ Karen E. Seymour \\ Dissertation submitted to the Faculty of the Graduate School of the \\ University of Maryland, College Park, in partial fulfillment \\ of the requirements for the degree of \\ Doctor of Philosophy \\ 2010
}

Advisory Committee:

Associate Professor Andrea M. Chronis-Tuscano, Chair

Professor Carl Lejuez

Associate Professor Michael R. Dougherty

Assistant Professor Stacey B. Daughters

Assistant Professor Natasha Cabrera 
(C) Copyright by

Karen E. Seymour

2010 


\section{Dedication}

This work is dedicated to my family and friends whose undying love and support made the completion of this degree possible. I would especially like to thank my husband Brian, parents Larry and Donna Seymour, the Shirlington crew, Tutu, Rachel, girls of the ADHD lab, and all of the other people who have made the accomplishment of this goal possible. 


\section{Acknowledgements}

Several people were instrumental in the completion of this study. First, the author would like to acknowledge the contributions of my academic advisor, Dr. Chronis, and the other members of my dissertation committee, Drs. Lejuez, Dougherty, Daughters, and Cabrera. Furthermore, the author would like to acknowledge the efforts of Thorhildur Halldorsdottir, Kristian D. Owens, and Talia Sacks who served as research assistants on this project. Without their diligence and extraordinary efforts, this project would not have been possible. Finally, the author acknowledges the parents and youths who kindly participated in this study. 


\section{Table of Contents}

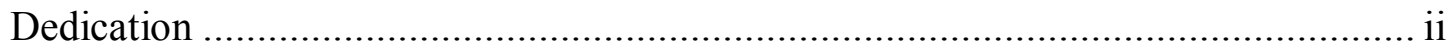

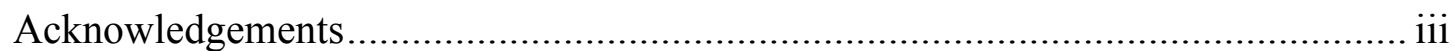

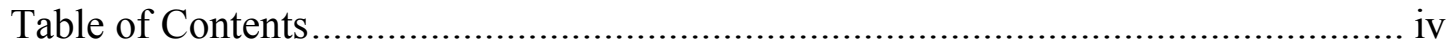

List of Tables ............................................................................................. vi

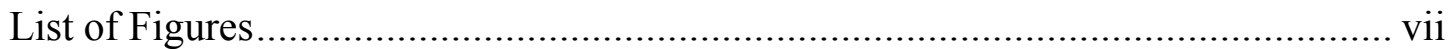

Chapter 1: Introduction ............................................................................... 1

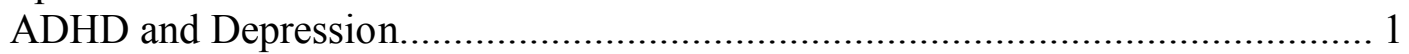

Depression in Children and Adolescents ..................................................... 1

Impairments Associated with Comorbid ADHD and Depression ................. 9

Limitations of Previous Research ............................................................. 11

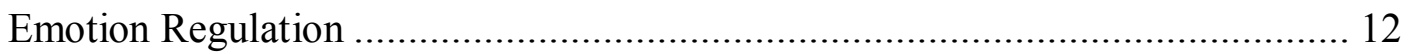

Function and Definition ................................................................................ 12

The Role of Attentional and Inhibitory Control in ER................................ 16

Effortful Control in Youth with ADHD: A Primary Deficit......................... 19

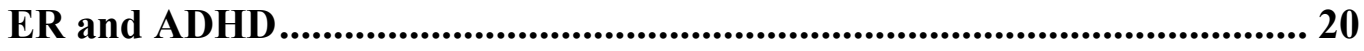

ADHD and Depression ............................................................................... 22

Theoretical Models for the Relationship between Effortful Control, ER and

Depression .................................................................................................. 24

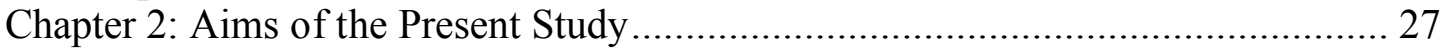

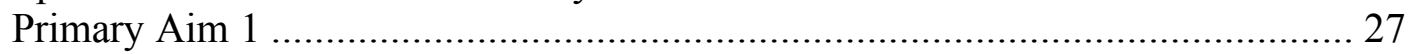

Hypothesis 1............................................................................................ 27

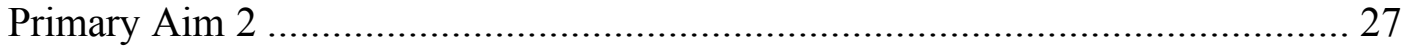

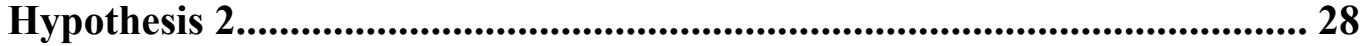

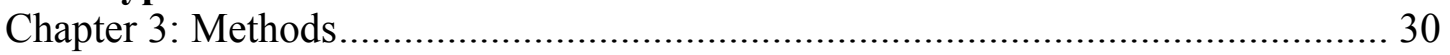

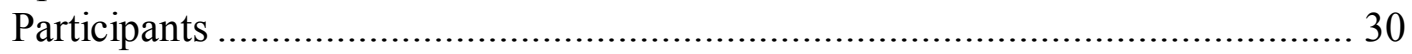

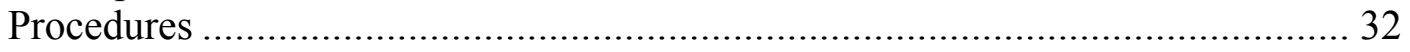

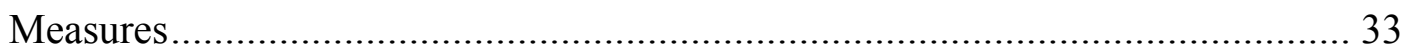

Assessment of Youth ADHD ........................................................................ 33

Assessment of Youth Depression ...................................................................... 35

Emotion Regulation....................................................................................... 38

Distress Tolerance .................................................................................. 40

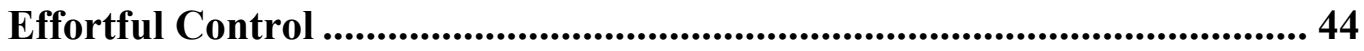

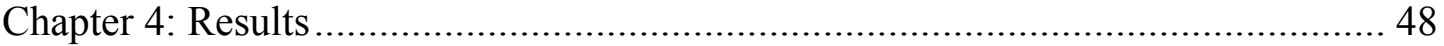

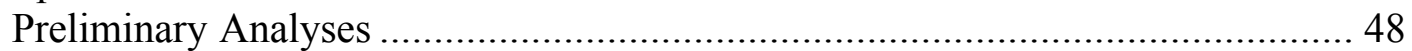

Variable Examination ................................................................................. 48

Data Reduction ............................................................................................ 49

Manipulation Check.................................................................................... 51

Comparison of Groups on ADHD, ODD, and CD Symptoms and Overall Impairments ................................................................................................... 52

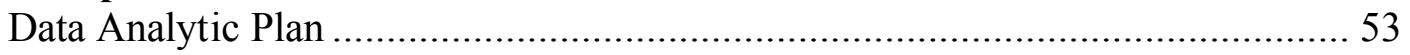

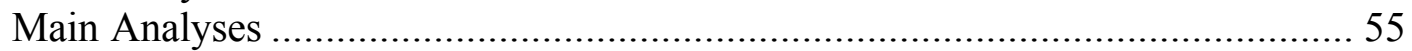

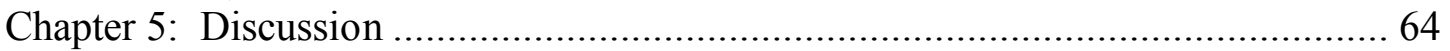

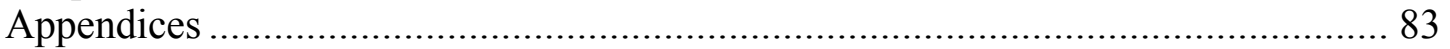




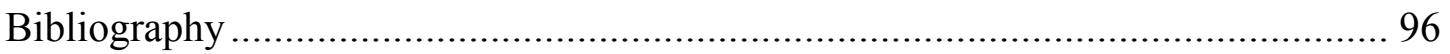




\section{List of Tables}

Table 1 Youth and Parent Participant Demographics

Table 2 Correlation Matrix of Independent, Dependent, Mediator and Demographic Variables

Table 3 Depressive symptoms, ER, DT and Effortful Control by Group

Table 4 Fit statistics for Model 1

Table 5 Structural Equations for Model 1

Table 6 Fit statistics for Model 2

Table 7 Structural Equations for Model 2 


\section{List of Figures}

Figure 1 The relationship between Effortful Control, ER and Depression

Figure 2 Proposed Path Analysis- Model 1 (using Effortful Control and ER as mediators)

Figure 3 Proposed Path Analysis- Model 2 (using Effortful Control and DT as the mediators)

Figure 4 Disposition of participants

Figure 5 Computer Display of the BIRD

Figure 6 Computer display for the MTPT-C

Figure $7 \quad$ Model 1 with paths defined

Figure $8 \quad$ Model 2 with paths defined

Figure $9 \quad$ Path analysis indexes for Model 1

Figure $10 \quad$ Revision of Model 1

Figure 11 Model 2 with standardized and unstandardized beta weights 


\section{Chapter 1: Introduction}

\section{$\underline{A D H D \text { and Depression }}$}

Depression in Children and Adolescents ${ }^{1}$

Depression has an estimated prevalence of $2 \%$ in children and $4 \%-8 \%$ in adolescents (Avenevoli, Knight, Kessler, \& Merikangas, 2008; Birmaher, Ryan, Williamson, et al., 1996; Kessler, Avenevoli, Ries-Merkangas, 2001; Shaffer, Fisher, Dulkan, et al., 1996). Approximately $15 \%-20 \%$ of youth will experience a depressive episode by mid-adolescence (Birmaher, et al., 1996; Lewinsohn, Hops, Roberts, Seeley \& Andrews. 1993). Rises in depressive symptoms during adolescence may be attributed to increases in stressful life events and physiological and psychological changes during this developmental period (Bond, Toumbourou, Thomas, Catalano, \& Patton, 2005; Kim, Conger, Elder, \& Lorenz, 2003; Rhode, Beevers, Stice, O’Neil, 2009). Adolescent-onset depression most often has a chronic, episodic course which continues into adulthood and is associated with substantial life-long morbidity (Copeland, Shanahan, Costello, \& Angold, 2009; Weissman, Wolk, Goldstein, Moreau, Adams \& Greenwald, 2000; Weissman, Wolk, Wickramaratne, Goldstein, Adams \& Greenwald, 1999).

A number of detrimental outcomes are associated with depression in youth.

First, depression is a major risk factor for suicide (Apter \& King, 2006; Bridge et al.,

\footnotetext{
${ }^{1}$ The child and adolescent literature on both ADHD and depression often combines children and adolescents within one sample (e.g., with participants ranging in age from 7-16 years old; Bird et al., 1988; Blackman et al., 2005; Milberger et al., 1995). In order to avoid excessive wording, the author will refer to this population as "youth" with the understanding that the age range often includes adolescents as well. However, samples that are strictly either child or adolescent will be referred to as such to avoid confusion.
} 
2005; Jacobson \& Gould, 2009; Lewinsohn et al., 2001), and depressed youth have a thirty-fold increased risk of completed suicide (Kovacs, 1996; Kovacs \& Goldston, 1991). In fact, suicide is the third leading cause of death for youth between the ages of 15 to 24 years and the sixth leading cause of death for those between the ages of 5 and 14 (Anderson \& Smith, 2003). Additionally, depression in youth is associated with a number of negative outcomes including: decreased school performance, highrisk sexual behavior (including early pregnancy), increased physical illness, increased risk of substance abuse, and impaired social relationships, making it a significant public health concern (Birmaher, et. al., 2004; Kaminer \& Bukstein, 2008; KeenanMiller, Hammen, \& Brennan, 2007; Kovacs, 1996; Rice, Lifford, Thomas, \& Thapar, 2007; Rohde, Lewinsohn \& Seeley, 1994; Stolberg, Clark \& Bongar, 2002).

In recent years, it has been argued that comorbidity in youth is the most pressing issue in developmental psychopathology research and practice (Angold, Costello, \& Erkanli, 1999; Jensen, 2003). Specifically, Lilienfeld (2003) called for the systematic exploration of potential mechanisms involved in the development of comorbid conditions. Of particular relevance to the current study is the exploration of processes that underlie and mediate the relationship between attentiondeficit/hyperactivity disorder (ADHD) and depression in youth.

Moderate to high rates of comorbidity between ADHD and mood disorders in youth have been established in cross-sectional studies including both community (Anderson, Williams, McGee \& Silva, 1987; Angold, Costello \& Erkanli, 1999; Bauermeister et al., 2007; Bird, Canino, Rubio-Stipec, Gould, Ribera, Sesman et al., 1988; Blackman, Ostrander \& Herman, 2005) and clinical samples (Daviss, 2009; 
Elia, Ambrosini \& Wade, 2008; Milberger, Biederman, Faroane, Murphy \& Tsuang, 1995; Souza, Pinheiro, Denardin, Mattos, \& Rohde, 2004). Cross-sectional studies of community-based samples suggest that the co-occurrence rates of Attention Deficit Disorder (ADD, DSM-III-R, American Psychological Association, 1987) and/or Attention Deficit/Hyperactivity Disorder (ADHD, DSM-IV, American Psychological Association, 2000) and mood disorders range from $0 \%$ (McGee et al., 1990) to $75 \%$ (Biederman, Newcorn, Spirch,1991) (for reviews see Angold \& Costello, 1993, 1999; Jensen, Martin \& Cantwell, 1997). Research examining DSM-III prevalence rates in youth ages 4 to 16 years-old in Puerto Rico found that $17 \%$ of youth who met criteria for ADD also met criteria for an affective disorder (Bird et al., 1988).

In another study conducted by Blackman and colleagues (2005), results suggested that the rate of depression in children with ADHD was greater than expected in the general population. Specifically, $9 \%$ of children with ADHD in the sample were diagnosed with depression, whereas prevalence rates of depression in epidemiological studies suggest rates of only $2 \%$ for school-age children and approximately $5 \%$ for adolescents (see Kashani \& Sherman, 1988; Weller, Weller, \& Svadjian, 1996). These increased rates in children with ADHD are stunning in light of the stringent diagnostic criteria employed for depression in this study (i.e., in order to be included in the "depressed" group, children with ADHD had to: (1) receive a score of at least 12 on the CDI and (2) meet full criteria for either dysthymia or major depression according to a structured interview (Blackman et al., 2005).

Additionally, a meta-analysis of 21 epidemiological studies found that the median odds ratio for the co-occurrence of ADHD and depression is $5.5(95 \% \mathrm{CI}=$ 
3.5-8.4), such that the odds of a youth with ADHD also being diagnosed with depression are increased more than five-fold relative to youth without ADHD (Angold, Costello \& Erklanli, 1999). Greater than expected rates of comorbid ADHD and depression have even been demonstrated in youth as young as 4-years-old (Lavigne, LeBailly, Hopkins, Gouze \& Binns, 2009).

A number of factors have been shown to impact the variability in reported rates of comorbidity ADHD and depression, including the nature of the sample (i.e. community vs. clinical) and definitions of the constructs of ADHD and depression. For example, comorbidity tends to be lower in community-based or epidemiological samples (e.g. Anderson et al., 1987; Bird et al., 1988, McGee, et al., 1990) in comparison to clinical samples (Biederman, Faraone, et al., 1990; Butler et al., 1995). Additionally, in community-based samples, participant age and ADHD severity have been found to predict higher odds ratios, with youth ages 10 and older, and those having more ADHD symptoms being at increased risk (Angold et al., 1999). Furthermore, research which utilizes more inclusive diagnostic categories (i.e., all affective disorders, rather than just major depression; dimensional vs. categorical/diagnostic examination of depression, etc.) may reveal higher prevalence rates (Jensen et al., 1997).

Cross-sectional studies examining the co-occurrence of ADHD and depression in clinically-referred youth suggest higher rates of comorbidity than those found in community samples. Specifically, in clinical samples of youth between the ages of 5 to 18 years, comorbidity rates of ADHD and depression range from $29 \%-39 \%$ (Daviss, 2009; Elia, et al., 2008; Milberger, et al., 1995; Souza, et al., 2004). In a 
large clinical sample of youth ages 6 to 18 years, Elia and colleagues (2008) found a comorbidity rate of $21.6 \%$ for ADHD and Depression/Dysthymia. Subgroup analyses revealed that comorbidity with Depression/Dysthymia was highest in the ADHDCombined Type (ADHD-CT) group, followed by ADHD-Primarily Inattentive Type (ADHD-IA), and then ADHD-Primarily Hyperactive/Impulsive Type (ADHD-HI) ${ }^{2}$ (Elia, Ambrosini \& Wade, 2008). Additionally, high comorbidity rates remain even when researchers control for the overlapping symptoms of ADHD and depression, such as difficulty concentrating and psychomotor agitation. For example, Milberger et al. (1995) examined the overlap of DSM-III-R ADHD and major depression in 6 to 17 year old boys and found that, using the subtraction method to examine comorbidity (i.e., omitting overlapping symptoms), $79 \%$ of participants with ADHD maintained their initial diagnosis of major depression despite the removal of overlapping items. These results suggest that high rates of comobid ADHD and depression are not solely due to overlapping symptoms.

Prospective longitudinal studies examining the development of depression in children with ADHD followed into adolescence or adulthood provide mixed evidence for the prevalence of this comorbidity. A number of studies have suggested that children with ADHD do not demonstrate increased rates of depression during adolescence and young adulthood as compared to children without ADHD (Bagwell \& Molina, 2006; Claude \& Firestone, 1995; Gittleman, Mannuzza, Shenker, \&

\footnotetext{
${ }^{2}$ DSM-IV diagnostic criteria specify the following requirements for various subtypes of ADHD: for a diagnosis of ADHD-IA, youth are required to have 6/9 symptoms of inattention; for a diagnosis of ADHD-HI, youth must have 6/9 symptoms of hyperactivity/impulsivity; and for a diagnosis of ADHDCT youth are required to meet both of the above criteria. In all subtypes, youth must also present with impairments in at least two settings and onset of symptoms must be present before the age of 7-yearsold (APA, 1994).
} 
Bondura, 1985; Manuzza \& Gittleman, 1984; Mannuzza \& Klein, 1991, 1998). For example, Bagwell and Molina (2006) followed both youth first diagnosed with ADHD between the ages of 5 to 17 years-old and control youth until mid- to lateadolescence. Results suggested no differences between groups on rates of mood disorders in mid- to late-adolescence (Bagwell \& Molina, 2006). For youth with ADHD, childhood externalizing symptoms and social problems were predictive of mood disorders (Bagwell \& Molina, 2006). However, one significant limitation of the previous research should be noted. Many of the studies that demonstrated null findings included only male participants (Claude \& Firestone, 1995; Gittleman et al., 1985; Mannuzza \& Klein, 1991,1998), which is problematic in light of the gender differences in rates of depressive disorders beginning in adolescence (e.g., NolenHoeksema \& Girguas 1994, Nolen-Hoeksema, 2002, Hilt \& Nolen-Hoeksema, 2009). In contrast, more recent longitudinal research has suggested increased rates of mood disorders (Biederman, Ball, Monuteaux, Mick, Spencer, McCreary, et al., 2008; Green et al., 1997; Fisher, Barkley, Smallish \& Fletcher, 2002; Biederman, Monuteaux, Mick, Spencer, Wilens, Silva, et al., 2006; Monuteaux, Faraone, Gross \& Biederman, 2007) and depressive symptoms (Hinshaw et al., 2006; Lahey et al., 2007; Lee et al., 2008) in children diagnosed with ADHD in comparison to children without ADHD. Greene and colleagues (1997) examined 6-17 year-old boys with and without $\mathrm{ADHD}$ and found that boys with ADHD demonstrated greater levels of unipolar depression than non-ADHD comparison boys at the 4-year follow-up. In a femaleonly sample, ADHD diagnosis between the ages of 6 to 18 years independently predicted one-year prevalence rates of Major Depressive Disorder (MDD) at 5-year 
follow-up (Monuteaux, Faraone, Gross \& Biederman, 2007). Similarly, females with ADHD between the ages of 6 to 12 were 5.1 times more likely to experience MDD than non-ADHD comparison females at 5-year follow-up (Biederman, Ball, et al., 2008).

One limitation of the aforementioned research has been the reliance on singlesex samples. However, research involving samples of both males and females with and without ADHD has also yielded significantly higher rates of lifetime MDD during adulthood in youth with ADHD in comparison to non-ADHD controls (Biederman, Monuteaux, et al., 2006; Biederman et al., 1996; Fisher, Barkley, et al., 2002). Therefore, while initial longitudinal studies examining the increased risk for depressive disorders in youth with ADHD over non-ADHD comparison youth suggested no differences, recent studies provide more compelling evidence for the increased risk for depressive disorders faced by youth with ADHD in comparison to their non-ADHD peers.

In addition to being at increased risk for diagnosable depression, longitudinal studies have also suggested that youth with ADHD are at an increased risk for elevated symptoms of depression relative to non-ADHD comparison youth. Results from a 5-year follow-up study comparing females with ADHD-IA, ADHD-CT, and non-ADHD comparison females (ages 6 to 12 at baseline) suggested that, while females with ADHD were not at increased risk for MDD diagnoses, females with both ADHD subtypes exhibited higher scores on parent and teacher reports of internalizing symptoms than non-ADHD comparison females (Hinshaw, Owens, Sami, \& Fargeon, 2006). Additionally, females in the ADHD-CT group reported 
higher levels of depression than non-ADHD comparison females. Lahey and colleagues (2007) conducted an 8-year follow-up study of young children, ages 4 to 6, which evaluated children who had been diagnosed with ADHD and non-ADHD comparison children on a number of outcomes including depressive symptoms. Participants were assessed annually, and results suggested that, in comparison to the non-ADHD group, both boys and girls with ADHD had higher levels of youth- and parent-reported depressive symptoms during adolescence, even after controlling for baseline internalizing and conduct symptoms. Furthermore, a steeper increase in depressive symptoms from baseline to wave 9 was demonstrated for girls with ADHD in comparison to boys with ADHD. Taken together, cross-sectional and longitudinal studies seem to suggest that youth diagnosed with ADHD may be at increased risk for mood disorders as well as increased risk for elevated symptoms of depression in comparison to non-ADHD youth, which highlights the need for a more comprehensive understanding of mechanisms which explain this comorbidity.

With regard to the temporal relationship between ADHD and depression, research suggests that ADHD most often precedes the onset of depression in youth (Costello, Foley, Angold, 2006; Rohde, Lewinsohn, Seeley, 1993). In order to meet DSM-IV diagnostic criteria for ADHD, symptoms and impairment must occur before the age of seven; therefore, by definition, the onset of ADHD occurs early in development (American Psychological Association, 1994). In contrast, depression appears to have a later onset and increases in prevalence from late childhood to adolescence (Kessler, 2002). By mid-adolescence, $15-20 \%$ of youth will have experienced a depressive episode (Birmaher et al., 1996; Lewinsohn et al., 1993). In 
fact, one-year prevalence rates of clinical depression increase six-fold from $3 \%$ to $18 \%$ between the ages of 15 to 18 years (Hankin, Abramson, Moffitt, Silva, McGee, \& Angell, 1998). Given that ADHD occurs early in development, while depression has a later onset, ADHD may be considered a developmental precursor to depression. In fact, longitudinal results from the Great Smoky Mountain Study which examined psychiatric comorbidity in youth suggest that the overall prevalence of any psychiatric disorder is highest between the ages of 9 to 10 years (Costello, Mustillo, Erklani, Keeler \& Angold, 2003). Additionally, elevations in depressive symptomatology are noticeable by the age of 12 and reach diagnostic levels by age 13 (Angold, Erkanji, Silberg et al., 2003). Therefore, given the temporal relationship between ADHD and depression, the developmental period of late childhood to early adolescence appears to be a critical period of increased risk for examining the overlap of ADHD and depression.

Impairments Associated with Comorbid ADHD and Depression

The combination of ADHD and depressive disorders results in more serious impairments and worse outcomes than those resulting from either disorder alone. Comorbidity, in general, is associated with increased risk for behavioral disinhibition, substance use, violence, and suicide, and tends to be treatment refractory (Capaldi, 1992; Rohde, Lewinsohn, \& Seeley, 1991). Specifically, youth with ADHD and depression require significantly more intensive interventions, experience higher levels of stress, are at greater risk for developing bipolar disorder and Oppositional Defiant Disorder (ODD), and have more psychosocial and familial problems than youth with ADHD alone (Biederman et al., 1996; Jensen et al., 1993). Moreover, a recent review 
suggests that a diagnosis of comorbid ADHD and depression, as opposed to a diagnosis of ADHD alone, significantly worsens the prognosis for an individual (Daviss, 2008). Maternal anxiety and depression are more common in families of youth with ADHD and Dysthymic Disorder (DD) in comparison to families of youth with ADHD alone, which may also contribute to children's symptoms, impairment, and overall levels of environmental stress (Harris, Boots, Talbot, \& Vance, 2006). Furthermore, youth with ADHD and depression have more negative self-perceptions than youth with ADHD alone (Schmidt, Stark, Carlson, \& Bruno, 1998).

In comparison to youth with MDD alone, youth with comorbid ADHD and depression demonstrate an earlier onset and longer duration of depressive episodes (Biederman, et al., 2008), increased risk for recurrence (Rohde et al., 2001), and higher rates of suicidality and psychiatric hospitalization (Biederman et al., 2008). Of particular concern is research suggesting that children with comorbid mood disorders and ADHD are three times more likely to complete suicide that those diagnosed with either disorder alone (James, Lai, \& Dahl, 2004). Taken together, these increased $\underline{\text { impairments and deleterious outcomes underscore the need for a more comprehensive }}$ understanding of processes which underlie the relationship between ADHD and depression.

To date, only one study has examined factors that are associated with the development of depression among youth with ADHD. Ostrander and Herman (2006) examined the role of parental behavior management (i.e., parent-rated use of effective and consistent positive reinforcement and monitoring) and youth locus of control (i.e., the extent to which a youth perceived that success or failure was within his/her 
control) as mediators of the relationship between ADHD and depression in a large community sample of 8 to 10 year-old youth with and without ADHD. Parent behavior management partially or fully mediated the relationship between ADHD and depression across age groups, whereas locus of control partially or fully mediated the relationship for youth older than age 9 .

\section{Limitations of Previous Research}

Ostrander and Herman's (2006) work provides an initial investigation of potential factors underlying the development of depression in youth with ADHD; however, a significant limitation must be acknowledged. Noticeably absent from this work is the role of emotion regulation (ER) in the relationship between ADHD and depression in youth. Abundant empirical evidence from the fields of neuroscience (Davidson, 1998), developmental psychology (Zeman, Shopman \& Suveg, 2002), and personality psychology (Clark, 2005) has linked poor ER to depression in adults and youth. ER may be particularly important in understanding the development of depression in youth with ADHD because research supports the need for both attentional control and inhibitory control in the regulation of emotion (Calkins \& Dedmon, 2000; Calkins, Dedmon, Gill, Lomax, \& Johnson, 2002; Eisenberg \& Spinrad, 2004). Moreover, theoretical models of ADHD posit that emotion regulation is a core deficit in youth with ADHD due to their difficulties with attentional and inhibitory control (Barkley, 1997). Taken together, this research suggests that ER and attentional/inhibitory control may be important processes to examine in the relationship between ADHD and depression in youth. Yet to date, ER has not been examined as a mediator in the relationship between ADHD and depression in youth. Furthermore, no research has 
examined attentional/inhibitory control as the mechanism by which youth with ADHD may have deficits in ER ability.

\section{Emotion Regulation}

Function and Definition

It has been suggested that problems in the regulation of emotion may underlie maladaptive behavior and may be viewed as precursors to later psychopathology (Keenan, 2000; Calkins \& Fox, 2002). The capacity to regulate emotions begins in the first year of life and is important for the development of appropriate and adaptive social behavior (Eisenberger et al., 1996, Thompson, 1994). However, within this literature, there has been a lack of consensus on a definition of ER (see Bridges, Denham, \& Ganniban, 2004; Cole, Martin, \& Dennis, 2004; Eisenberg \& Spinrad, 2004). Within the developmental and clinical literatures, ER has numerous definitions, some of which focus more on the regulatory functions of emotions in organizing internal processes (e.g., attention, memory), and others of which focus on the manner in which emotion is regulated (e.g., cognitive control, internalization of social expectations) which allow an individual to monitor, delay, and adjust their reactions to the situational demands (Cole, Michel \& Teti, 1994). In an early definition, Kopp (1989) stated that ER refers to the processes and the characteristics involved in coping with heightened levels of positive and negative emotions including joy, pleasure, distress, anger, and fear. For the purposes of the current study, ER is conceptualized as the internal and external processes involved in "initiating, avoiding, inhibiting, maintaining, and modulating the occurrence, form, 
intensity, or duration of internal feeling states, emotion-related physiological, attentional processes, motivational states and/or the behavioral concomitants of emotion in the service of accomplishing affect-related biological or social adaptations or achieving individual goals" (Eisenberg \& Spinard, 2004, p. 338). ${ }^{3}$ This definition is particularly relevant for youth with ADHD, as these youth often have impairments in the underlying processes involved in ER (i.e., attentional control, inhibitory control, etc.) and in the ability to engage in the goal-oriented behaviors necessary for regulating emotion.

Emotion dysregulation in the child and adolescent literature refers to: difficulties with the flexible integration of emotion with other processes (e.g., homeostatic regulation, cognitions, etc.) (Cicchetti, Ganiban, \& Barnett, 1991; Katz \& Gottman, 1991); poor control over affective experience and expression (Izard, 1977; Kopp, 1989; Thoits, 1985); and interference in the processing of information or events (e.g. Dodge, 1991a; Plutick, 1980). In a review of both the child and adult literatures examining emotion regulation and dysregulation, Gratz and Roemer (2004) have synthesized the definitions and conceptualizations of emotion dysregulation suggesting that it is "a multidimensional construct involving the following: (a) lack of awareness, understanding, and acceptance of emotions; (b) lack of access to adaptive strategies for modulating the intensity and/or duration of emotional responses; (c) an unwillingness to experience emotional distress as part of pursuing desired goals; and

\footnotetext{
${ }^{3}$ To be clear, emotion regulation is not being used synonymously with "negative emotionality." While the constructs of emotion regulation, negative emotionality, and control-related characteristics (e.g., impulsivity) appear to be related, they are conceptualized as separate aspects of temperament (e.g., Rothbart, Ahadi, Hershey, \& Fisher, 2001).
} 
(d) the inability to engage in goal-directed behaviors when experiencing distress" (Gratz \& Roemer, 2004, p. 52; Mennin, Heimberg, Turk, \& Fresco, 2005).

This inability to engage in goal-directed behaviors when experiencing distress is referred to in the adult literature as poor distress tolerance. Distress tolerance (DT) ${ }^{4}$ refers to the behavioral assessment of persistence in goal-directed behavior in the face of emotional distress (e.g., frustration, disappointment, anger; Brown et al., 2005), and can be considered a behavioral index of ER. Distress tolerance is commonly measured using behavioral tasks such as the Paced Auditory Serial Addition TaskComputerized (PASAT-C; Lejuez, Kahler, \& Brown, 2003) or The Computerized Mirror-tracing Persistence Task (MTPT-C; Daughters, Lejuez, Bornovalova et al., 2005) which serve to elicit psychological distress (measured pre- and post-task).

Based on the definition of DT, it appears that DT may in fact be one facet of ER. Specifically, DT may serve as a behavioral index of ER. However, to date, only one study has directly examined the relationship between ER and DT. In a study comparing adults with borderline personality disorder (BPD), a disorder characterized by deficits in ER, to individuals without any personality disorder, results demonstrated group differences in the willingness to experience emotional distress in order to pursue goal-directed behavior. Individuals with BPD were more likely to quit the DT tasks prematurely than those without personality disorders (Gratz, Rosenthal, Tull, Lejuez, \& Gunderson, 2006). Additionally, for individuals with BPD, selfreports of emotion dysregulation and experiential avoidance were significantly negatively correlated with latency to quit on the DT tasks. When examining group

\footnotetext{
${ }^{4}$ A more detailed discussion of distress tolerance and its relation to adult and youth psychopathology is presented in Appendix A.
} 
differences between those with BPD who quit the DT tasks versus those with BPD who did not quit, differences in emotion dysregulation continued to be significant even after controlling for BPD symptom severity. Specifically, BPD individuals who quit DT tasks earlier demonstrated higher levels of emotion dysregulation than BPD individuals who persisted on DT tasks. These results suggest that the measure of emotion dysregulation was not just measuring symptoms of BPD (Gratz, et al., 2006). Therefore, this study demonstrates an inverse relationship between ER and DT, and suggests that DT may in fact be viewed as a behavioral index of ER.

With regards to DT in youth, only one study has examined DT in adolescents, and no studies have examined DT in relation to youth with ADHD. In a community sample of adolescents ages 9-13, Daughters and colleagues (2009) examined the relationship between DT and internalizing and externalizing problems. When examining externalizing behaviors, results suggested an interaction of DT and adolescent ethnicity such that higher levels of alcohol use were found in Caucasian youth with low levels of DT than in either Caucasian youth with high levels of DT or in African-American youth regardless of DT level. In terms of delinquent behavior, African-American youth with low levels of DT demonstrated higher levels of delinquent behavior than either African-American youth with higher levels of DT or Caucasian youth regardless of DT level. Results for internalizing problems suggested an interaction of both adolescent gender and ethnicity with distress tolerance. First, females with low levels of DT reported higher levels of internalizing symptoms than females with higher levels of distress tolerance, but for males there was no effect of DT on internalizing symptoms. Additionally, African-American adolescents with low 
levels of DT reported greater levels of internalizing symptoms than African-American adolescents with high DT. There was no effect of DT on internalizing symptoms in Caucasian youth. These results suggest the potential importance of DT in both externalizing and internalizing disorders. When viewed together, the research examining DT suggests that it is related to ER and may be viewed as a behavioral index of ER, but also that in adolescents, DT is significantly related to both externalizing and internalizing disorders.

The Role of Attentional and Inhibitory Control in ER

Intrinsic factors involved in ER refer to individual differences within a person (i.e., "innate") which contribute to the development of ER (Fox \& Calkins, 2003). Some important intrinsic factors involved in the regulation of emotion include an individual's temperament, physiological and neural response systems, cognitive skills, and executive functioning. Two executive functions, attentional and inhibitory control, are particularly critical in the ability to regulate emotion.

Attentional control refers to the ability to voluntarily bias attention toward goal-relevant information (i.e., top-down control of attention), and is an essential part of successful performance in situations where multiple stimuli or stimulus features compete for a limited set of resources (Blasi, Goldberg, Elvevag, Rasetti, Bertolino, Cohen et al., 2007, Desimone \& Duncan, 1995; Kastner \& Ungerleider, 2001). Essentially, attentional control consists of the abilities to focus attention and to be flexible and adapt/shift attention (Rothbart \& Bates, 2006). Attentional control develops in the first year of life (Rothbart, 1989) and has been deemed a central process in the development of ER (Kopp, 2002). In fact, individual differences in the 
ability to sustain focus and shift attention are implicated in the development of the effortful control of behavior (Ahadi \& Rothbart, 1994).

Research from the developmental literature highlights the relationship between attentional control and ER. First, attentional control has been inversely related to negative emotionality in infants during distressing situations (Rothbart, Posner, \& Boylan, 1990). Cross-sectional studies of early infancy suggest that infants who are classified as easily frustrated are observed to be less attentive and more active than less easily frustrated infants in laboratory observations (Calkins, Dedmon, Gill, Lomax, \& Johnson, 2002). Furthermore, in the presence of negative affectivity, a child's ability to explore and maintain on-task behavior has been shown to diminish (Calkins \& Dedmon, 2000). The relationship between attentional control and affectivity is even demonstrated at a physiological level. Research by Perez-Edgar and Fox (2000) demonstrated that in 9 month-old infants, greater attentional focus and lower levels of distractibility were related to higher levels of positive affect, less social withdrawal, lower cortisol levels, and greater relative left frontal EEG symmetry. Also, easily frustrated infants who demonstrate poor attentional control are more physiologically reactive than less frustrated infants (Calkins et al., 2002). Therefore, in the developmental literature, the positive relationship between attentional control and ER has been well-established.

Inhibitory control is another important aspect of executive function related to ER. Inhibitory control refers to the ability to inhibit processes or actions that are not relevant to the task at hand (Rothbart \& Posner, 1985). Deficits in inhibitory control such as failures to anticipate or prepare behavioral responses, impulsive responses to 
stimuli, and failures to adjust behavior after making an error, are the hallmark of youth with ADHD (Pliszka, Glahn, Semrud-Clikeman, Franklin, Perez, Xiong, et al., 2006). In childhood, inhibitory control develops around the age of 4 , such that 4 yearold children use rules to inhibit a dominant response (Gerardi, Rothbart, Posner, \& Kepler, 1996). Examination of inhibitory control and ER in children suggests that children who are rated by parents and/or teachers as high on inhibitory control are less likely to express negative emotions (as measured by observation), which is believed to result from their increased ability to manage their attention, emotions, and behavioral responses (Eisenberg \& Spinrad, 2004). Investigations of individual differences in youth have found that laboratory performance on tasks of inhibitory control positively correlate with parent-reported inhibitory control and ER (Carlson \& Moses, 2001; Gerardi-Caulton, 2000; Jones, Rothbart \& Posner, 2003; Kochanska, Murray, \& Harlan, 2000). Lastly, a study of inhibitory control and ER in preschoolers ages 4 to 6 years-old demonstrated that individual differences in inhibitory control were significantly correlated with youths' ability to regulate their emotions, even after controlling for child age and verbal ability (Carlson \& Wang, 2007). Therefore, attentional control and inhibitory control, known together as effortful control, ${ }^{5}$ both demonstrate positive associations with ER.

\footnotetext{
${ }^{5}$ The term effortful control will be used to refer to the processes of attentional and inhibitory control for conciseness. This term is defined in the literature as the "efficiency of executive attention, including the ability to inhibit a dominant response and/or to activate a subdominant response, to plan, and to detect errors." (Rothbart, 1998, pg. 137). Effortful control includes the abilities to voluntarily manage attention (attentional regulation) and inhibit behavior (inhibitory control) as needed to adapt (Eisenberg, 2005 taken from the Encyclopedia on Early Childhood Development).
} 
Effortful Control in Youth with ADHD: A Primary Deficit

By definition, youth with ADHD demonstrate extreme deficits in effortful control (DSM-IV, 1994; Barkley, 1997). In fact, perhaps the most widely-established theory of ADHD, Barkley's behavioral inhibition model (1997), highlights the role of effortful control in ADHD. Specifically, Barkley argues that youth with ADHD possess a deficit in behavioral inhibition which refers to three inter-related processes: (a) inhibition of the initial proponent response to an event; (b) stopping of an ongoing response, which allows for a delay in response decision-making; and (c) inference control, or the ability to inhibit an incorrect response while still engaging in the prepotent response (i.e., the ability to inhibit the disruption from competing events or responses).

A considerable amount of empirical evidence supports Barkley's theory of behavioral inhibition. For example, individuals with ADHD make more commission errors on computerized tasks of sustained attention and inhibitory control than nonADHD comparison participants (Lijffijt, Kenemans, Verbaten, \& Engeland, 2005; Losier, McGrath, \& Klein, 1996; Oosterlaan, Logan \& Sergeant, 1998). Additionally, individuals with ADHD demonstrate poorer stopping behavior during stop-signal tasks as compared to non-ADHD comparison youth (for reviews see: Corkum \& Sigel, 1993; Lijffijt, et al., 2005; Losier, et al.,1996; Oosterlaan, et al., 1998). Moreover, meta-analyses examining studies of Stroop performance in individuals with ADHD support a deficit in interference control (i.e., the ability to select relevant information while filtering out irrelevant distracting information), which requires substantial effortful control (Lansbergen, Kenemans, \& Van Engeland, 2008; Van 
Mourik, Oosterlaan, \& Sergeant, 2005). Youth with ADHD also demonstrate significantly slower mean reaction times (MRT), greater reaction time variability (SDRT), and slower stop-signal task reaction time (SSRT) in the face of competing events or responses than non-disordered youth, suggesting deficits in effortful control (Lijffijt, et al., 2005; Oosterlaan, et al., 1998). When considered together, the empirical evidence on the importance of effortful control in ER and the evidence suggesting primary deficits in effortful control in individuals with ADHD suggest that individuals with ADHD would likely also have difficulties with ER, due to their poor effortful control.

ER and ADHD

Studies of ER in youth with ADHD initially examined task persistence, as youth with ADHD often demonstrate difficulties persisting in tasks during times of increased emotional distress and/or frustration (Walcott \& Landau, 2004). In an observational study, 6-11-year-old boys with and without ADHD, boys with ADHD were less effective in regulating emotion during a frustrating peer competition than agematched, non-ADHD comparison boys. That is, boys with ADHD displayed more signs of negative or frustrated emotion than non-ADHD comparison boys. Furthermore, in comparison to non-ADHD comparison boys, boys with ADHD demonstrated an enduring pattern of disinhibition (as measured by longer stop-signal reaction time; SSRT) before and after the frustration task (Walcott \& Landau, 2004). Another study demonstrated that 6-12 year-old youth with ADHD were more likely to quit a frustrating puzzle task before completion, more likely to report frustration, and less likely to engage in mood repair than non-ADHD comparison youth (Scime \& 
Norvilitis, 2006). Increased levels of frustration and decreased task persistence by youth with ADHD have been reported during both academic and non-academic tasks (e.g. videogames, mapping task) (Lawrence, Houghton, Tannock, Douglas, Durkin \& Whiting, 2002). Additionally, youth with ADHD have difficulty identifying and processing negative emotions (Norvilitis, Casey, Brooklier, \& Bonello, 2000; Singh et al., 1998), which may interfere with their ability to persist in goal-directed activity as well.

Direct examination of ER in youth with ADHD is also suggestive of impairments in this domain. In a study of 49 first-grade boys and girls with and without hyperactivity, participants were asked to engage in a conceptual learning task involving non-contingent negative feedback. Results suggested that children with hyperactivity expressed greater negative affect (i.e., negative verbal statements) in response to negative feedback than children without hyperactivity (Rosenbaum \& Baker, 1984). Relative to non-ADHD comparison youth, youth diagnosed with ADHD also become more aroused and excitable in response to rewards and more visibly frustrated in the wake of declining reinforcement (Douglas, 1983). In social communication, youth with ADHD are more emotional and negative in communications with their non-ADHD peers (Pelham \& Bender, 1982) and display greater emotional intonation in their verbal interactions with their mothers in comparison to youth without the disorder (Mash, 1993).

More recently, Melnick and Hinshaw (2000) examined ER in 6 to 12 year-old boys with and without ADHD. Participants and their families were observed during a 3- segment family interaction designed to elicit frustration and distress (e.g., building 
a Lego model with pieces missing). Boys with ADHD displayed significantly less constructive patterns of emotional coping (e.g., inability to continue task in wake of frustration, inability to seek help from parents when frustrated, extreme levels of negative affect, inability to problem-solve, and extreme focus on negative aspects of task) than did non-ADHD comparison boys. Furthermore, boys' overall negative emotion during the Lego task predicted their non-compliance during a naturalistic summer camp program, even when core ADHD symptoms were controlled in the analyses. In a similar study, Maedgen and Carlson (2002) examined ER during disappointing and non-disappointing tasks in youth ages 8 to 11 years old diagnosed with ADHD (both ADHD-CT and ADHD-IA) and non-ADHD comparison youth. Results demonstrated that youth with ADHD-CT were rated as more intense and less effective at ER (based on global ratings of overall disappointment) relative to youth with ADHD-IA. In contrast, youth with ADHD-IA were no different than nonADHD comparison youth in ER, suggesting that youth with ADHD-IA may have more intact ER abilities, which is consistent with Barkley's (1997) hypothesis that youth with ADHD-IA are not characterized by an inhibitory deficit. Taken together, this literature provides strong support for the difficulties youth with ADHD experience with ER. In particular, youth with ADHD who demonstrate symptoms of both inattention and hyperactivity/impulsivity may have greater difficulties with ER than ADHD youth with symptoms of inattention alone.

\section{ADHD and Depression}

A vast amount of research in the adult and child literatures has demonstrated a negative association between ER and depression (e.g., Campbell-Sills, Barlow, 
Brown, \& Hoffman, 2006; Garber, Braafladt, \& Weiss, 1995; Gross \& John, 2003;

Larson, et al., 1990; Nolen-Hoeksema \& Morrow, 1993; Rude \& McCarthy, 2003). Specifically, depressive affect and depressive disorders have been related to dysfunctional ER (i.e., maladaptive ER strategies and a limited repertoire of strategies) in both community (Larson, et al., 1990; Nolen-Hoeksema \& Morrow, 1993; Reijntejes, Stegge, Terwogt, \& Hurkens, 2007; Silk, Steinberg, \& Morris, 2003) and clinical samples of youth (Garber, Braafladt, \& Weiss, 1995; Ladouceur, et al., 2005). For example, in a series of studies comparing youth diagnosed with depressive disorders and those without such disorders, Garber and colleagues (1991, 1995) found that youth with depressive disorders reported poorer ER strategies (e.g., used fewer problem-focused and active distraction strategies and more avoidant, passive, and aggressive strategies) than youth in the comparison group. Additionally, youth in the depressed group reported lower expectations that the use of ER strategies would ameliorate their negative emotions than did youth in the comparison group.

Dysregulated emotion has been hypothesized to precede the onset of depressive disorders (Chaplin, Cole, Zahn-Waxler, 2005; Cole, Teti, \& Zahn-Waxler, 2003); however, few studies have examined this relationship longitudinally. In a study examining antecedents of early internalizing problems, Shaw and colleagues (1997) found that difficulties with ER in infancy predicted higher levels of continuous depressive symptoms during preschool. Furthermore, a recent longitudinal study of girls who were between the ages of 5 and 8 at baseline found that difficulties with ER predicted depressive symptoms at age 10 (Feng, Keenan, Hipwell, Henneberger, Rischall, Butch et al., 2009). 
Additionally, a growing literature has examined the relationship between effortful control and symptoms of depression (Eisenberg, et al., 2001, 2005; Muris, 2006, 2007a, 2007b; Oldehinkel et al., 2007, Verstraeten, Vasey, Raes, Bijttebier, 2009). Muris et al. (2008) examined self-reported effortful control and depressive symptoms in a community sample of 8 to 12 year-old youth. Results suggested significant negative correlations between depressive symptoms and effortful control (Muris et al., 2008). A similar relationship between effortful control and depressive symptoms has been found in adolescents (Verstraeten et al., 2009). Moreover, Muris (2006) concluded that effortful control significantly moderated the relationship between negative affectivity and depressive symptoms in adolescents; however, the temporal relationship between effortful control and depressive symptoms has not yet been established in longitudinal studies.

Theoretical Models for the Relationship between Effortful Control, ER and Depression

When considering a theoretical model for the relationship between ER and depression, effortful control appears paramount. Specifically, vulnerability models of psychopathology suggest that certain traits predispose individuals to or protect them from certain kinds of psychopathology in some contexts, but that these traits are inconsequential in other contexts (Shiner \& Caspi, 2003; Tackett \& Krueger, 2005; Watson et al., in press). When applied to depression, effortful control can be viewed as one such mechanism. Therefore, poor effortful control may lead to poor ER, and therefore increased levels of depressive symptoms in the wake of various other risk factors for depression (Figure 1). 
Figure 1. The relationship between Effortful Control, ER and Depression

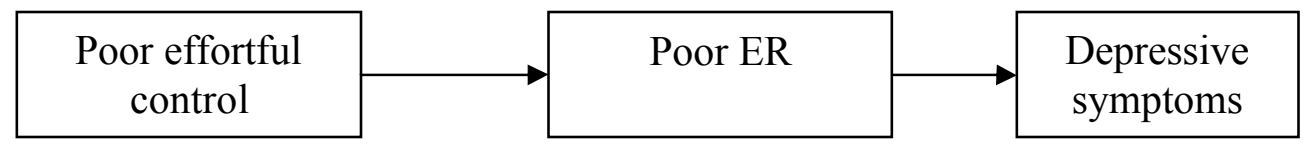

This model is particularly important when considering the relationship between ADHD and depression because, as reviewed herein, youth with ADHD: (1) by definition, have deficits in effortful control (APA, 2004; Barkley, 1997, Nigg, 2000);

(2) have difficulties with ER (Maedgen \& Carlson, 2002; Melnick \& Hinshaw, 2000); and (3) demonstrate higher levels of depression than non-ADHD comparison youth (Fisher, et al., 2002; Biederman, Monuteaux, et al., 2006; Biederman, Ball, et al., 2008; Hinshaw et al., 2006; Lahey et al., 2007; Lee et al., 2008; Monuteaux, Faraone, et al., 2007). Therefore, based on the literature, it appears that ER may mediate the relationship between ADHD and depression in youth, and that effortful control may mediate the relationship between ADHD and ER ability.

The present study will address the gaps in the literature on comorbid ADHD and depression in youth in a number of ways. First, the current study will be the first to examine ER as a mediator in the relationship between ADHD and depressive symptoms in youth. While the longitudinal and cross-sectional research suggests moderate to high rates of comorbidity between ADHD and depression (Biederman, Ball, et al., 2008; Biederman, Monuteaux, et al., 2006; Fisher, et al., 2002; Green et al., 1997; Hinshaw et al., 2006; Lahey et al., 2007; Lee et al., 2008; Monuteaux, et al., 2007) little research has examined underlying mechanisms in this relationship. ER may be particularly important in this relationship as research has demonstrated that 
youth with ADHD demonstrate poor ER (Maedgen \& Carlson, 2002; Melnick \& Hinshaw, 2000). Moreover, research has suggested a negative association between ER ability and depression (e.g., Campbell-Sills, et al., 2006; Garber, et al., 1995; Gross \& John, 2003; Larson, et al., 1990; Nolen-Hoeksema \& Morrow, 1993; Rude \& McCarthy, 2003).

Furthermore, the present study will also examine effortful control and a mediator in the relationship between ADHD and ER. The literature on the development of ER highlights the importance of effortful control in effectively regulating emotion, yet effortful control is significantly impaired in youth with ADHD. Therefore, it is suggested that effortful control may be one mechanism by which youth with ADHD demonstrate poor ER. Lastly, since the literature suggests that DT may be a behavioral index of ER (Gratz et al., 2006), this study will add to the literature by examining ER using traditional measures (i.e., parent/youth report) as well as through behavioral DT tasks. 


\section{Chapter 2: Aims of the Present Study}

\section{Primary Aim 1}

To compare youth ages 10-14-years-old both with and without ADHD on depressive symptoms, ER, DT and effortful control.

Hypothesis 1

It was hypothesized that youth with ADHD would demonstrate greater levels of depressive symptoms, lower levels of ER, and lower levels of effortful control than non-ADHD comparison youth. Additionally, it was hypothesized that youth with ADHD would be more likely to quit/demonstrate shorter latency to quit on behavioral tasks of DT.

\section{Primary Aim 2}

To examine ER as a mediator in the relationship between ADHD diagnosis and depressive symptoms in youth, and to examine effortful control as a mediator in the relationship between ADHD diagnosis and ER ability. ER was measured using both parent and youth report measures (ER; Figure 2) and using behavioral distress tolerance tasks (DT; Figure 3).

Figure 2. Proposed Path Analysis- Model 1 (using Effortful Control and ER as mediators)

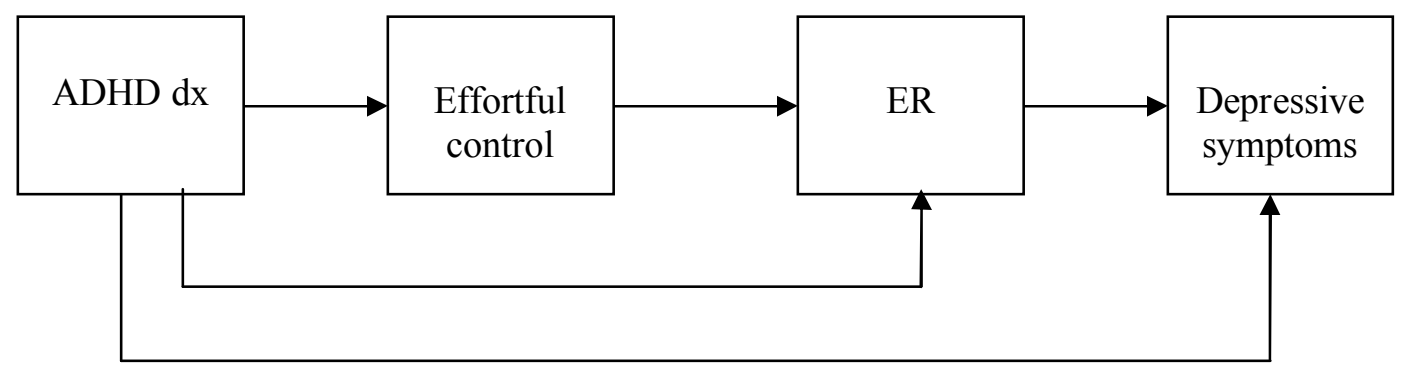


Figure 3. Proposed Path Analysis- Model 2 (using Effortful Control and DT as the mediators)

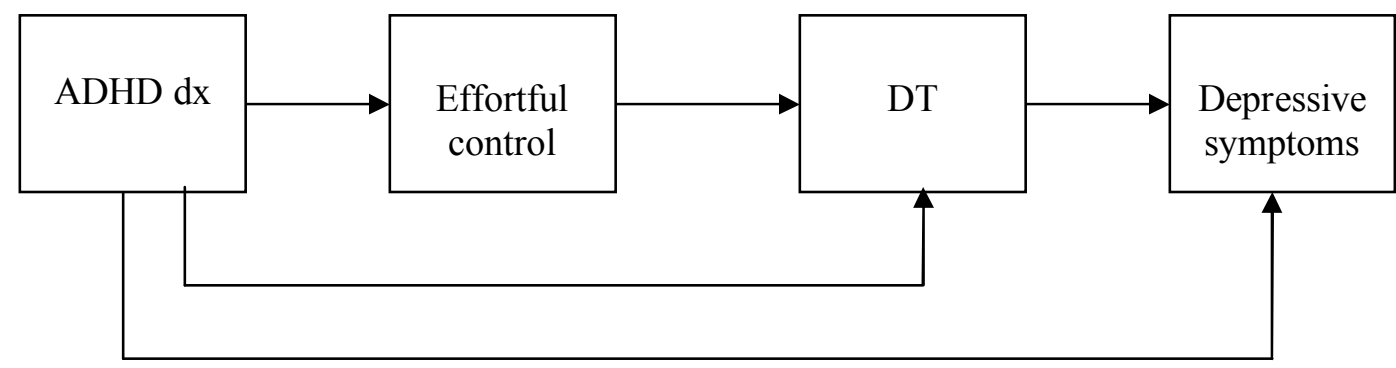

Hypothesis 2

For model 1, it was hypothesized that ADHD status would be negatively associated with effortful control and ER and that effortful control would be positively associated with ER. Moreover, it was hypothesized that the relationship between ADHD status and ER would no longer be significant when effortful control was included in the equation. That is, effortful control was expected to completely mediate the relationship between ADHD diagnosis and ER. Further, it was hypothesized that ADHD status would be positively associated with continuous levels of depression, and that ER would be negatively associated with continuous levels of depression. Lastly, it was hypothesized that ER would completely mediate the relationship between ADHD and depressive symptoms. Therefore, both effortful control and ER are specified as complete mediators in the model.

For model 2, in which DT was substituted for ER, the same hypotheses as above were predicted. That is, it was hypothesized that ADHD status would be negatively associated with effortful control and DT and that effortful control would be positively associated with DT. Moreover, it was hypothesized that the relationship between ADHD status and DT would no longer be significant when effortful control 
as included in the equation (i.e., would completely mediate the relationship). Further, it was hypothesized that ADHD status would be positively associated with continuous levels of depression and that DT would be negatively associated with continuous levels of depression. Lastly, it was hypothesized DT would completely mediate the relationship between ADHD and depressive symptoms. Therefore, both effortful control and DT are specified as complete mediators in the model. 


\section{Chapter 3: Methods}

\section{$\underline{\text { Participants }}$}

Participants included 69 youth ages 10-14-years-old with $(n=37)$ or without $(n=32)$ DSM-IV ADHD. Participants were recruited through mailings to University of Maryland employees as well as treatment providers, schools, and community centers in the Washington, D.C. metropolitan area, including families who had previously been seen at the University of Maryland ADHD Program. For inclusion in the study, youth were required to: (1) be between the ages of 10 and 14; (2) be fluent in reading and writing English (i.e., could understand and complete questionnaires); and (3) have at least one parent/guardian (i.e., mother or father) who was willing to participate and could complete the study measures in English. Youth were excluded if there was evidence of mental retardation (intelligence quotient $[\mathrm{IQ}]<70$ ) based on a brief IQ screen or evidence of psychosis, bipolar disorder or pervasive developmental disorders (PDD). For inclusion in the ADHD group, youth had to meet full DSM-IV criteria for ADHD according to diagnostic interview and parent and teacher report on well-validated rating scales. Youth taking ADHD medications were included in the study, but medication status was examined as a covariate in the analyses. For inclusion in the non-ADHD comparison group, youth were not allowed to have more than 3 symptoms of DSM-IV ADHD according to parent or teacher report.

The disposition of participants following screening and assessment is outlined in Figure 4. 
Figure 4. Disposition of participants

99 Screened via telephone

5 Ineligible

3 Child age (i.e., too young)

2 Child history of PDD

94 Scheduled for initial assessment

77 Completed an initial assessment

$17 \mathrm{Cancel} /$ no show for appointment

37 youth met criteria for ADHD group

32 youth met criteria for the non-ADHD comparison group

8 youth were Ineligible

5 Had 3+ symptoms of ADHD, but did not meet full ADHD criteria

1 Met past ADHD criteria, but not current

1 Presented with significant PDD symptoms

1 General Medical Condition that mimicked ADHD

Two youth were included in the non-ADHD comparison group who had more

than 3 symptoms of ADHD according to parent/teacher report, but did not

demonstrate impairment. That is, when compared both groups (i.e., ADHD and

control), these individuals were significantly different than the ADHD group, but not different from the non-ADHD comparison group in terms of total ADHD symptoms, $F(2,66)=94.810, p<.001 ;$ total symptoms of inattention, $F(2,66)=109.062, p<.001$; total symptoms of hyperactivity/ impulsivity, $F(2,66)=32.026, p<.001$; and parent and teacher ratings of impairment, $F(2,66)=37.352, p<.001$ and $F(2,43)=20.889$, $p<.001$ respectively. 
Therefore, following the initial assessment, 37 youth met criteria for the ADHD group (DSM-IV diagnosis of ADHD) and 32 youth met criteria for the nonADHD comparison group. Overall, mean participant age was 11.67 years $(S D=1.37)$. Fifty-seven percent of the youth sample was male and 54\% was Caucasian. Furthermore, all parent participants were female except for one male (1.4\%). Demographic characteristics for parent and youth participants by group are presented in Table 1. The ADHD and non-ADHD groups differed significantly based on parental education level, $F(1,56)=10.238, p<.01$. Specifically, parents in the nonADHD comparison group evidenced a higher mean level of education than parents in the ADHD group. Groups also differed based on youth gender, $\chi^{2}(1, N=69)=3.961$, $p<.05$, and ethnicity/race, $\chi^{2}(2, N=69)=5.729, p<.05$. Youth in the ADHD group were more likely to be male whereas youth in the non-ADHD comparison group were more likely to be female. Moreover, youth in the non-ADHD comparison group were more likely to be Caucasian. As a result, these demographic factors were included as covariates in the subsequent analyses.

\section{Procedures}

Participants completed a telephone screen to determine initial eligibility, and if eligible, participants were scheduled for a single assessment at the University of Maryland, College Park. During the assessment, parents completed a diagnostic interview about the youth's past and current ADHD and depression symptoms as well as rating scales about youth $\mathrm{ADHD}$, ODD and conduct disorder (CD) symptoms, youth impairment in various functional domains, youth overall psychopathology including depression symptoms, youth ER, parental depression symptoms, and a 
parent/youth demographics questionnaire. Youth participants completed a diagnostic interview about past and current depression symptoms, self-report measures of depression symptoms, overall psychopathology and ER, a Stroop task measuring effortful control, and two behavioral distress tolerance tasks. Youth also completed a brief IQ screen using the Wechsler Intelligence Scale for Youth, 4th Edition (WISCIV) Block Design and Vocabulary subtests (WISC-IV, Wechsler, 1991). The utility of the Vocabulary and Block Design subscales to estimate full scale IQ has been demonstrated in a number of studies (e.g., Campbell, 1998; Seguin, Nagin, Assaad, \& Tremblay, 2004). Furthermore, this method has been shown to be the most appropriate manner of estimating IQ in clinical samples of youth demonstrating a .92 correlation with full scale IQ (Campbell, 1988). Youth were paid $\$ 25$ for their participant and parents were allowed to attend a free workshop offered by the PI on "Parenting an Adolescent". Following the assessment, rating scales of ADHD, ODD and $\mathrm{CD}$ symptoms and impairment were sent to youth's teachers.

\section{$\underline{\text { Measures }}$}

Assessment of Youth ADHD

The diagnosis of youth ADHD was made using a well-validated parent interview and well-validated parent and teacher rating scales to assess symptoms and impairments associated with ADHD. Parents/guardians of all youth were interviewed using the Schedule for Affective Disorders for School-Aged Youth-Present and Lifetime Version (K-SADS-PL; Kaufman, Birmaher, Brent, Rao \& Ryan, 1997), a semi-structured clinical interview assessing DSM-IV youth psychopathology. Parents were administered the Behavioral Disorders module (ADHD, ODD, CD). All 
interviews were conducted by the principal investigator, an advanced graduate student in clinical psychology, who was supervised by a licensed clinical psychologist (Andrea Chronis-Tuscano, Ph.D.). The K-SADS-PL provides information about current clinical diagnoses as well as whether symptoms/diagnoses have ever been present. On the K-SADS-PL each symptom was rated on a three-point scale, ranging from 1 (not present) to 3 (threshold: definitely present), and symptoms were counted as clinically significant if the clinician rated it as a " 3 " based on parent report. The KSADS-PL demonstrates strong psychometric properties of reliability (Ambrosini, 2000) and validity (Kaufman et al., 1997). Specifically, the K-SADS-PL has been shown to demonstrate inter-rater reliability for diagnoses of ADHD, ODD and CD with the following kappa scores, .77, .51, .68, respectively (Ambrosini, 2000). Additionally, criterion validity for this measure was established via high correlations between diagnoses on the K-SADS and scores in the clinical range for the Internalizing and Externalizing subscales of the Child Behavior Checklist and the scores in the clinical range on the Conners' Parent Rating Scale for ADHD (Kaufman et al., 1997).

Parents and teachers also completed the Disruptive Behavior Disorders (DBD) symptom checklist (Pelham et al., 1992) which assesses ADHD, ODD and CD symptoms. Parent and teacher ratings were utilized as data suggests that each informant contributes a unique variance in identifying youth with ADHD (Hart et al., 1994; Jensen et al., 1999). On the DBD, symptoms rated as occurring "pretty much" or "very much" are considered present. Internal consistency for the DBD was high to adequate on the $\operatorname{ADHD}(\alpha=0.95), \operatorname{ODD}(\alpha=0.90)$ and $\operatorname{CD}(\alpha=0.75)$ scales. 
For both parent interviews and the completion of parent and teacher measures, informants were requested to report on youth's behavior while off medication. Diagnoses of ADHD were made by counting symptoms either parents or teachers endorsed as occurring to a clinically significant degree on any of these measures (Piacentini, Cohen, \& Cohen, 1992).

In addition to exhibiting symptoms of inattention, hyperactivity and/or impulsivity, youth also had to demonstrate cross-situational impairment in order to meet DSM-IV criteria for ADHD (APA, 1994, 2000). Impairment was measured using the Children's Impairment Rating Scale (CIRS; Fabiano et al., 2006) which was completed by both parents and teachers. On the CIRS, informants assess the youth's impairment and need for treatment across multiple domains, including peer/sibling relations, self-esteem, academic achievement, and parent-child relations. Ratings are made on a 7-point scale, with scores above the midpoint indicating clinically significant impairment. The CIRS has demonstrated concurrent validity with other established measures of youth impairment, and has been shown to accurately discriminate between youth with ADHD and non-disordered youth (Fabiano et al., 2006). Test-retest correlations for the parent CIRS range from $0.51-0.69(p<0.001)$ and for the teacher CIRS from 0.40-0.58 $(p<0.001)$. Internal consistency for both parent- and teacher-rated CIRS was high $(\alpha=.947 ; \alpha=.876$ respectively).

\section{Assessment of Youth Depression}

Youth depression was measured both categorically and continuously. Both parents and youth were administered the Mood Disorders module of the KSADS-PL to establish diagnoses of Major Depression and Dysthymia. However, given low base 
rates of these disorders in youth, for the present study, depression was examined continuously.

Youth completed two self-report ratings of depression, the Children's Depression Inventory (CDI; Kovacs \& Beck, 1977, Kovacs, 1992) and the Behavioral Assessment System for Children or Adolescents-Self-Report (BASC-SRS; BASC-SRS for adolescents; Reynolds \& Kamphaus, 1992) Depression subscale. The CDI is a widely-used 27 -item self-report inventory designed for use in 8-17 year olds. The CDI inquires about depressive symptoms within the last 2 weeks and is scored on a 3point scale ranging from 0 (absence of the symptom) to 3 (presence of symptom at a severe level), with a total range of 0 to 54 . Scores of 19 and above are thought to be associated with clinically significant depression (Smucker, Craighead, Craighead \& Green, 1986). In addition to total score, 5 subscales can be derived which include: Negative Mood, Interpersonal Problems, Ineffectiveness, Anhedonia, and Negative Self-Esteem (Kovacs, 1992). Raw scores were converted to t-scores based on normative samples divided by age and sex (Kovacs, 1992). Good reliability and validity have been established for the CDI (Kazdin, French, Unis \& Esveldt-Dawson, 1983; Saylor, Finch, Spirito, \& Bennett, 1984). For instance, construct and criterion validity studies have demonstrated that the CDI relates to self-esteem, hopelessness, cognitive processing, and depression as measured by other instruments (Kazdin, 1989b, 1990; Kovacs, 1992). Additional studies have found internal consistency to be in the .80s (Cole \& Carpentieri, 1990; Kovacs, 1992). Internal consistency for the current study was high $(\alpha=.90)$. 
Youth also completed the BASC-SRS, a multidimensional measure used to assess adaptive and behavior problems in both children and adolescents. The BASC was constructed using structural equation modeling; therefore, the subscales represent a "pure" index of the constructs being assessed, as there is no overlapping content (Weis \& Smenner, 2007). Depending on their age, participants completed either the BASC-SRS-2 (for children ages 6-11) or the adolescent version (for ages 12-21). Computerized scoring of the BASC produces t-scores for all subscales based on youth age and gender (Reynolds \& Kampaus, 1992). For the present study, the Depression subscale, which is composed of 17 items that assess feelings of unhappiness, inability to experience pleasure, and dejection was used. The BASC Depression subscale demonstrates strong internal consistency $(\alpha=.88)$ and test-retest reliability $(r=.75)$ (Reynolds \& Kamphaus, 1992), and when compared to other measures of emotional and behavioral functioning (parent, self and other report), the Depression subscale offers good convergent and discriminate validity (Ostrander \& Herman, 2006).

Parents completed the Behavioral Assessment System for Children or Adolescents- Parent-Report (BASC-PRS; BASC-PRS for adolescents; Reynolds \& Kamphaus, 1992) in order to report on youth depressive symptoms. Depending on child age, parents completed either the BASC-PRS-2 for children ages 6-11 or the BASC-PRS-2 for adolescents ages 12-21. Both measures contain between 130-160 items and use a 4-choice response format ranging from 0 (never) to 3 (always). Again, the Depression subscale (t-score) was utilized and very good internal consistency $(\alpha=.86)$ and test-retest reliability $(r=.87)$ have been reported (Reynolds \& Kamphaus, 1992). Furthermore, the depression subscale has demonstrated good 
convergence with other measures of affective disturbance (Ostrander \& Herman, 2006).

Emotion Regulation ${ }^{6}$

Parent- and youth- rated measures of ER were collected. Parents completed the Emotion Regulation Checklist (ERC; Shields \& Cicchetti, 1997), a 24-item measure of caregivers' perceptions of their youth's ability to regulate emotion. Items on the ERC assess the frequency with which youth exhibit a variety of positive and negative emotion-regulation related behaviors (e.g. "Can say when s/he is feeling sad, angry or mad, fearful or afraid", "Shows positive feelings in response to friendly or helpful gestures by adults"), and are rated on a 4-point Likert scale ( 1 = rarely/never; $4=$ almost always). The ERC contains two separate orthogonal factors: (1) Lability/Negativity which reflects items assessing mood swings, angry reactivity, emotional intensity and dysregulation of positive emotion, and (2) Emotion Regulation, which reflects processes central to the adaptive regulation of emotion including equanimity, emotional understanding and empathy (Shields \& Cicchetti, 1997). For the purposes of the present study, only the Emotion Regulation subscale was used in statistical analyses. On the ER subscale, higher scores are reflective of a

\footnotetext{
${ }^{6}$ One limitation frequently cited in studies of ER, is that measures of ER often contain items that overlap with symptoms of depression making the independence of these constructs difficult to assess (see Abela \& Hankin, 2007; Gotlib \& Hammen, 2008; Nolen-Hoeksema \& Hilt, 2008, for reviews). Given this issue, the ER measures used in the current study were examined for overlapping items with depressive symptoms. It was noted that 2 items on the ER subscale of the ERC (i.e., Is a cheerful child; Seems sad or listless) and 3 items on the DERS (i.e., When I'm upset, I believe that I'll end up feeling very depressed; When I'm upset, I have difficulty concentrating; When I'm upset, I start to feel very bad about myself.) overlapped with depressive symptoms. When these items were removed internal consistency for the ER scale on the ERC dropped from .75 to .65 and on the DERS from .92 to .91 . Given the reduction of internal consistency for the ERC, analyses presented in the results section do not have the overlapping items removed. However, to ensure that the relationship between ER and depression in the current study was not due to measurement error, all analyses were re-run with the overlapping items removed from the ER measures. A detailed description of these analyses can found in Appendix C. It should be noted that even with removal of these overlapping items, ER still mediated the relationship between ADHD and depression.
} 
greater ability to regulate one's emotions. Previous research with the ERC has demonstrated good construct validity (i.e., has been associated with other measures of childhood ER) and has been shown to discriminate between well-adjusted and maltreated youth between the ages of 6 to 12 years (Shields \& Cicchetti, 1997, 1998; 2001); however, the measure has been used with adolescents as well (Gratz, Tull, Reynolds, Daughters, and Lejuez, in press). Internal consistency for the ER subscale was adequate $(\alpha=0.75)$.

Youth participants completed a self-report measure of ER, the Difficulties in Emotion Regulation Scale (DERS, Gratz \& Roemer, 2004). The DERS is a 36-item measure that assesses six domains of emotion dysregulation: nonacceptance of negative emotions, inability to engage in goal-directed behaviors when distressed, difficulties controlling impulsive behaviors when distressed, limited access to ER strategies perceived as effective, lack of emotional awareness, and lack of emotional clarity. A total score reflecting overall emotion dysregulation is also derived with higher scores reflecting greater difficulties in regulating emotion. The DERS has high internal consistency $(\alpha=.93)$, good test-retest reliability $\left(\rho_{1}=.88, p<.01\right)$, and adequate construct and predictive validity (Gratz \& Roemer, 2004). Furthermore, in a youth sample of adolescents' ages 11-17-years-old, confirmatory factor analysis demonstrated the same six factor structure shown with adult populations, and DERS scores were meaningfully related to youth ratings of externalizing and internalizing problems (Newmann, van Lier, Gratz \& Koot, 2009). Internal consistency for the current study was high $(\alpha=.92)$. 


\section{Distress Tolerance}

In addition to parent and youth report of ER, two distress tolerance tasks were completed by youth participants as behavioral indices of ER. The order of task presentation was randomized. One of the tasks was the Behavioral Indicator of Resiliency to Distress (BIRD; Daughters, Danielson, Ruggiero, \& Lejuez, 2005), which is a developmentally-sensitive adaptation of an adult psychological distress tolerance task, the Paced Auditory Serial Addition Task (PASAT; Lejuez, Kahler, \& Brown, 2003). The BIRD was developed for use with children and adolescents (Daughters, Danielson, Ruggiero, \& Lejuez, 2005), but has only been used in one published study of adolescent distress tolerance (Daughters et al., 2009). Similar to the PASAT, the BIRD measures distress tolerance by determining how long a participant persists on a task in which difficulty increases to the point where success on the task is virtually impossible.

During the task, participants saw a row of boxes with numbers (1-10) displayed on the computer screen (see Figure 5).

Figure 5. Computer Display of the BIRD

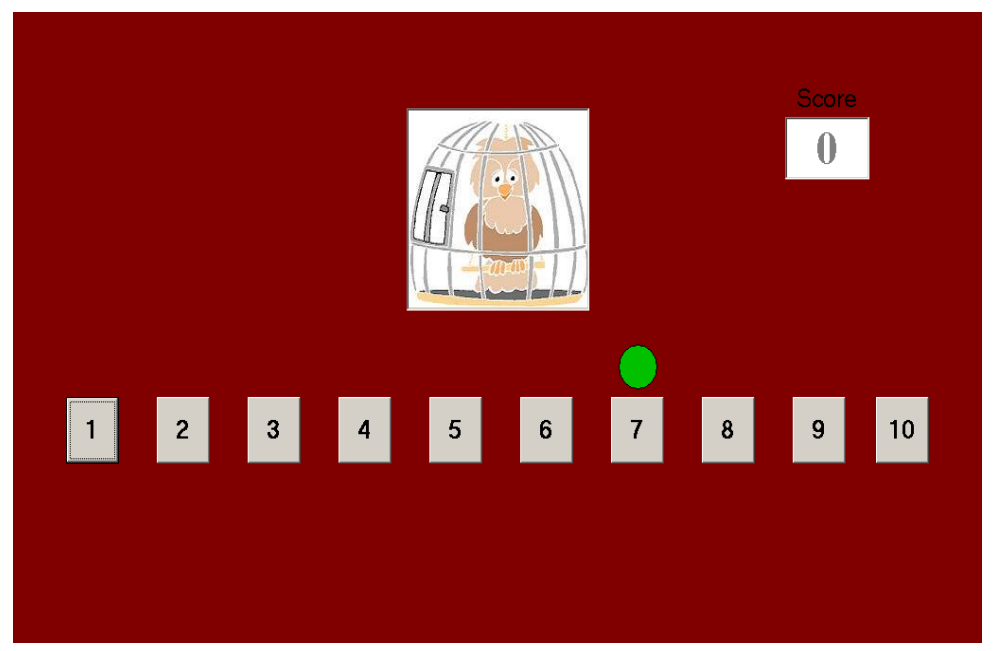


Participants were instructed that the green dot would appear over one of the number boxes and that they were to use the computer's mouse to click on the number box below the green dot before the dot disappeared. If the number box was clicked before the dot disappeared, the "bird" on the screen was let out of the cage and the computer made a chirping noise. However, if the green dot disappeared before the participant clicked on the number, a loud and abrasive noise was heard and the bird remained in its cage. For each time the participant freed the bird from the cage (i.e., clicked on the number box before the dot disappeared), he/she received a point. No points were awarded for missed green dots.

The task consisted of three levels with varying latencies between dot presentations. Specifically, the first level of the BIRD lasted 3 minutes and began with a 5-second latency between dot presentations. The latency in this phase was titrated by 0.5 seconds based on participant performance. For example, a correct response reduced the latency by 0.5 seconds (to $4.5 \mathrm{sec}$ ) whereas an incorrect answer or non-response increased the latency by 0.5 seconds $(5.5 \mathrm{sec})$. In the second level, which lasted for 5 minutes, the average latency determined from the first level was used for dot presentation during the first four minutes. However, during the last minute of the second level, the latency of dot presentation was reduced in half making the task extremely difficult (i.e., challenge latency). Following the second level, participants received a brief rest period and then began the final level which lasted for up to 5 minutes and utilized the extremely difficult challenge latency. During the final level, participants could utilize the "escape option" which terminated the task. 
Specifically, participants were informed prior to beginning the task that once the final level began they could quit the task by clicking the 'quit game' button on the computer screen. However, they were also informed that the magnitude of their cash prize was dependent on how well they did on the task, but were not given specific "criteria" to determine their earnings. Throughout the task, the participant had the opportunity to see how many points he/she had earned as displayed on the right-hand side of the screen. Distress tolerance was indicated by persistence on the final level of the task which was examined as a continuous variable (i.e., latency to quit) (Daughters et al., 2005). Total score on the first two levels of the game was recorded to control for the effects of skill on persistence. Due to technical issues, data for 3 individuals (2 ADHD and 1 control participant; 4\%) was missing.

Before beginning the BIRD (i.e., before Level 1) and after Level 2, participants completed the Positive and Negative Affect Schedule for Children (PANAS-C, Laurent et al., 1999) to measure the extent to which the BIRD elicited distress (i.e., manipulation check). The PANAS-C is a child adaptation of the PANAS (Watson, Clark, Tellegen, 1988), which has been demonstrated to reliably measure positive and negative affect in children and adolescents (Laurent et al., 1999). The measure is composed of two subscales: one which measures Positive Affect (5 items) (e.g., excited, interested, happy, energetic, and proud) and one that measures Negative Affect (5 items) (e.g., mad, frustrated, upset, embarrassed, nervous). All items are rated on a 5-point Likert scale ranging from: $1=$ very slightly or not at all to $5=$ extremely. The PANAS-C has demonstrated good psychometric properties of reliability and validity with elementary age youth (in $4^{\text {th }}$ through $8^{\text {th }}$ grades) (Laurent 
et al., 1999). Internal consistency for the pre- and post-Negative affect scale were high ( $\alpha=0.80$ and 0.78 , respectively) as was the internal consistency for pre-and postPositive scale ( $\alpha=0.89$ and 0.91 , respectively).

The other distress tolerance task completed by participants was the Computerized Mirror-Tracing Persistence Task (MTPT-C; Strong, Lejuez, Daughters, Marinello, Kahler, \& Brown, 2003) which is a computerized version of the Mirror Tracing Persistence Task (MTPT; Quinn, Brandon, \& Copeland, 1996). During this task, participants were required to trace a red dot along the lines of a star using the computer's mouse (Figure 6). In order to make the task frustrating and therefore elicit distress, the mouse was programmed to move the red dot in the reverse direction that the mouse was moved. For example, if the participant moved the mouse to the left then the red dot moved to the right and so on. To increase the difficulty level and frustration, if the participant moved the red dot outside of the lines of the star or if the participant stalled for more than 2 seconds, a loud, aversive buzz sounded and the red dot returned to the starting position.

Figure 6. Computer display for the MTPT-C

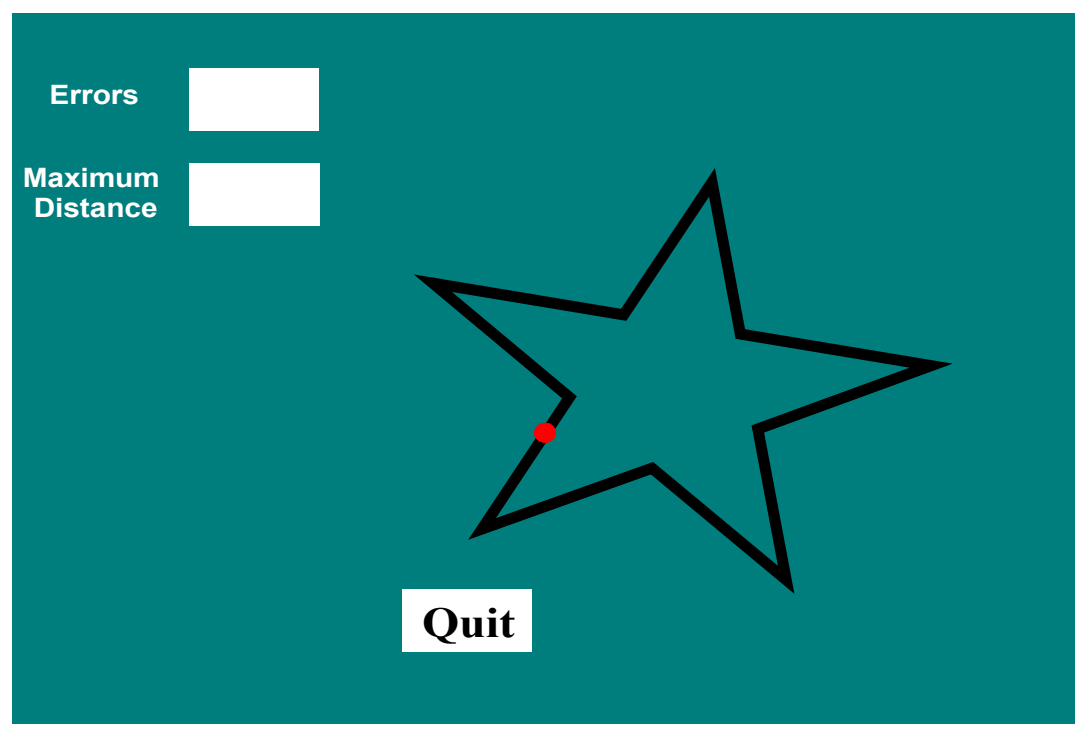


Participants were told that they could end the task at any time by pressing any key on the computer keyboard, but they were also reminded that how well they did on the task affected how much money they would earn. After receiving instructions, participants began the task and worked independently until the five minute maximum or until they quit. Participants were not told the maximum duration prior to beginning the task. Due to technical issues, data from 5 individuals (2 ADHD and 3 control participants; 7\%) was missing.

Similar to the BIRD, distress tolerance was measured as a continuous variable (latency to quit). Because the MTPT-C is comprised of only a single level, dysphoria could not be assessed without confounding termination latency. However, before and after the task, participants rated their current: irritability, frustration, anxiety, difficulty concentrating and bodily discomfort on a scale of $0-100$, and these ratings were examined as a manipulation check. Given the aim of the current study to examine DT in an ADHD and non-ADHD sample, the item of "difficulty concentrating" was removed from the manipulation check in order to not bias results. Internal consistency for pre-task and post-task ratings was adequate $(\alpha=0.80$, and 0 . 74 respectively)

\section{Effortful Control}

The Stroop task (1935) is one measure of executive function used to assess selective attention and cognitive flexibility. The Stroop task measures an individual's ability to shift cognitive set (Spreen \& Strauss, 1998), which allows for the measurement of cognitive inhibition (Archibald \& Kerns, 1999; Boone, Miller, Lesser, Hill \& D'Elia, 1990) and the ability to inhibit a dominant response (i.e., 
reading) in order to complete a required task (i.e., color-naming) (Spreen \& Strauss, 1998). Research on the Stroop task has suggested that two processes are involved: an automatic response which requires very little attention (word-reading) and a more controlled response which requires attention and voluntary control (color-naming) (Cohen et al., 1990).

While many cognitive tasks exist to examine effortful control in youth (e.g., Stop Signal task, antisaccade tasks, Stroop task, etc), a great deal of literature has examined interference control/response inhibition in youth with ADHD using the Stroop task (Homack \& Riccio, 2004). While results have been mixed as to whether the Stroop task distinguishes between ADHD and non-ADHD participants (e.g., Boonstra, et al., 2005; Scheres et al., 2004; Homack \& Riccio, 2004; Schwartz \& Verhaeghen, 2008), a significant number of studies have suggested poorer performance on the Stroop task by ADHD individuals in comparison to controls (Homack \& Riccio, 2004). Furthermore, despite these mixed findings, the Stroop task still remains the most frequently used task to examine response inhibition (Schwartz \& Verhaeghen, 2008). Therefore, a computerized Stroop task was used to measure effortful control in the present study.

All Stroop tasks involve words and symbols (i.e., stimuli) being presented in various colors of ink. Participants were instructed to respond to the color of the ink presented, not what the word said. For example, if the word RED was presented in BLUE ink, the participant should have responded "BLUE". A computerized Stroop task was utilized for the present study. Specifically, the task was administered on laptop computer using DirectRT Precision Timing Software v. 2006.2.0.28C (Blair 
Jarvis, Ph.D.; www.empirisoft.com). Instructions and stimuli were presented in Times New Roman, font size 54. Stimuli consisted of four single color words ('RED'. 'BLUE', 'YELLOW' and 'GREEN') and non-word stimuli (*) in corresponding length to mimic color word length (i.e., ${ }^{* * *}$ for red vs. $* * * * * *$ for yellow) presented in red, blue, green or yellow ink colors. Prior to stimuli presentation, participants were oriented to the computer screen using a priming symbol $(+)$ in the middle of the screen. Participants made responses on the keyboard using the following key response codes: $\mathrm{A}=$ red, $\mathrm{S}=$ blue, $\mathrm{K}=$ yellow, $\mathrm{L}=$ green. To assist participants, these keys were labeled with a colored dot that corresponded to the response key color. Directions for the task were read by the examiner as follows:

"During this game, you are going to see words and symbols on the computer screen. The words and colors will be printed in different colors of ink. Your job is to press the colored key on the keyboard that is the same color as the color of the ink, not what the word says. For example, if you see the word "blue" written in red ink, which button would you press? What if you saw the word "green" written in yellow ink, which button would you press? Ok, now that you know what to do, let's practice a few. Remember to respond as quickly, but as correctly as you can. Press any key to continue."

During the instructions, if participants made a correct response they were told, "Great job, that's exactly right!"; however, if they made any incorrect response they were corrected (i.e., "Actually the word reads 'blue' but it is written in red ink, so you would say red"). Following the instructions, participants engaged in a 2 minute 
practice trial with the examiner standing in the room. Following the practice trial, the actual trials began which lasted for 10 minutes.

The Stroop task consisted of three types of trials: 144 congruent trials in which the word and the color presented were the same (e.g., the word green written in green ink), 24 incongruent trials in which the word and the color presented were different (e.g., the word green written in red ink) and 24 baseline trials in which symbols (e.g., ${ }^{* * * * * * *}$ ), rather than words were presented, in various colors. Both between group and within group randomization occurred during the presentation of trials and stimuli were presented in 750ms intervals. Participant responses times (RT) were recorded in milliseconds for every trial. Each participant's data for every trial was stored in a separate Excel spreadsheet. For every participant, the following variables were calculated for congruent trials, incongruent trials and baseline trials: number correct, percent correct, number incorrect, mean RT correct, and mean RT incorrect. Stroop effect (i.e., Stroop interference) was calculated for both RT data and percent correct data. For both types of data, Stroop effect was calculated by subtracting mean $\mathrm{RT} /$ percent correct for incongruent trials from the mean RT/percent correct for baseline trials. Stroop facilitation was calculated by subtracting mean RT congruent trials from mean RT baseline trials. Due to technical issues, data from 14 individuals (8 ADHD and 6 control participants; 20\%) was missing. Split halfreliability for Stroop effect (RT) was poor $(r=-.168, p=$ n.s. $)$ 


\section{Chapter 4: Results}

\section{$\underline{\text { Preliminary Analyses }}$}

All data were double-entered by two independent research assistants, and the databases were compared, cleaned and verified by the principal investigator using SPSS Statistics GradPack 17.0.0 (www.spss.com). Prior to conducting planned analyses, all variables were examined for distributional properties and outliers using methods discussed by Tabachnick \& Fidell $(1996,2001,2007)$. Prior to the main analyses, preliminary analyses were conducted to examine if composite factors could be created for youth depression and youth ER, so as to utilize the information provided by both parent and youth report. Additionally, ER was measured in two ways: (1) using a composite measure of parent and youth report, and (2) using behavioral tasks of DT. Lastly, manipulation checks were conducted for the distress tolerance tasks to ensure they elicited distress.

\section{Variable Examination}

Normality was assessed for all variables via visual inspection of the distribution graphs and assessment of skewness and kurtosis values (Field, 2005; Hair, et al., 2006; Tabachnick \& Fidell, 2001, 2007). First, all variables were examined for outliers using both visual inspection of Boxplots and statistically by converting the variables to standardized scores (z-scores) and examining those with zscores greater than 3.29 (Tabachnick \& Fidell, 2001, 2007). The only variable which produced significant outliers was effortful control (i.e., Stroop effect measured as RT). One significant outlier was found, and examination of this participant's 
individual trial data during the task revealed an overall pattern of markedly delayed response; therefore, this participant's effortful control data was removed from subsequent analyses.

Once outliers were removed from the data, z-scores were computed for skewness and kurtosis using the standard error term, for all variables, and variables demonstrating z-scores equal to or less than 3.29, the criterion recommended for small samples (Field, 2005; Hair, et al., 2006), were included. One of the youth measures of depression, the BASC-SRS, demonstrated significant levels of skew, $z$ $=5.70$, and kurtosis, $z=3.29$, and as such was dropped from subsequent analysis. Therefore, only two measures of depression, youth-rated CDI and parent-rated BASC were included in for the depression composite score discussed below. Furthermore, one of the Stroop variables, Stroop effect measured through percent correct, also displayed significant levels of skew, $z=-4.364$, and kurtosis, $z=8.548$. Therefore, this variable was not used for subsequent analyses. Distribution statistics, including mean, standard deviation, range, skewness and kurtosis are presented in Appendix B.

\section{Data Reduction}

\section{Depression composite}

Preliminary analyses were conducted to examine the association between parent-(BASC- Depression subscale t-score) and youth- (CDI total t-score) rated continuous youth depression scores. As mentioned previously, the youth-rated BASC score was not included due to non-normal distribution of scores. Results examining parent and child depressive symptoms ratings suggested a high degree of relatedness. Specifically, parent report was significantly positively related to youth report, $r=.401$, 
$p<.01$. As a result, t-scores for these two measures were averaged to create a composite depression score in which higher scores are reflective of higher levels of depressive symptoms. T-scores were averaged to create a composite (instead of conducting PCA) because t-scores provide clinically meaningful data as they utilize clinical cut-points which distinguish between those with significant levels of a disorder and those without significant levels of a disorder. Essentially, t-scores are more interpretable than composites completed by PCA.

\section{ER composite}

Principal components factor analysis (PCA) was conducted with parent- (ERC ER subscale) and youth- (DERS total score) reported ER variables to examine whether these variables could be examined as a singular composite construct of ER. It should be noted that on the ERC, higher scores are reflective of a greater ability to regulate one's emotions whereas for the DERS higher scores reflect greater difficulties in regulating emotion. A significant negative correlation was found between parent and youth report, $r=-.413, p<.000$, indicating that as DERS scores decrease (i.e., indicating greater regulation or less dysregulation), ER subscale scores increase (indicating greater ER ability). The Kaiser-Meyer-Olkin measure of sample adequacy was acceptable, $\mathrm{KMO}=.500$, as was Bartlett's test of sphericity, $\chi^{2}(1)=$ 12.41, $p<.000$ (Field, 2005; Hair, et al., 2006). Using the Kaiser (1960) criteria for eigenvalues, results of PCA demonstrated a one factor solution (eigenvalue $=1.413$ ) which accounted for $70.6 \%$ of the variance (communality extraction value $=.706$ ). Use of a scree plot as proposed by Catell (1966) also produced a one factor solution. Component scores from the coefficient matrix were .595 and -.595 for the ERC ER 
subscale and DERS total score, respectively. Therefore, PCA analyses supported use of an ER composite in which higher scores are reflective of a greater ability to regulate one's emotions.

\section{Manipulation Check}

Manipulation checks were conducted on both distress tolerance tasks. If the DT tasks indeed elicited distress, we would expect differences between pre- and posttask scores on measures of negative affect (e.g., PANAS) in which post scores demonstrated higher levels of negative affect than pre-task scores. On the BIRD, individuals persisted for an average of 272.89 seconds $(S D=61.03)$ and only $26 \%$ quit the task before the 5 minute time limit expired. Paired t-tests did not indicate a significant increase in the level of self-reported negative affect during the first two levels of the task, $t(68)=-1.081, p=$ n.s. These results are inconsistent with the only other published study that used the BIRD with youth ages 9-13 which found that approximately $50 \%$ of the sample quit the task before the 5-minute time limit (Daughters et al., 2009). Moreover, manipulation checks conducted by Daughters and colleagues (2009) using the PANAS-C suggested a significant $(p<.001)$ increase in negative affect from pre- to post-task ratings. Skill on the BIRD task, as indicated by the number of correct responses during the first two levels of the game, was examined in relation to latency to quit. Results suggested that skill level was not related to persistence on the task $(p=$ n.s. $)$. Therefore, the BIRD task did not elicit distress in this sample, and was therefore not used in subsequent analyses.

On the Mirror-tracing task, individuals persisted for an average of 139.41 seconds $(S D=109.67)$, and $73 \%$ of participants quit the task before the five minute 
time limit expired. Participants reported experiencing moderate amounts of distress as a result of the Mirror-tracing task, as demonstrated through a paired t-test comparison of pre-task and post-task distress, $t(63)=-7.435, p<.000$. Additionally, the relationship between the error count (number of errors an individual made during the task) and latency to quit was significant, such that individuals who made more errors were significantly more likely to quit the task, $r=.592, p<.01$. Therefore, results suggested that the Mirror-tracing task adequately elicited distress, and as such latency to quit on the Mirror-tracing task was used as the overall measure of DT. Lastly, BIRD latency to quit and Mirror tracing latency to quit were not significantly associated with one another, $r=.178, p=$ n.s.

Comparison of Groups on ADHD, ODD, and CD Symptoms and Overall Impairments

General linear models multivariate analysis of variance (GLM MANOVA) analyses were conducted to compare groups on ADHD, ODD, and CD symptoms and parent-rated overall impairment. A separate ANOVA was conducted for teacher-rated overall impairment given the reduction in sample size due to missing teacher data ( $n=46$ versus $n=69$ ). Child gender and ethnicity/race as well as parental education were included as covariates in these analyses as these variables were significantly different between groups (see Table 1). The multivariate test of differences between groups on $\mathrm{ADHD}$, $\mathrm{ODD}$, and $\mathrm{CD}$ symptoms and parent-rated impairment using the Wilks Lamba criterion was statistically significant, $F(5,60)=38.437, p=.000, \eta^{2}=$ .762. Follow-up ANOVAs demonstrated significant differences between groups in which youth in the ADHD group demonstrated greater levels of total ADHD 
symptoms, inattentive symptoms, hyperactivity/impulsivity symptoms, ODD symptoms, CD symptoms, parent-rated overall impairment and teacher-rated overall impairment, than youth in the non-ADHD comparison group (see Table 1).

\section{Data Analytic Plan}

To address primary aim 1, GLM MANOVA analyses were conducted to compare the ADHD group and non-ADHD comparison group on depressive symptoms, ER, DT and effortful control (operationalized as RT).

With regard to Aim 2, mediation effects can be assessed in a variety of ways including those explained by James and Brett (1984), in which theoretical mediation models are thought of as causal models. In such models, "M is considered to be a mediator of the probabilistic function $\mathrm{Y}=\mathrm{f}(\mathrm{X})$ is $\mathrm{M}$ is a probabilistic function of $\mathrm{X}$ and $\mathrm{Y}$ is a probabilistic function of $\mathrm{M}$ where $\mathrm{X}, \mathrm{M}$, and $\mathrm{Y}$ have different ontological content” (James, Mulaik, \& Brett, 2006, pg. 234).

Path analysis, a variant of structural equation modeling (SEM), which takes a confirmatory (i.e., hypothesis testing) approach to multivariate analysis of a structural theory of a specified phenomenon (Byrne, 1998) is often used to test mediation models. Path analysis explores causal associations represented by a series of structural equations (i.e., regression equations) which are also pictorially represented to allow for a clear conceptualization of the relationships under investigation (Byrne, 1998). Specifically, using LISREL, models are tested to describe the strength, direction (i.e., positive or negative), and statistical significance of the path from $\mathrm{X}$ to the mediator, the path from the mediator to $\mathrm{Y}$, and the path from $\mathrm{X}$ to $\mathrm{Y}$, controlling for the mediator. 
The use of SEM to test mediation presents some distinct advantages over other mediation approaches (e.g., those laid out by Barron and Kenny, 1986). While these advantages are discussed more fully elsewhere (see James et al., 2006 for a complete review), one of the greatest differences between these methods includes that the Baron and Kenny model for mediation does not require investigators to make an a priori commitment to partial or complete mediation; thus, absolving investigators from having to explain a model's lack of complete mediation. Thus, path analysis was used to examine Aim 2 (see Figures 7 and 8 below), with the hypotheses that effortful control would partially mediate the relationship between ADHD and ER, and that ER would mediate the relationship between ADHD and depression.

Figure 7. Model 1 with paths defined

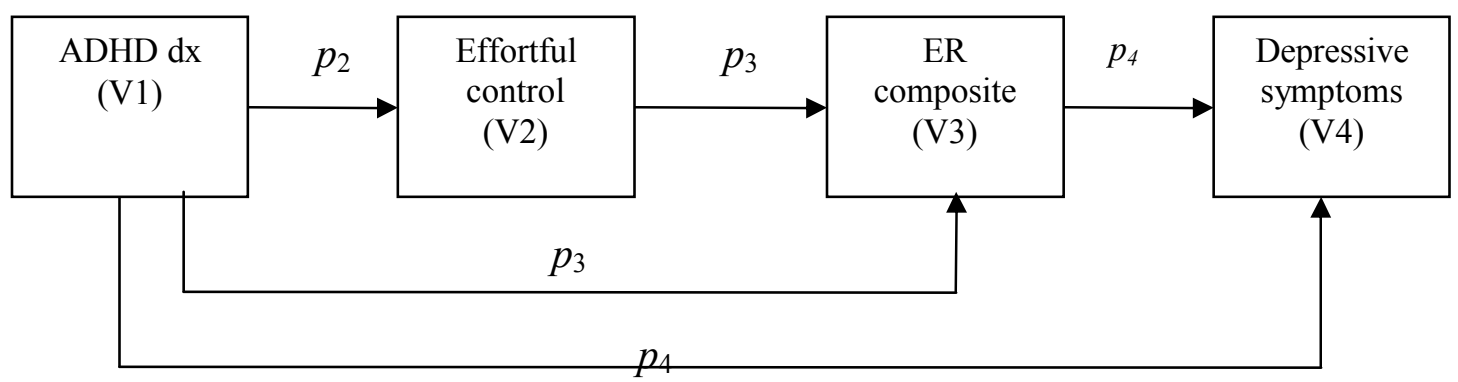

Figure 8. Model 2 with paths defined

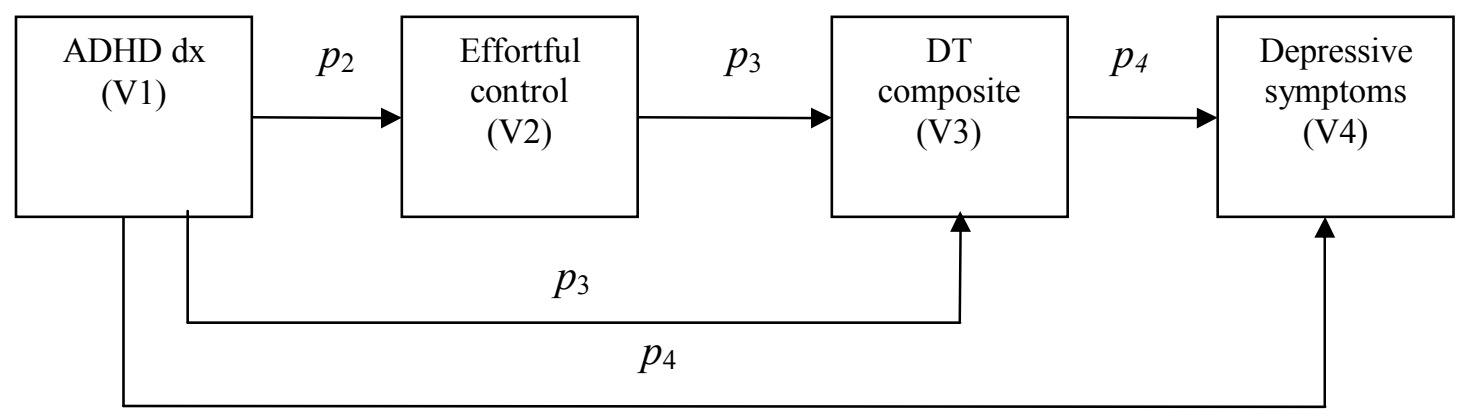


In the proposed path analyses, all variables $(\mathrm{Vx})$ of interest are denoted. ADHD diagnosis represents an exogenous variable while effortful control, ER/DT and depressive symptoms represent endogenous variables. The paths (pxy) between variables are denoted using the numbers of the specific variables involved in the relationship. For example, the path between ADHD diagnosis (labeled as V1 or variable 1) and effortful control (labeled as V2 or variable 2) is represented as p21 because it relates variables 1 and 2 .

\section{Main Analyses}

\section{Primary Aim 1: To compare youth with and without ADHD on depressive symptoms, ER, DT and effortful control (RT).}

Correlation analyses were conducted to examine the relationships between the independent, dependent, mediator and demographic variables of interest. Pearson product-moment correlations were used to examine the relationships between continuous variables while Kendall's tau was used to examine the relationships between dichotomous variables or a dichotomous and a continuous variable. The resulting correlation matrix is presented in Table 2 .

Results indicated that ADHD diagnosis was positively related to depressive symptoms, $\tau=.386, p<.01$, and negatively related to $\mathrm{ER}, \tau=-.397, p<.01$. However, ADHD was not significantly related to either effortful control or DT. Depression and ER were negatively related, $r=-.701, p<.01$, but depression was not related to DT or effortful control. Lastly, ER was not significantly related to youth DT, $r=.182, p=$ n.s. Given these findings, exploratory analyses were conducted examining the relationship 
between DT and parent-rated ER and youth-rated ER separately. Results suggested that DT was not significantly related to either parent-rated ER, $r=-.097$, $p=$ n.s., or youth-rated ER, $r=.210, p=$ n.s. Furthermore, when relationship between ER and DT was examined in each group separately, results still suggested no significant relationship between these constructs.

In terms of demographic variables, child ethnicity/race was positively related to ADHD diagnosis, $\tau=.239, p<.05$, such that youth in the ADHD group were more likely to be non-Caucasian while youth in the control group were more likely to be Caucasian. Child race/ethnicity was also related to overall depression score, $\tau=.242$, $p<.01$, and ER, $\tau=-.301, p<.01$, such that African-American youth demonstrated higher levels of depression and poorer ER than Caucasian youth. Child gender was significantly related to ADHD diagnosis, $\tau=-.240, p<.05$, in that youth with ADHD were more likely to be male while non-ADHD comparison youth were more likely to be female. Parental education was significantly related to ADHD diagnosis, $\tau=-.290$, $p<.01$, such that parents of youth in the non-ADHD comparison group were more highly educated that parents of youth in the ADHD group. Furthermore, higher levels of parental education were related to greater ER ability, $\tau=.202, p<.05$. Therefore, child ethnicity/race, child gender and parent education were included in the subsequent ANOVAs.

Once preliminary correlation analyses were conducted, GLM ANOVA analyses were conducted to compare groups on depressive symptoms, ER, DT and effortful control. ANOVA was selected due to the different sample sizes for each variable due to missing data. Results are presented in Table 3. Results demonstrated 
that youth in the ADHD group displayed significantly higher levels of depression than youth in the non-ADHD comparison group, $F(4,65)=6.55, p<.001$. Furthermore, youth in the non-ADHD comparison group demonstrated a greater ability to regulate their emotions relative to youth with $\mathrm{ADHD}, F(4,65)=5.003, p<.001$.

Groups did not differ significantly on either DT, $F(4,60)=0.645, p=$ n.s., or effortful control $^{7}, F(4,51)=0.432, p=n . s$. It should be noted that for both DT and effortful control, group sizes were reduced due to technical difficulties with the Mirror-tracing $(n=64)$ and Stroop $(n=55)$ tasks, respectively.

Primary Aim 2: To examine to examine effortful control as a mediator in the relationship between ADHD diagnosis and ER ability. Furthermore, to examine ER, measured as self/parent report of ER and DT, as a mediator in the relationship between ADHD diagnosis and depressive symptoms in youth between the ages of 10 to 14 years.

Path analyses were used to examine primary aim 2. LISREL VIII (Joreskog \& Sorbom, 1996) was used to test the proposed path analysis models depicted in Figures 7 and 8. For SEM, it has been suggested that the ratio of the number of participants to the number of model parameters should ideally be 20:1; however, 10:1 is considered much more realistic while also being acceptable (Kline, 1998). In the current study,

\footnotetext{
${ }^{7}$ For exploratory purposes, Stroop effect measured as percent correct was examined in terms of correlation to other variables of interest and GLM ANOVA analyses were used to examine possible group differences. In terms of correlations, Stroop effect measures as percent correct was not significantly related to any variable aside from Stroop effect measured as RT $(r=-.271, p<.05)$. ANOVA analyses suggested no significant group differences between the ADHD and control group on Stroop effect measured as percent correct, $F(4,51)=.980, p=$ n.s.. In terms of correlations, Stroop effect measures as percent correct was not significantly related to any variable aside from Stroop effect measured as RT $(r=-.271, p<.05)$. ANOVA analyses suggested no significant group differences between the ADHD and control group on Stroop effect measured as percent correct, $F(4,51)=.980$, $p=$ n.s.
} 
each model specifies four parameters, suggesting a needed sample size of between 40-80 participants.

LISREL uses several fit indices to assess how well the proposed model fits the sample data. The likelihood ratio chi-square test (or model chi-square) is used to assess the overall fit of the specified model. For the chi-square test, the larger the value of $\chi^{2}$ (and consequently the more significant the p-value) the worse the model fits the data (Garson, 2009, Kenny 2010, Mueller \& Hancock, 2009). That is, when the chi-square test yields a significant p-value, the results indicate that the given model's covariance structure is significantly different from the observed covariance matrix.

A number of additional statistics are available to assess model fit; however, debate exists within the field as to which or how many fit statistics should be reported (e.g., Garson, 2009, Jaccard \& Wan, 1996; Kenny 2010, Kline, 1998a, Mueller \& Hancock, 2009). For example, Kline (1998a) suggests reporting at least four tests, such as chi-square; goodness-of-fit index (GFI), normed fit index (NFI), or comparative fit index (CFI); non-normed fit index (NNFI); and standardized root mean square residual (SRMR). In contrast, Garson (2009) recommends reporting chisquare, root mean square error of approximation (RMSEA), and one of the baseline fit measures (normed fit index [NFI], incremental fit index [IFI], CFI, etc) as well as a measure of parsimony (e.g., parsimony normed fit index [PNFI], parsimony comparative fit index [PCFI]) and an information theory measures (e.g., alkaike information criteria $[\mathrm{AIC}]$, bayesian information criteria [BIC], etc.) when comparing models. For the current study, Kline's reporting recommendations (i.e., chi square, 
GFI, NNFI, and SRMR) will be used in text; however, additional fit statistics will be presented in tables for review. The GFI represents the percent of observed covariance explained by the model, and larger values (.90 and greater) are related to better fit (Hu \& Bentler, 1995; Schumaker \& Lomax, 2004). NNFI values are used to compare the posited model (i.e., researcher's model) to the null model (Garson, 2009). It is recommended that NNFI values closer to 1 indicate a good fit. Specifically, $\mathrm{Hu}$ and Bentler (1999) suggested that NNFI values should be great than or equal to 95 . Lastly, the SRMR is the average difference between predicted and observed variance and covariance in the model based on standardized residuals, where values less than .05 are indicative of a good fit while values below .08 indicate adequate fit (Garson, 2009).

Path coefficients are reported as both standardized $(\beta)$ and unstandardized (B) beta weights. Standardized beta weights allow for comparisons among the relative importance of different variables tested, and research suggests that standardized beta weights $\geq 0.32$ indicate meaningful relationships (Billings \& Wroten, 1978; Garson, 2009). One limitation of standardized beta weights is that they do not allow for comparison across samples or studies (Gelfand, Mensinger, \& Tenhave, 2009; Little, Card, Bovaird, Preacher \& Crandall, 2007; Stage, Carter, Nora, 2004). Therefore, unstandardized beta weights were also reported to allow for the comparison across studies and samples.

In order to account for the effects of significantly-related demographic variables (i.e., child gender, child ethnicity/race, and parent education), a series of linear regression analyses were conducted. Specifically, four regressions (one for 
each dependent variable: depression, effortful control, ER and DT) were conducted in which the specified demographic variables were entered simultaneously as predictors, and the unstandardized residuals were saved. The use of unstandardized residuals allows for the removal of the variance in the exogenous variables (i.e., depression, effortful control, ER and DT) accounted for by the specified demographic variables. The unstandardized residuals created by the regressions were then used as the variables of interest (depression, effortful control [RT], ER and DT) in the subsequent path analyses. Prior to being entered as independent variables, child gender and race/ethnicity were recoded using error coding (i.e., 1 and -1). Parental education was entered as a continuous variable.

Results examining Model 1 suggested that the model was a moderate to good fit for the data, $\chi^{2}=2.93, d f=1, p=0.09$. Therefore, additional fit statistics were reviewed. GFI (0.98), CFI (0.95), and SRMR (.05) statistics all indicated a strong fit while the NNRI value was 0.68 possibly suggesting the need to re-specify the model. Additional fit statistics are presented in Table 4.

Examination of the paths specified in the model indicated that ADHD diagnosis significantly predicted ER ability, $\beta=-0.30, p=.012$, such that youth with ADHD demonstrated poorer ER than non-ADHD comparison youth. Emotion regulation was significantly related to depressive symptoms, $\beta=-0.60, p=.000$, such that youth with greater levels of emotion regulation displayed lower levels of depressive symptoms. Moreover, the path between ADHD and depression became non-significant, $\beta=0.15, p=.130$, when ER was included, suggesting a mediating effect of ER. ADHD diagnosis was not related to effortful control, $\beta=0.05, p=\mathrm{n} . \mathrm{s}$, 
and effortful control was not related to emotion regulation, $\beta=-0.03, p=$ n.s. The tested model with standardized and unstandardized beta weights is presented in Figure 9, and the results of the structural equations are presented in Table 5.

Figure 9. Path analysis indexes for Model 1. Standardized path coefficients are presented with unstandardized coefficients in parentheses. Significant paths are represented by $*(\mathrm{p}<.01)$

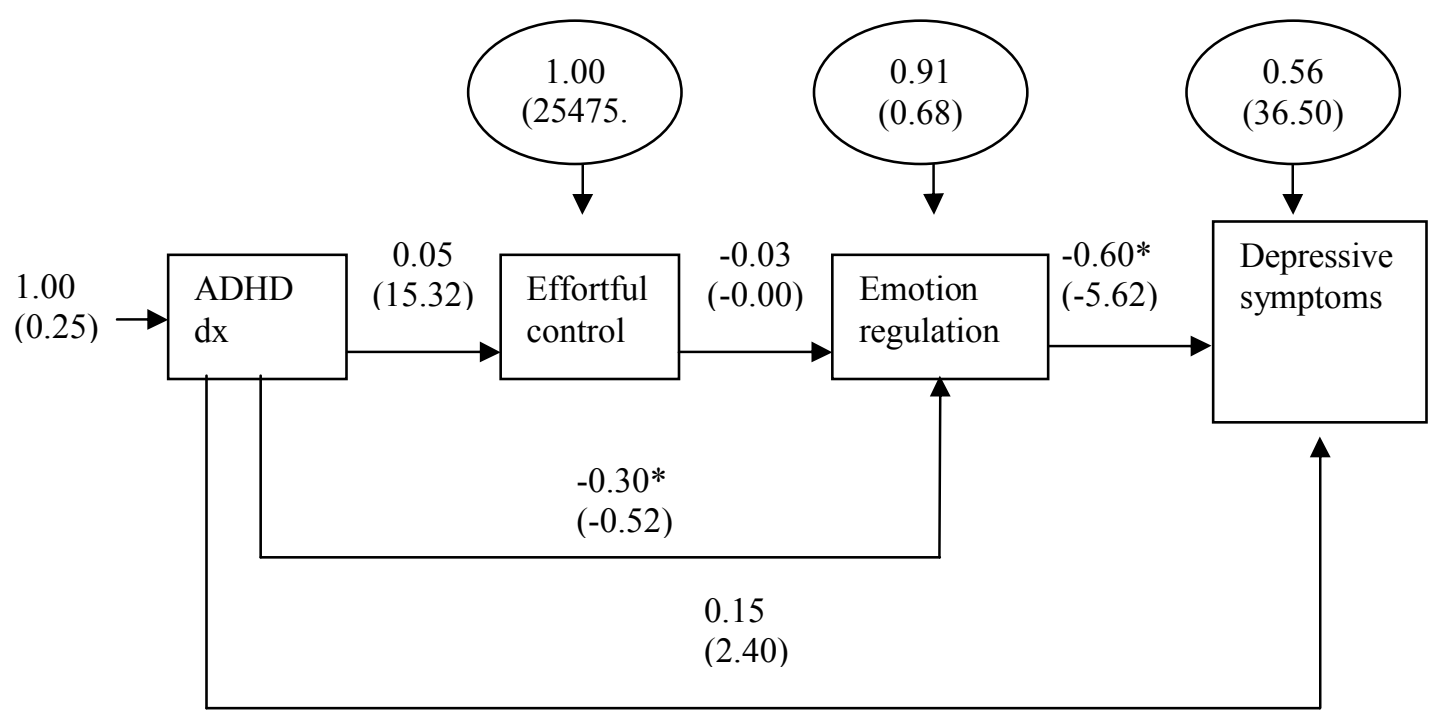

ER mediated the relationship between ADHD diagnosis and depressive symptoms, accounting for $44 \%$ of the variance in the model. In fact, when ER was added as a mediator into the relationship between ADHD and depression, the unstandardized beta weight for ADHD diagnosis dropped from 5.33 to $2.40 .^{8}$

\footnotetext{
${ }^{8}$ Given the shared method variance in measures of depressive symptoms and ER (i.e., both involved composite parent and youth ratings), path analysis were also conducted in which parent-rated ER was examined as a mediator to youth-rated depressive symptoms and vice versa (youth-rated ER as a mediator of parent-rated depressive symptoms). When parent-rated ER was examined as a mediator to youth-rated depressive symptoms, the model still suggested that ER completely mediated the relationship between ADHD and depressive symptoms, accounting for $14 \%$ of the variance. However,
} 
As mentioned previously in a footnote, one significant limitation frequently cited in studies of ER, is that measures of ER often contain items that overlap with symptoms of depression making the independence of these constructs difficult to assess (see Abela \& Hankin, 2007; Gotlib \& Hammen, 2008; Nolen-Hoeksema \& Hilt, 2008, for reviews). Therefore, the path analysis in Model 1 was re-run with the overlapping depression items removed from the ER construct. Again, ER mediated the effect of ADHD diagnosis on depressive symptoms, accounting for $36 \%$ of the variance in the model. In fact, when ER was added as a mediator into the relationship between ADHD and depression, the unstandardized beta weight for ADHD diagnosis dropped from 4.84 to 2.68 . A detailed description of these follow-up analyses can be found in Appendix C.

Given the lack of parsimony in the original model suggested by the fit statistics, the model was re-structured removing effortful control as it was not significantly related to ADHD diagnosis or ER (see Table 2) (Figure 10). Again ER mediated the effect of ADHD diagnosis on depressive symptoms, accounting for $44 \%$ of the variance in the model.

when youth-rated ER was examined as a mediator of parent-rated depressive symptoms, the model was no longer significant. 
Figure 10. Revision of Model 1. Standardized path coefficients are presented with unstandardized coefficients in parentheses. Significant paths are represented by * $(\mathrm{p}<.01)$

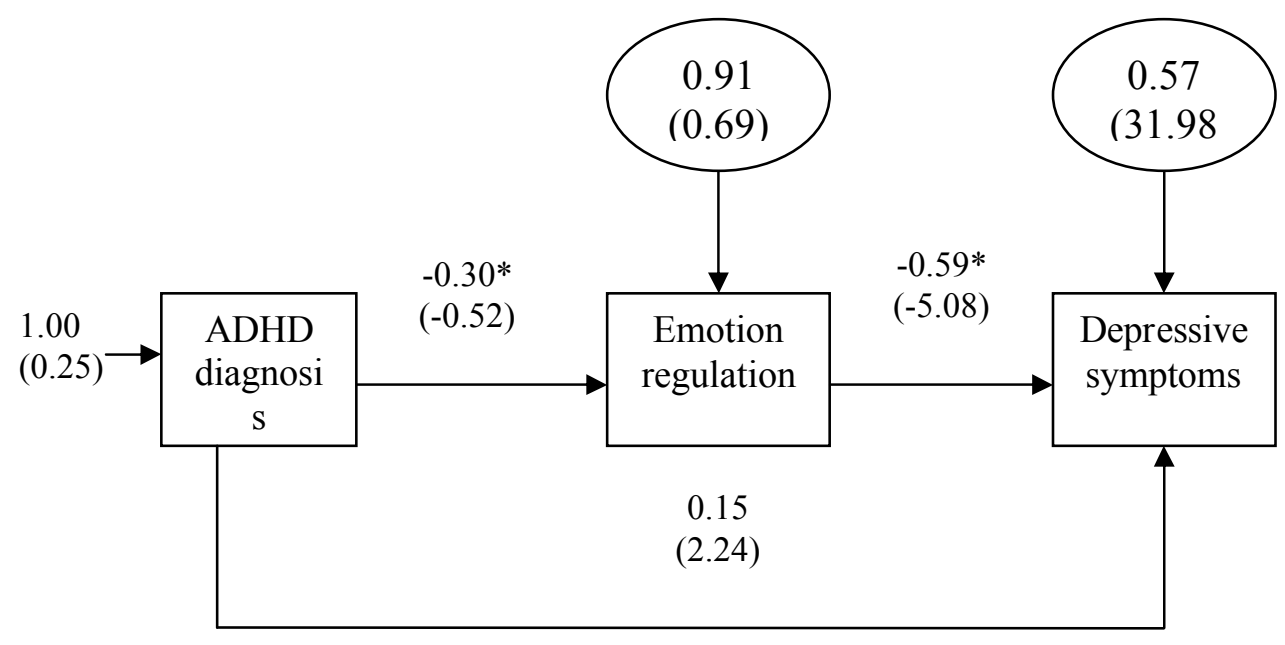

Similar methods were utilized to test Model 2 in which ER was replaced with DT as the mediator variable. Results examining Model 2 suggested that the model was a good fit for the data, $\chi^{2}=1.36, d f=1, p=0.24$. Goodness-of-fit index (0.99), CFI (0.93), and SRMR (.04) statistics all indicated a strong fit while the NNRI value was 0.61. Additional fit statistics are presented in Table 6. The tested model with standardized and unstandardized beta weights is presented in Figure 11 and the results of the structural equations are presented in Table 7. 
Figure 11. Model 2 with standardized and unstandardized beta weights (in parentheses) Significant paths are represented by $*(p<.01)$.

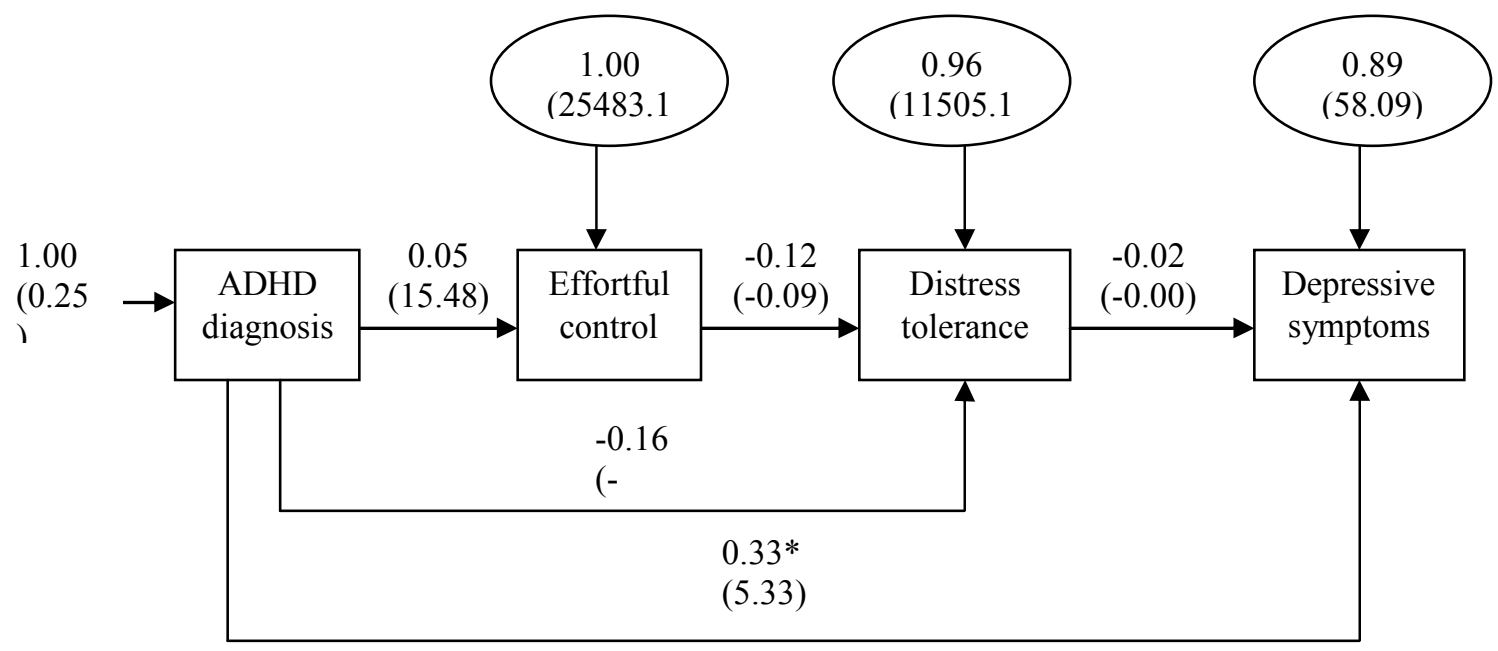

While Model 2 fit the data, examination of path coefficients suggested that the only significant relationship in the model was that between ADHD diagnosis and depressive symptoms, $(\beta=0.33, p=.006)$. ADHD diagnosis was not related to DT ( $\beta$ $=-0.16, p=.175)$ or effortful control $(\beta=0.05, p=.698)$. Effortful control was not related to DT $(\beta=-0.12, p=.308)$ and distress tolerance was not related to depressive symptoms $(\beta=-0.02, p=.984)$. Moreover, effortful control did not mediate the relationship between ADHD diagnosis and DT, and DT did not mediate the relationship between ADHD diagnosis and depressive symptoms.

\section{Chapter 5: Discussion}

Moderate to high rates of comorbid ADHD and mood disorders, ranging up to 75\%, have been found in youth (Bauermister et al., 2007 Biederman, Newcorn, Spirch, 1991; Daviss, 2009; Elia, Ambrosini \& Wade, 2008). Moreover, longitudinal 
research suggests increased rates of mood disorders (Biederman, et al., 2008; Green et al., 1997; Fisher, et al., 2002; Biederman, et al., 2006; Monuteaux, et al., 2007) as well as depressive symptoms (Hinshaw et al., 2006; Lahey et al., 2007; Lee et al., 2008) in youth diagnosed with ADHD in comparison to non-ADHD youth.

Unfortunately, youth with comorbid ADHD and depression demonstrate an earlier onset and longer duration of depressive episodes, increased risk for recurrence, higher rates of psychiatric hospitalization, require more intense interventions, and have more psychosocial and familial problems than youth with ADHD or depression alone (Biederman, et al., 2008, Biederman et al., 1996; Jensen et al., 1993 Rohde et al., 2001). However, perhaps the most compelling argument for obtaining a more comprehensive understanding of the processes which underlie the relationship between ADHD and depression is research suggesting that youth with comorbid mood disorders and ADHD are three times more likely to complete suicide that those diagnosed with either disorder alone (James, Lai, \& Dahl, 2004). The present study examined ER as a mediator in the relationship between ADHD and depressive symptoms in youth ages 10 to 14-years-old. Furthermore, effortful control was examined as a potential mechanism by which youth with ADHD have poor ER ability.

Results from path analyses indeed suggested that ER (as measured by composite parent and youth report) fully mediated the relationship between ADHD diagnosis and youth depressive symptoms. In fact, this relationship accounted for $44 \%$ of the variance in the model. Moreover, in a more stringent test of the model, in which overlapping symptoms of depression were removed from the measures of ER, 
ER continued to completely mediate the relationship between ADHD and depression accounting for $36 \%$ of the variance in the model and suggesting that this relationship was not merely the result of measurement error.

In contrast, effortful control did not mediate the relationship between ADHD diagnosis and ER ability. In fact, contrary to hypotheses, effortful control was not significantly related to either ADHD diagnosis or ER ability. These results may be interpreted in the context of the mixed literature examining Stroop task performance in ADHD samples. While the Stroop task is the most frequently used cognitive task of interference control and response inhibition in ADHD populations (Homack \& Riccio, 2004; Schwartz \& Verhaeghen, 2008), results have been mixed as to whether the Stroop task distinguishes between ADHD and non-ADHD participants (e.g., Boonstra et al., 2005; Scheres et al., 2004; Homack \& Riccio, 2004; Schwartz \& Verhaeghen, 2008). For example, in a meta-analysis of 25 studies of Stroop performance comparing individuals with and without ADHD, it was concluded that the Stroop interference effect was not greater for ADHD participants in comparison to non-ADHD participants (Schwartz \& Verhaeghen, 2008). The authors suggest that perhaps the Stroop task does not adequately assess response inhibition and inference control in individuals with ADHD, and therefore, other cognitive tasks of response inhibition may be more sensitive to these effects (Schwartz \& Verhaeghen, 2008). Therefore, perhaps it is not that effortful control is not involved in the relationship between ADHD and ER, but rather that the Stroop task did not provide a valid or adequate measure of the construct of effortful control. 
An alternative explanation may be that perhaps working memory (WM) deficits (Rapport et al., 2001, 2008a) rather than deficits in behavioral inhibition (Barkley, 1997; Sonuga-Barke, 2002) better explain the executive function deficits in individuals with ADHD. Models of WM suggest that WM is a limited capacity system which allows individuals to store and manipulate information for a brief period of time after the stimuli responsible for this information have terminated (Baddeley, 2003). Moreover, WM has been suggested to underlie complex higher order tasks such as learning, comprehension, reasoning and planning (Baddeley, 2003, 2007; Kane \& Engle, 2003). An essential feature suggested to coordinate the attentional activities and responses of WM is the central executive, which integrates information from the phonological loop and visuospatial sketchpad and provides access to information stored in memory (Kane \& Engle, 2003). In fact, studies that examine individual differences in WM are thought to be reflective of differences in the central executive system (Rosen \& Engle, 1997).

With relation to ADHD, early studies examining WM deficits and ADHD provided inconclusive findings; however, two recent meta-analytic reviews, which addressed a number of the previous methodological limitations in the literature, suggest that WM deficits do in fact exist in children with ADHD in comparison to control children (Martinussen et al., 2005; Willcutt et al., 2005). In fact, converging evidence suggests that in comparison to children without ADHD, children with ADHD demonstrate impairments in all three components of WM: the central executive, visuospatial storage/rehearsal and phonological storage/rehearsal (Martinussen et al. 2005; Marzocchi et al. 2008; Rapport et al., 2008a; Willcutt et al. 
2005). Therefore, perhaps youth with ADHD have difficulties with ER due to their difficulties with WM rather than behavioral inhibition. Indeed, evidence suggests that individuals with higher WM capacity are better able to suppress the expression of both negative and positive emotions, appraise emotional stimuli in an unemotional manner, and therefore experience and express less emotion in response to emotionally-laden stimuli than individuals with poorer WM (Schmeichel, Wolokhov \& Demaree, 2008). Therefore, future studies should examine the relationship between WM and ER in youth with ADHD.

The present study also examined DT as a behavioral index of ER. Results did not suggest a significant relationship between DT and ER. These results fall in contrast to the findings of Gratz and colleagues (2006) who found a significant negative relationship between DT and self-reported emotion dysregulation in adults both with and without personality disorders. This discordance may be the result of methodological differences between the studies as Gratz and colleagues (2006) utilized an adult population (ages 18 to 60 -years-old) whereas the present study examined DT and ER in late childhood/early adolescent youth. Moreover, Gratz's sample consisted of individuals with borderline personality disorder, a disorder characterized by emotional avoidance and distress intolerance (Linehan, 1993), whereas the present sample examined individuals with and without ADHD.

Furthermore, DT was not significantly associated with group status, and when DT was included as a mediator in the hypothesized models, DT did not mediate the relationship between ADHD diagnosis and depressive symptoms. The lack of associations found between DT and ADHD diagnosis appears disparate with previous 
research examining ER (and seemingly DT) in boys with ADHD (Melnick \& Hinshaw, 2000). Specifically, Melnick and Hinshaw (2000) found that boys with ADHD displayed significantly less constructive patterns of emotional coping including an inability to continue the task in the wake of frustration (i.e., poor DT) and extreme levels of negative affect, inability to problem-solve, and extreme focus on negative aspects of task (i.e., poor ER) than did non-ADHD comparison boys.

In comparing this research to the current study, two important methodological differences emerge. First, Melnick and Hinshaw (2000) utilized an observational paradigm in which the boys' overt behavioral responses to a frustrating stimuli (i.e., building a Lego model with 2 missing pieces) were coded for specific facets of ER (including a construct almost identical to DT) and well as overall ER ability. Second, the frustrating task was set in the midst of a family interaction (i.e., mother-child dyads), which given the abundant literature suggesting impaired parent-child relations in youth with ADHD (e.g., Johnston \& Mash, 2001), may have increased youth levels of frustration. Therefore, the entirety of a participant's expressions and behaviors in addition to the context in which the frustration is elicited may be particularly important in measuring DT in youth with ADHD.

Furthermore, in the current study, DT was only measured through one behavioral response, (i.e., quitting the task) rather than a contextual observation of a participant's response to the task as a whole (i.e., videotaping and coding youth facial expressions and behaviors while engaging in the task). However, Campos and colleagues (1989) suggest that observational coding allows the researcher to capture the context-specific expressions and "actions" used by participants in managing 
emotional responses while engaging in goal-directed behavior. As such, future studies examining DT in youth with ADHD should utilize observational coding systems which appear to more wholly capture the context-specific range of expressions and emotions demonstrated by youth with ADHD.

Alternatively, the lack of association between DT and ADHD status may be the result of the tasks being computer-based which may elicit less frustration for youth with ADHD than social paradigms, such as frustrating interactions with parents or peers. In fact, research has demonstrated a significant positive relationship between ADHD diagnosis and internet use in youth (Yoo, Cho, Ha, Yune, Kim, Hwang et al., 2004). Furthermore, in comparison to control youth, youth with ADHD have demonstrated greater intensity with video game play (Bioulac, Afri, \& Bouvard, 2008). Jensen and colleagues hypothesize that extensive exposure to television and video games may actually promote development of brain systems that scan and shift attention at the expense of those that focus attention (Jensen, et al., 1997). Therefore, for youth with ADHD, computerized tasks of DT may not yield distress, but rather increase engagement in the task due to the constant feedback provided by such tasks and constant shifts in attention.

Such research might also explain the results of the current study in which the BIRD, one of the behavioral DT tasks, did not appear to elicit distress in the current sample which is in contrast to the only other study that has utilized the BIRD with youth participants (Daughters et al., 2009). In the present study, results examining pre- and post- task measures of distress did not demonstrate significant differences in experienced "distress" as a result of the task; moreover, only $26 \%$ of the sample quit 
the task prior to the 5-minute task period in comparison to $73 \%$ on the Mirror tracing task. Therefore, it may be that distress was not in fact elicited by the BIRD in the present sample because youth viewed it as a "videogame".

An alternate interpretation for why the BIRD did not appear to elicit distress may be that individuals who did not report an increase in distress actually display higher levels of DT, and as such, were able to regulate their affect before it became detectable. In fact, Campos and colleagues (2004) describe, inhibition, a key process in the regulation of emotion, may actually precede the activation of the cerebral emotional circuits involved in the elicitation of an emotion. That is, prior to the actual demonstration of emotion, an individual with a good ability to regulate his/her emotions (i.e., high distress tolerance) may be able to inhibit their distress. However, this explanation does not fit with the literature suggesting that youth with ADHD actually have great difficulty inhibiting their frustration and frequently demonstrate negative behaviors when frustrated (Lawrence, Houghton, Tannock, Douglas, Durkin \& Whiting, 2002; Scime \& Norvilitis, 2006; Walcott \& Landau, 2004). Therefore, future studies should examine if the experimental paradigms or tasks which elicit distress are different for youth with and without ADHD. For example, it may be that tasks, such as those used by Melnick and Hinshaw (2000) are better able to elicit distress in youth with ADHD. Additionally, future studies using the BIRD, may find it useful to employ observational methods in order to assess pre- and post- task behavioral indicators of distress or negative affect, not just participant ratings.

The finding of the current study must be considered in the context of some limitations. The current study included a sample of 69 participants, which limited the 
number of parameters able to be specified in the present path analysis. As a result, other important variables such as various risk factors for depression including: parental psychopathology (Chronis et al., 2003a; Nigg \& Hinshaw, 1998), negative parent-child interactions (Johnston \& Mash, 2001), impaired peer relationships (Blachman \& Hinshaw, 2002; Hoza, Mrug, Gerdes, Hinshaw, Bukowski, Gold, et al., 2005; Mrug, Hoza, Gerdes, Hinshaw, Arnold, Hectman et al., 2009) and low selfesteem or self-efficacy (Hoza et a., 2004; Owens, Goldfine, Evangelista, Hoza, \& Kaiser, 2007) could not be included in the model. Additionally, a larger sample size would allow for the examination of the relationship between ADHD, ER and depressive disorders, not just depressive symptoms. Such examination was not possible given the low base rates of depressive disorders in youth (Avenevoli, et al., 2008; Birmaher, et al., 1996; Kessler, et al., 2001; Shaffer, et al., 1996). Furthermore, the current study was cross-sectional which does not provide information about the temporal relationship between ADHD, ER and depressive symptoms in youth. While the current study examined ER through parent and youth report, it does not provide information about specific ER strategies utilized by youth. The actual strategies employed by youth may be just as important as the ability to regulate emotion as research suggests that youth with depressive disorders demonstrate more avoidant, passive and aggressive strategies, and fewer problem-focused and active distraction emotion regulation strategies that youth without depressive disorder (Garber Braafladt, \& Zeman, 1991; Garber, Braafladt, \& Weiss, 1995).

Despite these limitations, the current study adds to the literature in a number of ways. Despite the deleterious outcomes, including the three fold risk of completing 
suicide (James, et al, 2004), for youth with comorbid ADHD and depressive symptoms, this study represents one of the first studies to examine potential mediators in the relationship between ADHD and depressive symptoms in youth. The identification of factors involved in this relationship, provides important information for future interventions. The present study examined the role of both effortful control and ER as mediators in the relationship between ADHD and depressive symptoms in youth. The results indicate the importance of ER in the relationship between ADHD and depression in youth providing a new avenue for intervention efforts, in particular teaching youth with ADHD ways to better identify and regulate distressing emotions.

Future research should examine which particular aspects of ER are important in this relationship. Additionally, future studies should focus on the longitudinal examination of ADHD, ER and depressive symptoms in large samples of youth. Such studies would allow for the examination of the temporal relationship between ADHD, ER and depression, but also a large sample size would allow a more comprehensive model, that includes the various risk factors for depression in youth, to be tested. Furthermore, the present study found that a number of demographic variables including child gender and ethnicity/race, as well as parent education were significant in the relationship between ADHD, ER and depressive symptoms. While matching groups based on these variables was not feasible in the current study, future studies should make efforts to match groups based on these demographic variables.

Furthermore, the present study did not demonstrate differences between youth with and without ADHD on the Stroop task suggesting that perhaps the Stroop task is 
not an appropriate measure of effortful control. As such, future research should examine alternate cognitive tasks (e.g., stop-signal task, anti-saccade task, etc) and their relation to effortful control. Another possibility is that perhaps the underlying deficit in youth with ADHD is not behavioral inhibition but rather a deficit in WM (Martinussen et al. 2005; Marzocchi et al. 2008; Rapport et al., 2008a; Willcutt et al. 2005). Further, given the increasing support that WM deficits are present in individuals with ADHD, research should examine the role of WM in ER in youth with ADHD. Lastly, given that youth with ADHD often demonstrate knowledge of appropriate actions, but often have difficulty in the appropriate execution of these actions (Whalen \& Henker, 1985), future studies of ADHD, ER and depression should examine ER through laboratory tasks which allow for the observation of ER during emotion-arousing stimulus in addition to parent and self-report measures of ER.

Lastly, this was the first study to examine DT in youth with ADHD. While it was initially hypothesized that youth with ADHD may have deficits in DT, results from the present study did not find a significant association between ER and DT. These results fall in contrast to the findings of Gratz and colleagues (2006); therefore, future research is needed to clarify this relationship including studies that examine this relationship in relation to various forms of psychopathology, developmental levels and genders.

A number of clinical implications arise from the results of the current study. Most importantly, the current study highlights the importance of ER in the relationship between ADHD and depression. These results suggest the importance of 
assessing for depressive symptoms and ER ability in clinical practice. Additionally, these results may suggest the need to provide youth with ADHD extensive training in the identification of emotions and the use of emotion-regulation strategies in order to prevent the serious negative outcomes associated with comorbid ADHD and depression. For example, Kovacs and colleagues (2006) piloted contextual emotionregulation therapy (CERT) in 20 youth, ages 7-12 years-old, with dysthymic disorder. CERT is based on the rationale that dysfunctional self-regulation of distress and dysphoria, key characteristics in youth with depression, precede the onset of depression. Therefore, youth experiences of environmental stress may interact with pre-existing regulatory difficulties and culminates in the progression of dysphoric emotion. Results of Kovac and colleagues (2006) small pilot study suggested that $53 \%$ of completers had full remission while $13 \%$ had partial remission of their dysthymia. Follow-up results collected 12-months post-treatment demonstrated that $92 \%$ of completers experienced full remission of their dysthymia. These results suggest the potential impact of teaching pre-adolescent youth with ADHD how to better regulate their emotions. 
Table 1. Youth and Parent Participant Demographics

\begin{tabular}{|c|c|c|c|c|}
\hline & & $\begin{array}{l}\text { ADHD } \\
(\mathrm{n}=37)\end{array}$ & $\begin{array}{l}\text { Control } \\
(\mathrm{n}=32)\end{array}$ & Significance level \\
\hline \multicolumn{5}{|l|}{ Youth Demographics } \\
\hline & Age, years & $11.81(1.47)$ & $11.50(1.24)$ & $F(1,67)=.884, p=n . s$. \\
\hline & Sex $(\%$ male $)$ & $68 \%(25)$ & $44 \%(14)$ & $\chi^{2}(1,69)=3.961 *$ \\
\hline & Race/Ethnicity & & & $\chi^{2}(2,69)=5.729 *$ \\
\hline & African-American & $30 \%(11)$ & $13 \%(4)$ & \\
\hline & Caucasian & $40 \%(15)$ & $68 \%(22)$ & \\
\hline & Biracial or Other & $30 \%(11)$ & $19 \%(6)$ & \\
\hline & WISC-IV scaled scores & & & \\
\hline & Block Design & $10.37(3.39)$ & $11.56(3.34)$ & $F(1,65)=2.094, p=$ \\
\hline & Vocabulary & $12.20(2.85)$ & $13.44(3.16)$ & $\begin{array}{l}\text { n.s. } \\
F(1,65)=2.842, p= \\
n . s .\end{array}$ \\
\hline \multicolumn{5}{|l|}{$\begin{array}{l}\text { Youth ADHD, ODD, } \\
\text { and CD symptoms }\end{array}$} \\
\hline & Total ADHD symptoms & $11.51(4.39)$ & $.72(1.46)$ & $F(1,64)=133.486^{* * *}$ \\
\hline & Inattentive symptoms & $7.03(2.55)$ & $.25(.62)$ & $F(1,64)=172.214 * * *$ \\
\hline & $\begin{array}{l}\text { Hyperactivity/impulsivity } \\
\text { symptoms }\end{array}$ & $4.49(2.84)$ & $.47(1.05)$ & $F(1,64)=39.586^{* * *}$ \\
\hline & ODD symptoms & $2.73(2.59)$ & $.41(1.16)$ & $F(1,64)=16.243 * * *$ \\
\hline & CD symptoms & $.70(1.20)$ & $.00(.00)$ & $F(1,64)=9.734 * *$ \\
\hline \multicolumn{5}{|l|}{ Youth Impairment } \\
\hline & $\begin{array}{l}\text { Parent-rated overall } \\
\text { impairment }\end{array}$ & $3.76(1.82)$ & $.49(1.22)$ & $F(1,64)=60.381 * * *$ \\
\hline & $\begin{array}{l}\text { Teacher-rated overall } \\
\text { impairment }^{\mathrm{a}}\end{array}$ & $3.54(1.82)$ & $.64(1.14)$ & $F(1,45)=41.368 * * *$ \\
\hline \multirow[t]{6}{*}{ Parent Demographics } & Parental age, years & $45.19(6.78)$ & $45.97(5.53)$ & $F(1,67)=.269, p=n . s$. \\
\hline & Parental marital status & & & $\begin{array}{l}\chi^{2}(1,69)=.528 \\
p=n . s\end{array}$ \\
\hline & Married & $81 \%(30)$ & $88 \%(28)$ & \\
\hline & Divorced/separated/other & $19 \%(7)$ & $12 \%(4)$ & \\
\hline & $\begin{array}{l}\text { Parental average educational } \\
\text { level }\end{array}$ & $\begin{array}{l}\text { Bachelor's } \\
\text { degree }\end{array}$ & $\begin{array}{l}\text { Master's } \\
\text { degree }\end{array}$ & $F(1,56)=10.238 * *$ \\
\hline & Average total family income & $\begin{array}{l}\$ 115,176 \\
(\$ 57,455)\end{array}$ & $\begin{array}{l}\$ 109,250 \\
(\$ 50,633)\end{array}$ & $\begin{array}{l}F(1,56)=.165, p= \\
\text { n.s. }\end{array}$ \\
\hline
\end{tabular}

Note. Results presented as M (SD) or as percent $(n)$. WISC scaled scores are presented in which the mean is 10.

Total ADHD, inattention, hyperactivity/impulsivity, ODD and CD symptoms were computed using the "or" rule

from Parent and Teacher DBD forms. $\mathrm{ADHD}=$ attention-deficit/hyperactivity disorder, $\mathrm{DBD}=\mathrm{Disruptive}$

Behavior Disorders symptom checklist, $\mathrm{ODD}=$ Oppositional Defiant Disorder, $\mathrm{CD}=\mathrm{Conduct}$ Disorder, WISC $=$

Wechsler Intelligence Scale for Children, $4^{\text {th }}$ edition.

${ }^{\mathrm{a}} \mathrm{n}=24$ and 22 respectively

$* p<.05$

$* * p<.01$ 


\begin{tabular}{|c|c|c|c|c|c|c|c|c|c|c|c|c|}
\hline Variables & 1 & 2 & 3 & 4 & 5 & 6 & 7 & 8 & 9 & 10 & 11 & 12 \\
\hline $\begin{array}{l}\text { 1. ADHD } \\
\text { diagnosis }\end{array}$ & -- & & & & & & & & & & & \\
\hline $\begin{array}{l}\text { 2. Depression } \\
\text { composite }\end{array}$ & $.386^{* *}$ & -- & & & & & & & & & & \\
\hline $\begin{array}{l}\text { 3. ER } \\
\text { composite }\end{array}$ & $-.397 * *$ & $-.701 * *$ & -- & & & & & & & & & \\
\hline $\begin{array}{l}\text { 4. Distress } \\
\text { Tolerance }\end{array}$ & -.112 & -.067 & .182 & -- & & & & & & & & \\
\hline $\begin{array}{l}\text { 5. Effortful } \\
\text { Control (RT) }\end{array}$ & .023 & -.104 & -.020 & -.148 & -- & & & & & & & \\
\hline $\begin{array}{l}\text { 6. Effortful } \\
\text { Control } \\
\text { (percent } \\
\text { accuracy) }\end{array}$ & .178 & -.067 & -.007 & -.021 & $-.271^{*}$ & -- & & & & & & \\
\hline 7. Child age & .093 & .161 & -.218 & .163 & -.042 & .052 & -- & & & & & \\
\hline $\begin{array}{l}\text { 8. Child } \\
\text { ethnicity/race }\end{array}$ & $.239 *$ & $.242 * *$ & $-.301 * *$ & -.007 & -.055 & .050 & .122 & -- & & & & \\
\hline $\begin{array}{l}\text { 9. Child } \\
\text { gender }\end{array}$ & $-.240^{*}$ & .121 & -.166 & .110 & -.005 & -.005 & -.061 & -.151 & -- & & & \\
\hline 10. Parent age & -.055 & -.097 & .200 & .132 & -.103 & .234 & $.244 *$ & -.104 & -.022 & -- & & \\
\hline $\begin{array}{l}\text { 11. Parent } \\
\text { education }\end{array}$ & $-.290 * *$ & -.128 & $.202 *$ & .010 & -.059 & .204 & -.080 & -.026 & .197 & $.199 *$ & -- & \\
\hline $\begin{array}{l}\text { 12. Parent } \\
\text { marital status }\end{array}$ & -.087 & .092 & -.016 & -.031 & .056 & .151 & .027 & .083 & -.017 & -.091 & .002 & -- \\
\hline
\end{tabular}

Note. Results are reported as Pearson product-moment correlations or Kendall's tau as appropriate. ADHD = Attention deficit/hyperactivity disorder, $\mathrm{ER}=$ Emotion regulation, $\mathrm{RT}=$ response time.

$* p<.05, * * p<.01$ 
Table 3. Depressive symptoms, ER, DT and Effortful Control by Group

\begin{tabular}{llll}
\hline Variables & $\begin{array}{l}\text { ADHD } \\
(\mathbf{n}=\mathbf{3 7})\end{array}$ & $\begin{array}{l}\text { Control } \\
(\mathbf{n}=\mathbf{3 2})\end{array}$ & Significance level \\
\hline Depression composite (t-scores) & $52.54(9.42)$ & $44.58(6.71)$ & $F(4,65)=6.55^{* * *}$ \\
Emotion Regulation composite & $-.434(.980)$ & $.502(.770)$ & $F(4,65)=5.003^{* * *}$ \\
Distress tolerance (latency to quit, & $125.38(102.15)$ & $156.35(117.69)$ & $F(4,60)=0.645, p=n . s$. \\
seconds) & & & \\
Effortful control (\% accuracy) ${ }^{\mathrm{b}}$ & $-.467(1.814)$ & $-.7692(.951)$ & $F(4,51)=.980, p=\mathrm{n} . \mathrm{s}$ \\
\hline Effortful control (RT, seconds) & $217.57(184.86)$ & $210.14(136.01)$ & $F(4,51)=0.432, p=n . s$. \\
\hline Note. Results presented as mean \pm SD. & & \\
${ }^{\mathrm{a}} \mathrm{n}=35$ and 29 respectively & & & \\
${ }^{\mathrm{b}} \mathrm{n}=29$ and 26 respectively & & & \\
$* * *<<01$ & & & \\
$* * * p<.001$ & & &
\end{tabular}




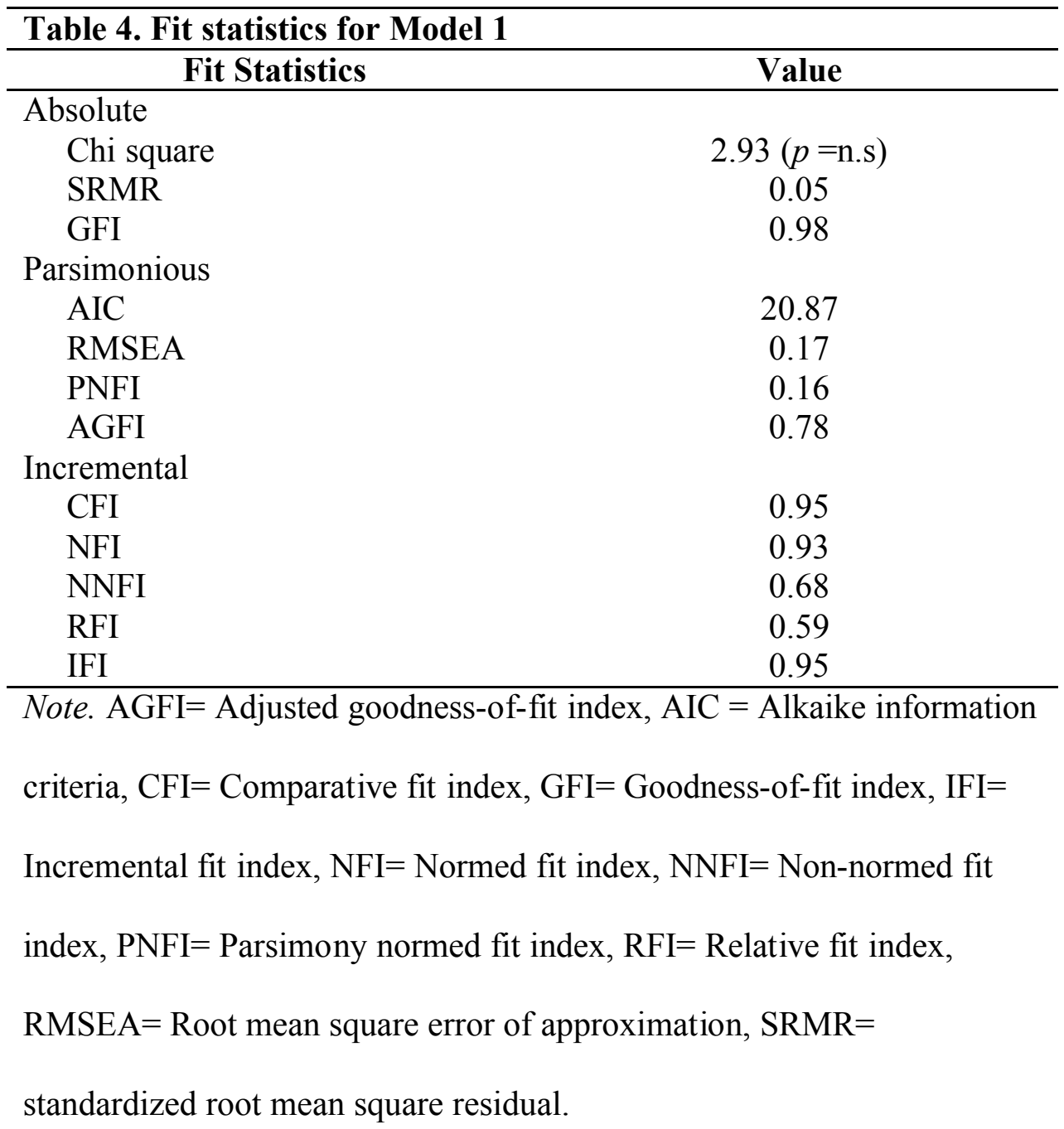




\begin{tabular}{|c|c|c|c|c|c|c|}
\hline Variable & $\begin{array}{c}\text { Standardized } \\
\text { beta weights } \\
(\beta)\end{array}$ & $\begin{array}{l}\text { Unstandardized } \\
\text { beta weights } \\
\text { (B) }\end{array}$ & $\begin{array}{c}\text { Standard } \\
\text { Error }\end{array}$ & $\begin{array}{c}t- \\
\text { value }\end{array}$ & $\begin{array}{c}p \text { - } \\
\text { value }\end{array}$ & $\mathbf{R}^{2}$ \\
\hline \multicolumn{7}{|c|}{ Dependent variable $=$ Depressive symptoms } \\
\hline ADHD & 0.15 & 2.40 & 1.91 & 1.51 & .130 & .44 \\
\hline ER & -0.60 & -5.62 & 0.91 & -6.15 & .000 & -- \\
\hline \multicolumn{7}{|c|}{ Dependent variable $=\mathbf{E R}$} \\
\hline ADHD & $-\mathbf{0 . 3 0}$ & -0.52 & 0.21 & -2.50 & .012 & .091 \\
\hline Effortful & -0.03 & -0.00017 & 0.00065 & -0.24 & .807 & -- \\
\hline \multicolumn{7}{|c|}{ Dependent variable $=$ Effortful control } \\
\hline ADHD & 0.05 & 15.32 & 39.90 & 0.38 & .701 & .0023 \\
\hline
\end{tabular}


Table 6. Fit statistics for Model 2

\begin{tabular}{lc}
\hline \multicolumn{1}{c}{ Fit Statistics } & Value \\
\hline Absolute & $1.36(p=\mathrm{n} . \mathrm{s})$ \\
Chi square & 0.04 \\
SRMR & 0.99 \\
GFI & 19.27 \\
Parsimonious & 0.07 \\
AIC & 0.15 \\
RMSEA & 0.90 \\
PNFI & 0.93 \\
AGFI & 0.88 \\
Incremental & 0.61 \\
CFI & 0.28 \\
NFI & 0.97 \\
NNFI & \\
RFI & \\
IFI & \\
Note. AGFI= Adjusted goodness-of-fit index, AIC $=$ Alkaike information \\
criteria, CFI= Comparative fit index, GFI= Goodness-of-fit index, IFI= \\
Incremental fit index, NFI= Normed fit index, NNFI= Non-normed fit \\
index, PNFI= Parsimony normed fit index, RFI= Relative fit index, \\
RMSEA= Root mean square error of approximation, SRMR= \\
standardized root mean square residual.
\end{tabular}


Table 7. Structural Equations for Model 2

\begin{tabular}{|c|c|c|c|c|c|c|}
\hline Variable & $\begin{array}{c}\text { Standardized } \\
\text { beta weights } \\
(\beta)\end{array}$ & $\begin{array}{l}\text { Unstandardized } \\
\text { beta weights } \\
\text { (B) }\end{array}$ & $\begin{array}{c}\text { Standard } \\
\text { Error }\end{array}$ & $\begin{array}{c}t- \\
\text { value }\end{array}$ & $\begin{array}{c}p \text { - } \\
\text { value }\end{array}$ & $\mathbf{R}^{2}$ \\
\hline \multicolumn{7}{|c|}{ Dependent variable $=$ Depressive symptoms } \\
\hline ADHD & 0.33 & 5.33 & 1.58 & 2.76 & .005 & .11 \\
\hline DT & -0.02 & -0.00 & 0.008 & 0.02 & .984 & -- \\
\hline \multicolumn{7}{|c|}{ Dependent variable $=\mathrm{DT}$} \\
\hline ADHD & -0.16 & -35.35 & 0.21 & -1.32 & .175 & .044 \\
\hline Effortful & -0.12 & -0.09 & 0.000 & -1.02 & .308 & -- \\
\hline \multicolumn{7}{|c|}{ Dependent variable $=$ Effortful control } \\
\hline ADHD & 0.05 & 15.48 & 39.90 & 0.39 & .698 & .002 \\
\hline
\end{tabular}




\section{Appendices}

Appendix A. Discussion of Distress Tolerance and its Relationship to Psychopathology

Appendix B: Distribution statistics for all variables

Appendix C. Path analysis for Model 1 presented with overlapping depression items

removed from ER composite 


\section{Appendix A. Discussion of Distress Tolerance and its Relationship to Psychopathology}

\section{Distress Tolerance}

\section{Function and Definition.}

Another factor which may be important in the development of depression in youth with ADHD is distress tolerance (DT). The concept of DT was initially introduced by Marsha Linehan in her work with adults with borderline personality disorder (BPD), where an absence of DT was thought to underlie the maladaptive and impulsive behaviors common among these individuals (Linehan, 1993). DT has since been examined in the adult smoking cessation (Brown, Lejuez, Kahler, Strong, \& Zvolensky, 2005) and substance use literature (Daughters, Lejuez, Kahler, Strong \& Brown, 2005; Daughters, Lejuez, Bornovalova, Kahler, Strong \& Brown, 2005). DT refers to the behavioral assessment of persistence in goal-directed behavior in the face of emotional distress (e.g., frustration, disappointment, anger; Brown et al., 2005). According to Brown and colleagues (2005), DT is "the behavioral tendency to persist in pursuit of a goal despite encountering various states of affective discomfort which may be in response to perceived physical and/or psychological distress" (p. 718). In order to persist in the wake of affective discomfort, individuals must decline the immediate negative reinforcement available by quitting the pursuit of the goal, and instead continue in the goal-directed behavior with the long-term goal of completion and success. Therefore, low DT is characterized by an inability to persist in goaloriented behavior during an aversive situation and is reflective of how one copes with the negative affect resulting from environmental and interpersonal challenges 
(Brown et al., 2005). Furthermore, DT is directly related to an individual's ability to regulate negative emotion. In fact, DT involves an individual's evaluation and expectation of experiencing negative emotional states with regard to (a) tolerability

and aversiveness, (b) appraisal and acceptability, (c) tendency to absorb attention and disrupt functioning, and (d) regulation of emotions, in particular the ability to avoid or attenuate the experience (Simons \& Gaher, 2005). Since ER requires both the regulation of affect and the regulation of behavior by affective processes (i.e., use of emotion to regulate behavior)(Campos, Campos, \& Barrett, 1989; Carver, Lawrence \& Scheier, 1996), the inability to tolerate psychological distress (i.e., low DT) may influence how an individual manages his/her emotions and may moderate the effect that emotion has on behavior (Simons \& Gaher, 2005). Self-report and behavioral measures of DT have demonstrated moderate negative associations with measures of affect dysregulation (Simons \& Gaher, 2005). Given the relationship between DT and the regulation of negative emotions, DT may be particularly important in the development of depression in youth with ADHD.

\section{DT and Psychopathology.}

DT has been suggested to underlie maladaptive behaviors in a number of forms of psychopathology. At the current time, the examination of DT in clinical populations has been limited mostly to adults. Specifically, research has focused on how individuals with low levels of DT may have an inability to handle exposure to negative emotions caused by smoking cessation (Brown, Lejuez, Kahler \& Strong, 2002; Brown et al., 2005); abstinence from drugs and alcohol (Daughters, Lejuez, Kahler, et al., 2005; Daughters, Lejuez, Bornovalova, et al., 2005); treatment for 
eating disorders (Anestis, Selby, Fink \& Joiner, 2007; Waller, Corstorphine, \& Mountford, 2007); and cessation of self-harm behaviors in individuals with BPD (Gratz, 2003).

To date, only one study has examined DT in adolescents. In a community sample of adolescents ages 9 to 13, Daughters and colleagues (2009) examined the relationship between DT and internalizing and externalizing problems. The examination of externalizing problems suggested an interaction of DT and adolescent ethnicity such that higher levels of alcohol use were found in Caucasian youth with low levels of DT than in either Caucasian youth with high levels of DT or AfricanAmerican youth regardless of distress tolerance. In terms of delinquent behavior, African-American youth with low levels of DT demonstrated higher levels of delinquent behavior than either African-American youth with higher levels of DT or Caucasian youth regardless of distress tolerance. Results for internalizing problems suggested an interaction of both adolescent gender and ethnicity with distress tolerance. First, females with low levels of DT reported higher levels of internalizing symptoms than females with higher levels of distress tolerance, but for males there was no effect of DT on internalizing symptoms. Additionally, African-American adolescents with low levels of DT reported greater levels of internalizing symptoms than African-American adolescents with high DT. There was no effect of DT on internalizing symptoms in Caucasian youth. These results suggest the potential importance of DT in both externalizing and internalizing disorders as well as the importance of race/ethnicity and gender in the examination of DT. 
DT has never been examined in an ADHD sample. However, the previously reviewed literature illustrating that youth with ADHD have higher levels of frustration and lower levels of task persistence than their non-ADHD comparison peers in the wake of challenging puzzles or tasks may suggest that youth with ADHD may also have lower levels of distress tolerance. The inability of youth with ADHD to persist on a challenging puzzle task demonstrates an inability to persist in goaloriented behavior during an aversive situation, which is the hallmark of low distress tolerance. Based on the prior literature, it appears likely that youth with ADHD may have difficulties with distress tolerance. Given the relationship between DT and internalizing problems in some youth (Daughters et al., 2009) and the high comorbidity between ADHD and depression, distress tolerance appears to be a factor that warrants examination in the relationship between ADHD and depression. While the results of Daughters and colleagues (2009) have suggested the importance of DT and both internalizing and externalizing disorders, the focus of the current study is the relation between ADHD and the development of depression. 
Appendix B: Distribution statistics for all variables

\begin{tabular}{|c|c|c|c|c|c|c|c|}
\hline Variable & n & M (SD) & Range & Skew (SE) & $\begin{array}{c}\text { Skew } \\
\text { z-score }\end{array}$ & $\begin{array}{c}\text { Kurtosis } \\
\text { (SE) }\end{array}$ & $\begin{array}{c}\text { Kurtosis } \\
\text { z-score }\end{array}$ \\
\hline $\begin{array}{l}\text { BASC-SRS } \\
\text { Total } \\
\text { ADHD group } \\
\text { Control group }\end{array}$ & $\begin{array}{l}69 \\
37 \\
32\end{array}$ & $\begin{array}{c}47.94(9.82) \\
50.05(11.25) \\
45.50(7.28)\end{array}$ & $\begin{array}{l}40-80 \\
40-80 \\
40--71\end{array}$ & $\begin{array}{l}1.646(.289) \\
1.227(.388) \\
2.377(.414)\end{array}$ & $\begin{array}{l}5.700 \\
3.165 \\
5.734\end{array}$ & $\begin{array}{c}1.876(.570) \\
.494(.759) \\
5.600(.809)\end{array}$ & $\begin{array}{l}3.290 \\
0.065 \\
6.920\end{array}$ \\
\hline $\begin{array}{l}\text { BASC-PRS } \\
\text { Total } \\
\text { ADHD group } \\
\text { Control group }\end{array}$ & $\begin{array}{l}69 \\
37 \\
32\end{array}$ & $\begin{array}{c}51.58(11.07) \\
55.70(11.69) \\
46.81(8.15)\end{array}$ & $\begin{array}{l}37-88 \\
39-88 \\
37-71\end{array}$ & $\begin{array}{c}.897(.289) \\
.591(.388) \\
1.123(.414)\end{array}$ & $\begin{array}{l}3.107 \\
1.525 \\
2.709\end{array}$ & $\begin{array}{c}.484(.570) \\
.036(.759) \\
1.154(.809)\end{array}$ & $\begin{array}{l}0.850 \\
0.047 \\
1.426\end{array}$ \\
\hline $\begin{array}{l}\text { CDI } \\
\text { Total } \\
\text { ADHD group } \\
\text { Control group }\end{array}$ & $\begin{array}{l}69 \\
37 \\
32\end{array}$ & $\begin{array}{c}46.12(10.76) \\
49.38(11.44) \\
42.34(8.64)\end{array}$ & $\begin{array}{l}35-78 \\
35-78 \\
35-70\end{array}$ & $\begin{array}{c}1.303(.289) \\
.915(.388) \\
2.191(.414)\end{array}$ & $\begin{array}{l}4.515 \\
2.362 \\
5.287\end{array}$ & $\begin{array}{c}.858(.570) \\
.136(.759) \\
4.134(.809)\end{array}$ & $\begin{array}{l}1.504 \\
0.179 \\
5.108\end{array}$ \\
\hline $\begin{array}{l}\text { ERC } \\
\text { Total } \\
\text { ADHD group } \\
\text { Control group }\end{array}$ & $\begin{array}{l}69 \\
37 \\
32\end{array}$ & $\begin{array}{l}27.54(3.71) \\
26.14(3.71) \\
29.16(3.03)\end{array}$ & $\begin{array}{l}16-32 \\
16-32 \\
19-32\end{array}$ & $\begin{array}{c}-.883(.289) \\
-.473(.388) \\
-1.847(.414)\end{array}$ & $\begin{array}{l}-3.057 \\
-1.220 \\
-4.457\end{array}$ & $\begin{array}{l}.264(.570) \\
-.047(.759) \\
4.114(.809)\end{array}$ & $\begin{array}{c}0.463 \\
-0.062 \\
5.083\end{array}$ \\
\hline $\begin{array}{l}\text { DERS } \\
\text { Total } \\
\text { ADHD group } \\
\text { Control group }\end{array}$ & $\begin{array}{l}69 \\
37 \\
32\end{array}$ & $\begin{array}{l}73.23(21.08) \\
80.64(22.25) \\
64.66(16.06)\end{array}$ & $\begin{array}{l}37-134 \\
42-134 \\
37-106\end{array}$ & $\begin{array}{l}.756(.289) \\
.576(.388) \\
.524(.414)\end{array}$ & $\begin{array}{l}2.618 \\
1.487 \\
1.307\end{array}$ & $\begin{array}{l}.284(.570) \\
-.260(.759) \\
.037(.809)\end{array}$ & $\begin{array}{c}0.500 \\
-0.342 \\
0.046\end{array}$ \\
\hline $\begin{array}{l}\text { Stroop interference (RT) } \\
\text { Total } \\
\text { ADHD group } \\
\text { Control group }\end{array}$ & $\begin{array}{l}55 \\
29 \\
26\end{array}$ & $\begin{array}{l}214.06(162.17) \\
217.57(184.86) \\
210.14(136.01)\end{array}$ & $\begin{array}{c}-106.59-593.17 \\
-106.59-593.17 \\
-22.25-537.38\end{array}$ & $\begin{array}{l}.356(.322) \\
.273(.434) \\
.508(.456)\end{array}$ & $\begin{array}{l}1.108 \\
0.630 \\
1.114\end{array}$ & $\begin{array}{l}-.219(.634) \\
-.512(.845) \\
.109(.887)\end{array}$ & $\begin{array}{l}-.0 .345 \\
-0.605 \\
0.123\end{array}$ \\
\hline
\end{tabular}




\begin{tabular}{|c|c|c|c|c|c|c|c|}
\hline $\begin{array}{l}\text { Stroop interference (\% correct) } \\
\text { Total } \\
\text { ADHD group } \\
\text { Control group }\end{array}$ & $\begin{array}{l}55 \\
29 \\
26\end{array}$ & $\begin{array}{l}-.607(1.473) \\
-.467(1.814) \\
-.769(1.473)\end{array}$ & $\begin{array}{l}-7.00-2.00 \\
-7.00-2.00 \\
-3.00-1.00\end{array}$ & $\begin{array}{l}-1.392(.319) \\
-1.616(.427) \\
-.200(.456)\end{array}$ & $\begin{array}{r}-4.364 \\
-3.785 \\
0.439\end{array}$ & $\begin{array}{l}5.368(.628) \\
4.711(.833) \\
.107(.887)\end{array}$ & $\begin{array}{l}8.548 \\
5.655 \\
0.121\end{array}$ \\
\hline $\begin{array}{l}\text { MT (latency to quit) } \\
\text { Total } \\
\text { ADHD group } \\
\text { Control group }\end{array}$ & $\begin{array}{l}64 \\
35 \\
29\end{array}$ & $\begin{array}{l}139.41(109.68) \\
125.38(102.15) \\
156.35(117.69)\end{array}$ & $\begin{array}{c}6.70-300.00 \\
6.70-300.00 \\
15.05-300.00\end{array}$ & $\begin{array}{l}.502(.299) \\
.671(.398) \\
.299(.434)\end{array}$ & $\begin{array}{l}1.679 \\
1.688 \\
0.690\end{array}$ & $\begin{array}{l}-1.385(.590) \\
-.909(.778) \\
-1.832(.845)\end{array}$ & $\begin{array}{l}-2.346 \\
-1.169 \\
-2.168\end{array}$ \\
\hline $\begin{array}{l}\text { Depression composite } \\
\text { Total } \\
\text { ADHD group } \\
\text { Control group }\end{array}$ & $\begin{array}{l}69 \\
37 \\
32\end{array}$ & $\begin{array}{l}48.85(9.14) \\
52.54(9.42) \\
44.58(6.71)\end{array}$ & $\begin{array}{l}36.50-72.00 \\
37.00-72.00 \\
36.50-64.00\end{array}$ & $\begin{array}{l}.752(.289) \\
.304(.388) \\
1.407(.414)\end{array}$ & $\begin{array}{l}2.603 \\
0.784 \\
3.395\end{array}$ & $\begin{array}{l}-.396(.570) \\
-.827(.759) \\
1.644(.809)\end{array}$ & $\begin{array}{l}-0.694 \\
-1.091 \\
2.0314\end{array}$ \\
\hline $\begin{array}{l}\text { ER composite } \\
\text { Total } \\
\text { ADHD group } \\
\text { Control group }\end{array}$ & $\begin{array}{l}69 \\
37 \\
32\end{array}$ & $\begin{array}{l}.000(1.00) \\
-.434(.980) \\
.502(.770)\end{array}$ & $\begin{array}{l}-2.76-1.63 \\
-2.76-1.23 \\
-1.52-1.63\end{array}$ & $\begin{array}{l}-.580(.289) \\
-.267(.388) \\
-1.007(.414)\end{array}$ & $\begin{array}{l}-2.010 \\
-0.689 \\
-2.431\end{array}$ & $\begin{array}{l}-.317(.570) \\
-.489(.759) \\
1.043(.809)\end{array}$ & $\begin{array}{c}-0.556 \\
-0.645 \\
1.288\end{array}$ \\
\hline $\begin{array}{l}\text { Unstandardized residuals for } \\
\text { effortful control } \\
\text { Total } \\
\text { ADHD group } \\
\text { Control group }\end{array}$ & $\begin{array}{l}55 \\
29 \\
26\end{array}$ & $\begin{array}{c}.000(160.63) \\
10.98(179.60) \\
-12.24(138.95)\end{array}$ & $\begin{array}{l}-312.71-366.91 \\
-312.71-366.91 \\
-216.84-286.17\end{array}$ & $\begin{array}{l}.420(.322) \\
.289(.434) \\
.564(.456)\end{array}$ & $\begin{array}{l}1.306 \\
0.667 \\
1.238\end{array}$ & $\begin{array}{l}-.496(.634) \\
-.680(.845) \\
-.387(.887)\end{array}$ & $\begin{array}{l}-0.783 \\
-0.804 \\
-0.427\end{array}$ \\
\hline $\begin{array}{l}\text { Unstandardized residuals for ER } \\
\text { Total } \\
\text { ADHD group } \\
\text { Control group }\end{array}$ & $\begin{array}{l}69 \\
37 \\
32\end{array}$ & $\begin{array}{l}.000(.869) \\
-.245(.930) \\
.284(.706)\end{array}$ & $\begin{array}{l}-2.35-1.91 \\
-2.35-1.53 \\
-1.07-1.91\end{array}$ & $\begin{array}{l}-.283(.289) \\
-.093(.388) \\
-.012(.414)\end{array}$ & $\begin{array}{l}-0.981 \\
-0.241 \\
-0.030\end{array}$ & $\begin{array}{l}-.321(.570) \\
-.617(.759) \\
-.428(.809)\end{array}$ & $\begin{array}{l}-0.563 \\
-0.814 \\
-0529\end{array}$ \\
\hline
\end{tabular}




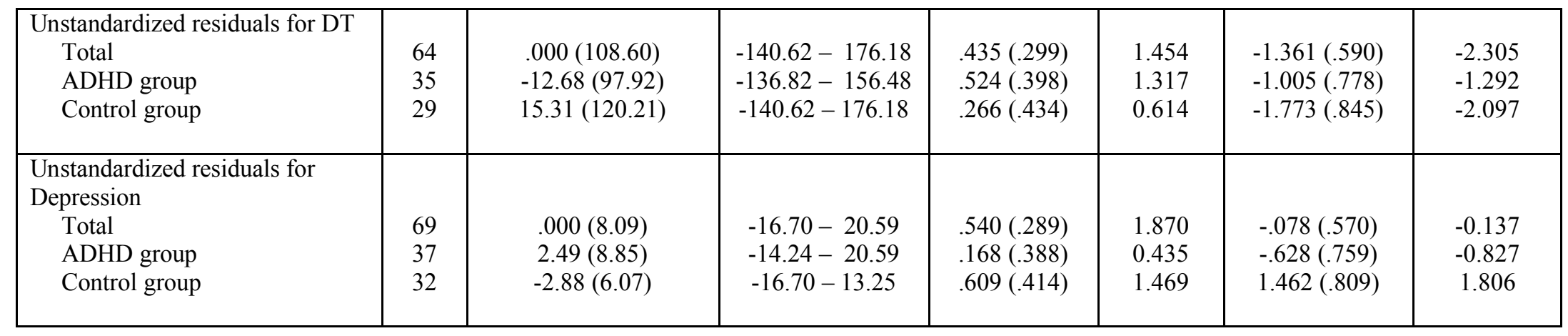




\section{Appendix C. Path analysis for Model 1 presented with overlapping depression items removed from ER composite}

As discussed in footnote 6, one problematic issue in the examination of ER and depression is that many measures of ER contain items that overlap with depressive symptoms (Abela \& Hankin, 2007; Gotlib \& Hammen, 2008; NolenHoeksema \& Hilt, 2008, for reviews). Therefore, to ensure that the findings of the current study (i.e., that completely ER mediates the relationship between ADHD and depression) are not spurious, the path analyses were re-run using a ER variable that had all items that overlapped with depression symptoms removed. Specifically, 2 items on the ER subscale of the ERC (i.e., Is a cheerful child; Seems sad or listless) and 3 items on the DERS (i.e., When I'm upset, I believe that I'll end up feeling very depressed; When I'm upset, I have difficulty concentrating; When I'm upset, I start to feel very bad about myself.) overlapped with depressive symptoms and were therefore removed. When these items were removed internal consistency for the ER scale on the ERC dropped from .75 to .65 and on the DERS from .92 to .91 .

\section{Preliminary analysis}

Despite the removal of these items, the ERC-ER subscale and DERS total score continued to be highly negatively correlated, $r=-.418, p<.000$, such that as DERS scores decreased (i.e., indicating greater regulation or less dysregulation), ER subscale scores increased (indicating greater ER ability). Given this correlation, PCA was used to assess whether a revised composite was indicated for ER. The KaiserMeyer-Olkin measure of sample adequacy was acceptable, $\mathrm{KMO}=.500$, as was

Bartlett's test of sphericity, $\chi^{2}(1)=12.74, p<.000$. Using the Kaiser (1960) criteria for 
eigenvalues, results of PCA demonstrated a one factor solution (eigenvalue $=1.418)$ which accounted for $70.9 \%$ of the variance (communality extraction value $=.709$ ). Use of a scree plot as proposed by Catell (1966) also produced a one factor solution. Component scores from the coefficient matrix were .594 and -.594 for the ERC ER subscale and DERS total score respectively. Therefore PCA analyses supported use of an ER composite despite the deletion of overlapping depression items. For the revised ER composite, higher scores are reflective of a greater ability to regulate one's emotions (i.e., better ER ability).

\section{Path analysis with revised ER composite}

Results examining Model 1 with the revised ER composite suggested that the model was a good fit for the data, $\chi^{2}=1.13, d f=1, p=0.29$. Therefore, additional fit statistics were reviewed. GFI (0.99), CFI (1.00), and SRMR (.03) and NNRI value (0.97) all indicated a strong fit. In fact, it appears that Model 1 with the revised ER composite is a better fit for the data than the initial Model 1 as the AIC value drops from 20.87 to 19.12 . Additional fit statistics are provided in Table 8 .

Examination of the paths specified in the model revealed that ADHD diagnosis significantly predicted ER ability, $\beta=-0.28, p=.002$, such that youth with ADHD demonstrated poorer ER than non-ADHD comparison youth. Emotion regulation was significantly related to depressive symptoms, $\beta=-0.52, p=.000$, such that youth with greater levels of emotion regulation displayed lower levels of depressive symptoms. Moreover, the path between ADHD and depression became non-significant, $\beta=0.18, p=.09$, when ER was included, suggesting a mediating effect of ER. ADHD diagnosis was not related to effortful control, $\beta=0.05, p=\mathrm{n} . \mathrm{s}$, 
and effortful control was not related to emotion regulation, $\beta=-0.04, p=$ n.s. The tested model with standardized and unstandardized beta weights is presented in Figure 12, and the results of the structural equations are presented in Table 9.

Figure 12. Path analysis indexes for Model 1 with revised ER composite.

Standardized path coefficients are presented with unstandardized coefficients in parentheses. Significant paths are represented by * $(\mathrm{p}<.01)$

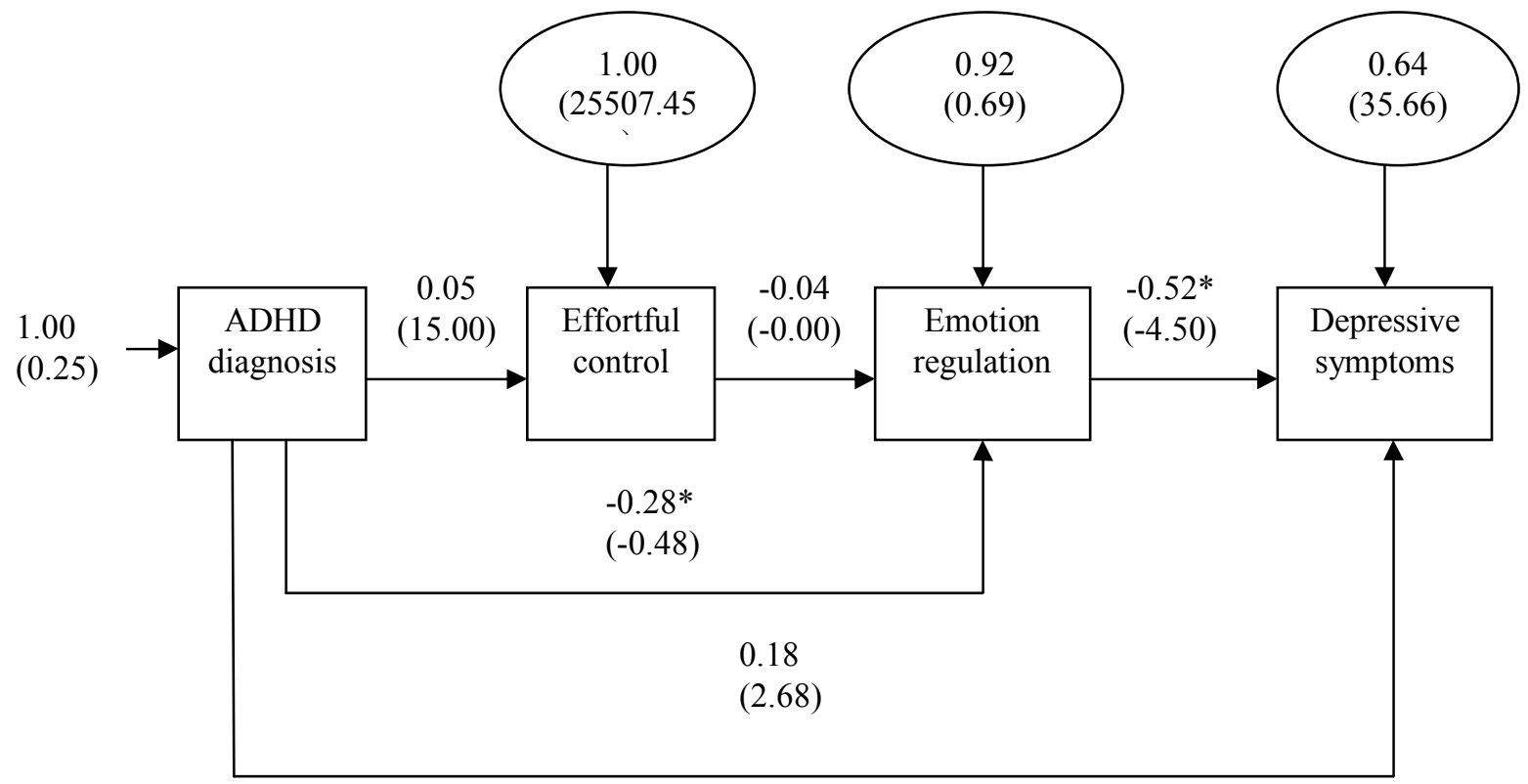

ER completely mediated the effect of ADHD diagnosis on depressive symptoms, accounting for $36 \%$ of the variance in the model. In fact, when ER was added as a mediator into the relationship between ADHD and depression, the unstandardized beta weight for ADHD diagnosis dropped from 4.84 to 2.68 . 
Table 8. Fit statistics for Model 1 with revised ER composite

\begin{tabular}{lc}
\hline \multicolumn{1}{c}{ Fit Statistics } & Value \\
\hline Absolute & $1.13(p=\mathrm{n} . \mathrm{s})$. \\
Chi square & 0.03 \\
SRMR & 0.99 \\
GFI & 19.12 \\
Parsimonious & 0.04 \\
AIC & 0.16 \\
RMSEA & 0.91 \\
PNFI & 1.00 \\
AGFI & 0.97 \\
Incremental & 0.97 \\
CFI & 0.80 \\
NFI & 1.00 \\
NNFI & \\
RFI & \\
IFI & \\
Note. AGFI= Adjusted goodness-of-fit index, AIC = Alkaike information criteria, \\
CFI= Comparative fit index, GFI= Goodness-of-fit index, IFI= Incremental fit index, \\
NFI= Normed fit index, NNFI= Non-normed fit index, PNFI= Parsimony normed fit \\
index, RFI= Relative fit index, RMSEA= Root mean square error of approximation, \\
SRMR= standardized root mean square residual.
\end{tabular}


Table 9. Structural Equations for Model 1 with revised ER composite

\begin{tabular}{|c|c|c|c|c|c|c|}
\hline Variable & $\begin{array}{c}\text { Standardized } \\
\text { beta weights } \\
(\beta)\end{array}$ & $\begin{array}{l}\text { Unstandardized } \\
\text { beta weights } \\
\text { (B) }\end{array}$ & $\begin{array}{c}\text { Standard } \\
\text { Error }\end{array}$ & $\begin{array}{c}t- \\
\text { value }\end{array}$ & $\begin{array}{c}p \text { - } \\
\text { value }\end{array}$ & $\mathbf{R}^{2}$ \\
\hline \multicolumn{7}{|c|}{ Dependent variable $=$ Depressive symptoms } \\
\hline ADHD & 0.18 & 2.68 & 1.55 & 1.72 & .085 & .360 \\
\hline ER & -0.52 & -4.50 & 0.90 & -5.02 & .000 & -- \\
\hline \multicolumn{7}{|c|}{ Dependent variable $=\mathbf{E R}$} \\
\hline ADHD & -0.28 & -0.48 & 0.21 & -2.29 & .022 & .078 \\
\hline $\begin{array}{c}\text { Effortful } \\
\text { control }\end{array}$ & -0.04 & -0.00 & 0.00 & -0.34 & .733 & -- \\
\hline \multicolumn{7}{|c|}{ Dependent variable $=$ Effortful control } \\
\hline ADHD & 0.05 & 15.00 & 39.93 & 0.38 & .707 & .002 \\
\hline
\end{tabular}




\section{Bibliography}

Abela, J.R.Z., \& Hankin, B.L. (2007). Handbook of Child and Adolescent Depression. Guilford Press.

Abramson, L., Metalsky, G., \& Alloy, L. (1989). Hopelessness depression: A theorybased subtype of depression. Psychological Review, 96(2), 358-372.

Ahadi, S., \& Rothbart, M. (1994). Temperament, development, and the Big Five. The developing structure of temperament and personality from infancy to adulthood (pp. 189-207). Hillsdale, NJ, England: Lawrence Erlbaum Associates, Inc.

Ambrosini, PJ. (2000). Historical Development and Present Status of the Schedule for Affective Disorders and Schizophrenia for School-Age Children (K-SADS). Journal of the American Academy of Child \& Adolescent Psychiatry, 39, 49-

58.

American Psychiatric Association. (1987). Diagnostic and statistical manual of mental disorders ( $3^{\text {rd }}$ ed. revised). Washington, DC: Author.

American Psychiatric Association. (1994). Diagnostic and statistical manual of mental disorders ( $4^{\text {th }}$ edition). Washington, DC: Author.

American Psychiatric Association. (2000). Diagnostic and statistical manual of mental ( $4^{\text {th }}$ edition, text-revised). Washington, DC: Author.

Anderson, J., Williams, S., McGee, R., \& Silva, P. (1987). DSM-III disorders in preadolescent children: Prevalence in a large sample from the general population. Archives of General Psychiatry, 44(1), 69-76. 
Anderson, R.N. \& Smith, B.L. (2003). Deaths: Leading causes for 2001. National Vital Statistics Report, 52, 1-96.

Anestis, M.D., Selby, E.A., Fink, E., \& Joiner, T.E. (2007). The multifaceted role of distress tolerance in dysregulated eating behaviors. International Journal of Eating Disorders, 40(8), 718-726.

Angold, A., \& Costello, E. (1993). Depressive comorbidity in children and adolescents: Empirical, theoretical, and methodological issues. American Journal of Psychiatry, 150(12), 1779-1791.

Angold, A., Costello, E., Erkanli, A., \& Worthman, C. (1999). Pubertal changes in hormone levels and depression in girls. Psychological Medicine, 29(5), 10431053.

Angold, A., Erkanli, A., Silberg, J., Eaves, L., \& Costello, E. (2002). Depression scale scores in 8-17-year-olds: Effects of age and gender. Journal of Child Psychology and Psychiatry, 43(8), 1052-1063.

Apter, A., \& King, R.A. (2006). Management of the depressed suicidal child or adolescent. Child and Adolescent Psychiatric Clinic of North America, 15(4).

Archibald, S., \& Kerns, K. (1999). Identification and description of new tests of executive functioning in children. Child Neuropsychology, 5(2), 115-129.

Avenevoli, S., Knight, E., Kessler, R., \& Merikangas, K. (2008). Epidemiology of depression in children and adolescents. Handbook of depression in children and adolescents (pp. 6-32). New York, NY US: Guilford Press.

Baddeley, A. (2003). Working Memory: Looking Back and Looking Forward. Nature Reviews Neuroscience, 4(10), 829-839. 
Baddeley, A., \& Larsen, J. (2007). The phonological loop: Some answers and some questions. The Quarterly Journal of Experimental Psychology, 60(4), 512518.

Bagwell, C., Molina, B., Kashdan, T., Pelham, W., \& Hoza, B. (2006). Anxiety and mood disorders in adolescents with childhood attention-deficit/hyperactivity disorder. Journal of Emotional and Behavioral Disorders, 14(3), 178-187.

Baker, T.B., Piper, M.E., McCarthy, D.E., Majeskie, M.R., \& Fiore, M.C. (2004). Addiction motivation reformulated: An affective processing model of negative reinforcement. Psychological Review, 111, 33-51.

Barkley, R. (1997b). ADHD and the nature of self-control. New York: Guilford Press. Barkley, R. A. (1997). Behavioral inhibition, sustained attention, and executive functions: Constructing a unifying theory of ADHD. Psychological Bulletin, 121, $65-94$.

Baron, R., \& Kenny, D. (1986). The moderator-mediator variable distinction in social psychological research: Conceptual, strategic, and statistical considerations. Journal of Personality and Social Psychology, 51(6), 1173-1182.

Bauermeister, J., Zimmerman, M., Barnett, T., \& Caldwell, C. (2007). Working in high school and adaptation in the transition to young adulthood among African American youth. Journal of Youth and Adolescence, 36(7), 877-890.

Biederman, J., Ball, S., Monuteaux, M., Mick, E., Spencer, T., McCreary, M., et al. (2008). New insights into the comorbidity between ADHD and major 
depression in adolescent and young adult females. Journal of the American Academy of Child \& Adolescent Psychiatry, 47(4), 426-434.

Biederman, J., Faraone, S., Keenan, K., \& Knee, D. (1990). Family-genetic and psychosocial risk factors in DSM-III attention deficit disorder. Journal of the American Academy of Child \& Adolescent Psychiatry, 29(4), 526-533.

Biederman, J., Monuteaux, M., Mick, E., Spencer, T., Wilens, T., Klein, K., et al. (2006). Psychopathology in Females with Attention-Deficit/Hyperactivity Disorder: A Controlled, Five-Year Prospective Study. Biological Psychiatry, 60(10), 1098-1105.

Biederman, J., Newcorn, J., \& Sprich, S. (1991). Comorbidity of attention deficit hyperactivity disorder with conduct, depressive, anxiety, and other disorders. American Journal of Psychiatry, 148(5), 564-577.

Billings, R., \& Wroten, S. (1978). Use of path analysis in industrial/organizational psychology: Criticisms and suggestions. Journal of Applied Psychology, 63(6), 677-688.

Bird, H., Canino, G., Rubio-Stipec, M., \& Gould, M. (1988). Estimates of the prevalence of childhood maladjustment in a community survey in Puerto Rico: The use of combined measures. Archives of General Psychiatry, 45(12), $1120-1126$.

Birmaher, B., Bridge, J.A., Williamson, D.E., Brent, D.A., Dahl, R.E., Axelson, D.A. et al. (2004). Psychosocial functioning in youths at high risk to develop major 
depressive disorder. Journal of the American Academy of Child \& Adolescent Psychiatry, 43(7), 839-846.

Birmaher, B., Ryan, N., Williamson, D., \& Brent, D. (1996). Childhood and adolescent depression: A review of the past 10 years, Part I. Journal of the American Academy of Child \& Adolescent Psychiatry, 35(11), 1427-1439.

Birmaher, B., Ryan, N., Williamson, D., \& Brent, D. (1996). Childhood and adolescent depression: A review of the past 10 years, Part II. Journal of the American Academy of Child \& Adolescent Psychiatry, 35(12), 1575-1583.

Blachman, D., \& Hinshaw, S. (2002). Patterns of friendship among girls with and without attention-deficit/hyperactivity disorder. Journal of Abnormal Child Psychology, 30(6), 625-640.

Blackman, G., Ostrander, R., \& Herman, K. (2005). Children with ADHD and depression: A multisource, multimethod assessment of clinical, social, and academic functioning. Journal of Attention Disorders, 8(4), 195-207.

Blasi, G., Goldberg, T., Elvevåg, B., Rasetti, R., Bertolino, A., Cohen, J., et al. (2007). Differentiating allocation of resources and conflict detection within attentional control processing. European Journal of Neuroscience, 25(2), 594602.

Bond, L., Toumbourou, J., Thomas, L., Catalano, R., \& Patton, G. (2005). Individual, Family, School, and Community Risk and Protective Factors for Depressive 
Symptoms in Adolescents: A Comparison of Risk Profiles for Substance Use and Depressive Symptoms. Prevention Science, 6(2), 73-88.

Boone, K., Miller, B., Lesser, I., \& Hill, E. (1990). Performance on frontal lobe tests in healthy, older individuals. Developmental Neuropsychology, 6(3), 215-223.

Boonstra, A., Oosterlaan, J., Sergeant, J., \& Buitelaar, J. (2005). Executive functioning in adult ADHD: A meta-analytic review. Psychological Medicine: A Journal of Research in Psychiatry and the Allied Sciences, 35(8), 10971108.

Bridge, J., Barbe, R., Birmaher, B., Kolko, D., \& Brent, D. (2005). Emergent Suicidality in a Clinical Psychotherapy Trial for Adolescent Depression. The American Journal of Psychiatry, 162(11), 2173-2175.

Bridge, J.A., Goldstein, T.R., \& Brent, D.A., (2006). Adolescent suicide and suicidal behavior. Journal of Child Psychology and Psychiatry, 47 (3/4), 372-394.

Bridges, L., Denham, S., \& Ganiban, J. (2004). Definitional Issues in Emotion Regulation Research. Child Development, 75(2), 340-345.

Brown, R., Lejuez, C., Kahler, C., \& Strong, D. (2002). Distress tolerance and duration of past smoking cessation attempts. Journal of Abnormal Psychology, 111(1), 180-185. 
Brown, R., Lejuez, C., Kahler, C., Strong, D., \& Zvolensky, M. (2005). Distress tolerance and early smoking lapse. Clinical Psychology Review, 25(6), 713733.

Butler, S., Arredondo, D., \& McCloskey, V. (1995). Affective comorbidity in children and adolescents with attention deficit hyperactivity disorder. Annals of Clinical Psychiatry, 7(2), 51-55.

Byrne, Barbara (1998). Structural equation modeling with LISREL, PRELIS, and SIMPLIS. Hillsdale, NJ: Lawrence Erlbaum.

Calkins, S., \& Dedmon, S. (2000). Physiological and behavioral regulation in twoyear-old children with aggressive/destructive behavior problems. Journal of Abnormal Child Psychology: An official publication of the International Society for Research in Child and Adolescent Psychopathology, 28(2), 103118.

Calkins, S., \& Fox, N. (2002). Self-regulatory processes in early personality development: A multilevel approach to the study of childhood social withdrawal and aggression. Development and Psychopathology, 14(3), 477498.

Calkins, S., Dedmon, S., Gill, K., Lomax, L., \& Johnson, L. (2002). Frustration in infancy: Implications for emotion regulation, physiological processes, and temperament. Infancy, 3(2), 175-197. 
Campbell, J. M. (1998). Internal and external validity of seven Wechsler Intelligence Scale for Children--Third Edition short forms in a sample of psychiatric inpatients. Psychological Assessment, 10, 431-434.

Campbell-Sills, L., Barlow, D., Brown, T., \& Hofmann, S. (2006). Acceptability and suppression of negative emotion in anxiety and mood disorders. Emotion, 6(4), 587-595.

Capaldi, D. (1992). Co-occurrence of conduct problems and depressive symptoms in early adolescent boys: II. A 2-year follow-up at Grade 8. Development and Psychopathology, 4(1), 125-144.

Carlson, S., \& Moses, L. (2001). Individual differences in inhibitory control and children's theory of mind. Child Development, 72(4), 1032-1053.

Carlson, S., \& Wang, T. (2007). Inhibitory control and emotion regulation in preschool children. Cognitive Development, 22(4), 489-510.

Cattell, R. B. (1966). The scree test for the number of factors. Multivariate Behavioral Research, 1, 245-276.

Chaplin, T., Cole, P., \& Zahn-Waxler, C. (2005). Parental Socialization of Emotion Expression: Gender Differences and Relations to Child Adjustment. Emotion, $5(1), 80-88$.

Chronis, A. M., Lahey, B. B., Pelham, W. E., Kipp, H., Baumann, B., \& Lee, S. S. (2003a). Psychopathology and substance abuse in parents of young children 
with Attention Deficit/Hyperactivity Disorder. Journal of the American Academy of Child and Adolescent Psychiatry, 42, 1425-1432.

Cicchetti, D., Ganiban, J., \& Barnett, D. (1991). Contributions from the study on high risk populations understanding the development of emotion regulation. In K. Dodge, \& J. Garber (Eds.). The development of emotion regulation (pp. 1548). New York: Cambridge University Press.

Claude, D., \& Firestone, P. (1995). The development of ADHD boys: A 12-year follow-up. Canadian Journal of Behavioural Science, 27(2), 226-249.

Cohen, J., Dunbar, K., \& McClelland, J. (1990). On the control of automatic processes: A parallel distributed processing account of the Stroop effect. Psychological Review, 97(3), 332-361.

Cole, D. A., \& Carpentieri, S. (1990). Social status and the comorbidity of child depression and conduct disorder. Journal of Consulting and Clinical Psychology, 58, 748-757.

Cole, P., Martin, S., \& Dennis, T. (2004). Emotion Regulation as a Scientific Construct: Methodological Challenges and Directions for Child Development Research. Child Development, 75(2), 317-333.

Cole, P., Michel, M., \& Teti, L. (1994). The development of emotion regulation and dysregulation: A clinical perspective. Monographs of the Society for Research in Child Development, 59(2), 73. 
Copeland, W., Shanahan, L., Costello, J., \& Angold, A. (2009). Childhood and adolescent psychiatric disorders as predictors of young adult disorders. Archives of General Psychiatry, 66(7), 764-772.

Corkum, P., \& Siegel, L. (1993). Is the Continuous Performance Task a valuable research tool for use with children with attention-deficit-hyperactivity disorder?. Journal of Child Psychology and Psychiatry, 34(7), 1217-1239.

Costello, E., Foley, D., \& Angold, A. (2006). 10-year research update review: The epidemiology of child and adolescent psychiatric disorders: II. developmental epidemiology. Journal of the American Academy of Child \& Adolescent Psychiatry, 45(1), 8-25.

Costello, E., Mustillo, S., Erkanli, A., Keeler, G., \& Angold, A. (2003). Prevalence and Development of Psychiatric Disorders in Childhood and Adolescence. Archives of General Psychiatry, 60(8), 837-844.

Daughters, S. B., Lejuez, C. W., Bornovalova, M. A., Kahler, C. W., Strong, D. R., \& Brown, R. A. (2005). Distress tolerance as a predictor of early treatment dropout in a residential substance abuse treatment facility. Journal of Abnormal Psychology, 114, 729-734.

Daughters, S. B., Lejuez, C. W., Kahler, C. W., Strong, D. R., \& Brown, R. A. (2005). Psychological distress tolerance and duration of most recent abstinence attempt among residential treatment seeking substance abusers. Psychology of Addictive Behaviors, 19, 208-211. 
Daughters, S.B., Reynolds, E.K., MacPherson, L., Kahler, C.W., Danielson, C.K., Zvolensky, M., Lejuez, C.W. (2009). Negative Reinforcement and Early Adolescent Externalizing and Internalizing Symptoms: The Moderating Role of Gender and Ethnicity. Journal of Child Psychology and Psychiatry.

Davidson, R. (1998). Anterior electrophysiological asymmetries, emotion, and depression: Conceptual and methodological conundrums. Psychophysiology, 35(5), 607-614.

Daviss, W. (2008). A review of co-morbid depression in pediatric ADHD: Etiologies, phenomenology, and treatment. Journal of Child and Adolescent Psychopharmacology, 18(6), 565-571.

Daviss, W., Diler, R., \& Birmaher, B. (2009). Associations of lifetime depression with trauma exposure, other environmental adversities, and impairment in adolescents with ADHD. Journal of Abnormal Child Psychology: An official publication of the International Society for Research in Child and Adolescent Psychopathology, 37(6), 857-871.

Desimone, R., \& Duncan, J. (1995). Neural mechanisms of selective visual attention. Annual Review of Neuroscience, 18, 193-222.

Dodge, K. (1991). Emotion and social information processing. The development of emotion regulation and dysregulation (pp. 159-181). New York, NY, US: Cambridge University Press. 
Douglas, V.I. (1983). Attention and cognitive problems. In M. Rutter (Ed.), Developmental Neuropsychiatry (pp. 280-329). New York: Guilford Press.

Eisenberg, N. \& Spinrad, T.L. (2004). Emotion-related regulation: Sharpening the definition. Child Development, 75, 334-339.

Eisenberg, N., Cumberland, A., Spinrad, T., Fabes, R., Shepard, S., Reiser, M., et al. (2001). The relations of regulation and emotionality to children's externalizing and internalizing problem behavior. Child Development, 72(4), 1112-1134.

Eisenberg, N., Fabes, R., Guthrie, I., \& Murphy, B. (1996). The relations of regulation and emotionality to problem behavior in elementary school children. Development and Psychopathology, 8(1), 141-162.

Eisenberg, N., Sadovsky, A., Spinrad, T., Fabes, R., Losoya, S., Valiente, C., et al. (2005). The Relations of Problem Behavior Status to Children's Negative Emotionality, Effortful Control, and Impulsivity: Concurrent Relations and Prediction of Change. Developmental Psychology, 41(1), 193-211.

Elia, J., Ambrosini, P., \& Berrettini, W. (2008). ADHD characteristics: I. Concurrent co-morbidity patterns in children \& adolescents. Child and Adolescent Psychiatry and Mental Health, 2,

Fabiano, G. A., Pelham, W. E., Waschbusch, D., Gnagy, E. M., , Lahey, B. B., Chronis, A. M., Onyango, A. N., Kipp, H., Lopez-Williams, A., \& BurrowsMacLean, L. (2006). A practical impairment measure: psychometric properties of the impairment rating scale in three samples of children with 
attention-deficit/hyperactivity disorder. Journal of Clinical Child and Adolescent Psychology, 35, 369-385.

Feng, X., Keenan, K., Hipwell, A., Henneberger, A., Rischall, M., Butch, J., et al. (2009). Longitudinal associations between emotion regulation and depression in preadolescent girls: Moderation by the caregiving environment. Developmental Psychology, 45(3), 798-808.

Field, A. (2004). Discovering Statistics Using SPSS-2 ${ }^{\text {nd }}$ edition. London. Sage Publications.

Fischer, M., Barkley, R., Smallish, L., \& Fletcher, K. (2002). Young adult follow-up of hyperactive children: Self-reported psychiatric disorders, comorbidity, and the role of childhood conduct problems and teen CD. Journal of Abnormal Child Psychology, 30(5), 463-475.

Fox, N., \& Calkins, S. (2003). The development of self-control of emotion: Intrinsic and extrinsic influences. Motivation and Emotion, 27(1), 7-26.

Garber, J., Braafladt, N., \& Weiss, B. (1995). Affect regulation in depressed and nondepressed children and young adolescents. Development and Psychopathology, 7(1), 93-115.

Garber, J., Braafladt, N., \& Zeman, J. (1991). The regulation of sad affect: An information-processing perspective. The development of emotion regulation and dysregulation (pp. 208-240). New York, NY US: Cambridge University Press. 
Garson, G. David (2009). "Structural Equation Modeling", from Statnotes: Topics in Multivariate Analysis. Retrieved from http://faculty.chass.ncsu.edu/garson/pa765/statnote.htm.

Gelfand, L., Mensinger, J., \& Tenhave, T. (2009). Mediation analysis: A retrospective snapshot of practice and more recent directions. Journal of General Psychology, 136(2), 153-176.

Gerardi, G., Rothbart, M.K., Posner, M.I., Kepler, S. (1996). The development of attentional control: Performance on a spatial Stroop-like task at 24, 30, and 36-38 months of age. Poster session presented at the annual meeting of the International Society for Infant Studies, Providence; Rhode Island.

Gerardi-Caulton, G. (2000). Sensitivity to spatial conflict and the development of self-regulation in children 24-36 months of age. Developmental Science, 3(4), 397-404.

Gittelman, R., Mannuzza, S., Shenker, R., \& Bonagura, N. (1985). Hyperactive boys almost grown up: I. Psychiatric status. Archives of General Psychiatry, 42(10), 937-947.

Gotlib, I., \& Hammen, C. (2009). Handbook of depression (2nd ed.). New York, NY US: Guilford Press. 
Gratz, K. (2003). Risk factors for and functions of deliberate self-harm: An empirical and conceptual review. Clinical Psychology: Science and Practice, 10(2), 192-205.

Gratz, K. L., Tull, M. T., Reynolds, E. K., Daughters, S. B., \& Lejuez, C. W. (Submitted for publication) Extending extant models of the pathogenesis of borderline personality disorder to childhood borderline pathology: The roles of affective dysfunction, disinhibition, and self- and emotion-regulation deficits.

Gratz, K., \& Roemer, L. (2004). Multidimensional assessment of emotion regulation and dysregulation: Development, factor structure, and initial validation of the difficulties in emotion regulation scale. Journal of Psychopathology and Behavioral Assessment, 26(1), 41-54.

Gratz, K., Rosenthal, M., Tull, M., Lejuez, C., \& Gunderson, J. (2006). An Experimental Investigation of Emotion Dysregulation in Borderline Personality Disorder. Journal of Abnormal Psychology, 115(4), 850-855.

Gross, J., \& John, O. (2003). Individual differences in two emotion regulation processes: Implications for affect, relationships, and well-being. Journal of Personality and Social Psychology, 85(2), 348-362.

Hair, J.F., Black, W.C., Babin, B.J., Anderson, R.E., \& Tatham, R.L. (2006). Multivariate Data Analysis-6 ${ }^{\text {th }}$ Edition. New Jersey, Pearson-Prentice Hill.

Hankin, B., Abramson, L., Moffitt, T., Silva, P., McGee, R., \& Angell, K. (1998). Development of depression from preadolescence to young adulthood: 
Emerging gender differences in a 10-year longitudinal study. Journal of Abnormal Psychology, 107(1), 128-140.

Harris, K., Boots, M., Talbot, J \& Vance A. (2006). Comparison of Psychosocial Correlates in Primary School Age Children with Attention Deficit/Hyperactivity Disorder- Combined Type, with and without Dysthymic Disorder. Child Psychiatry and Human Development, 36(4), 419-426.

Hart, E. L., Lahey, B.B., Loeber, R., \& Hanson, K. S. (1994). Criterion validity of informants in the diagnosis of disruptive behavior disorders in children: A preliminary study. Journal of Consulting and Clinical Psychology, 62, 410414.

Hilt, L., \& Nolen-Hoeksema, S. (2009). The emergence of gender differences in depression in adolescence. Handbook of depression in adolescents (pp. 111135). New York, NY US: Routledge/Taylor \& Francis Group.

Hinshaw, S., Owens, E., Sami, N., \& Fargeon, S. (2006). Prospective follow-up of girls with attention-deficit/hyperactivity disorder into adolescence: Evidence for continuing cross-domain impairment. Journal of Consulting and Clinical Psychology, 74(3), 489-499.

Homack, S., \& Riccio, C. (2004). A meta-analysis of the sensitivity and specificity of the Stroop Color and Word Test with children. Archives of Clinical Neuropsychology, 19(6), 725-743. 
Hoza, B., Gerdes, A., Hinshaw, S., Arnold, L., Pelham, W., Molina, B., et al. (2004). Self-Perceptions of Competence in Children With ADHD and Comparison Children. Journal of Consulting and Clinical Psychology, 72(3), 382-391.

Hoza, B., Gerdes, A., Mrug, S., Hinshaw, S., Bukowski, W., Gold, J., et al. (2005). Peer-Assessed Outcomes in the Multimodal Treatment Study of Children With Attention Deficit Hyperactivity Disorder. Journal of Clinical Child and Adolescent Psychology, 34(1), 74-86.

Hu, L., \& Bentler, P. (1995). Evaluating model fit. Structural equation modeling: Concepts, issues, and applications (pp. 76-99). Thousand Oaks, CA US: Sage Publications, Inc.

Hu, L., \& Bentler, P. (1999). Cutoff criteria for fit indexes in covariance structure analysis: Conventional criteria versus new alternatives. Structural Equation Modeling, 6(1), 1-55.

Izard, C. (1977). Human Emotions. Plenum Press, New York.

Jaccard, J., \& Wan, C. (1996). LISREL approaches to interaction effects in multiple regression. Thousand Oaks, CA US: Sage Publications, Inc.

Jacobson \& Gould (2009). Suicide and nonsuicidal self-injurious behaviors among youth: Risk and protective factors. Handbook of depression in adolescents. Nolen-Hoeksema, S. (Ed.); Hilt, L.M. (Ed.); pp. 207-235. New York, NY, US: Routledge/Taylor \& Francis Group. 
James, A., Lai, F., \& Dahl, C. (2004). Attention deficit hyperactivity disorder and suicide: A review of possible associations. Acta Psychiatrica Scandinavica, $110(6), 408-415$.

James, L. R., \& Brett, J. M. (1984). Mediators, moderators and tests for mediation. Journal of Applied Psychology, 69, 307-321.

James, L. R., Mulaik, S. A., \& Brett, J. M. (2006). A tale of two methods. Organizational Research Methods, 9(2), 233-244.

Jensen, J., \& Garfinkel, B. (1988). Neuroendocrine aspects of attention deficit hyperactivity disorder. Neurologic Clinics, 6(1), 111-129.

Jensen, P. S., Rubio-Stipec, M., Canino, G., Bird, H. R., Dulcan, M. K., SchwabStone, M. E., et al. (1999). Parent and child contributions to diagnosis of mental disorder: Are both informants always necessary? Journal of the American Academy of Child and Adolescent Psychiatry, 38, 1569-1579.

Jensen, P. S., Shervette, R. E., Xenakis, S. N., \& Richters, J. (1993). Anxiety and depressive disorders in attention deficit disorder with hyperactivity: New findings. American Journal of Psychiatry, 150, 1203-1209.

Jensen, P., Martin, D., \& Cantwell, D. (1997). Comorbidity in ADHD: Implications for research, practice, and DSM-V. Journal of the American Academy of Child \& Adolescent Psychiatry, 36(8), 1065-1079.

Jensen, P.S., Mrazek, D., Knapp, P.K., Steinberg, L., Pfeffer, C., Schowalter, J., \& Shapiro, T. (1997). Evolution and Revolution in Child Psychiatry: ADHD as a Disorder of Adaptation, Journal of the American Academy of Child and Adolescent Psychiatry, 36, 1672-1679. 
Johnston, C., \& Mash, E. J. (2001). Families of children with attentiondeficit/hyperactivity disorder: Review and recommendations for future research. Clinical Child and Family Psychology Review, 4, 183-207.

Jones, L., Rothbart, M., \& Posner, M. (2003). Development of executive attention in preschool children. Developmental Science, 6(5), 498-504.

Jöreskog, K. G. \& Sörbom, D. (1997). LISREL 8: A guide to the program and applications. Chicago, IL: SPSS Inc.

Kaminer, Yifrah (Ed.); Bukstein, Oscar G. (Ed.); Adolescent substance abuse: Psychiatric comorbidity and high-risk behaviors. New York, NY, US: Routledge/Taylor \& Francis Group, 2008.

Kane, M., \& Engle, R. (2003). Working-memory capacity and the control of attention: The contributions of goal neglect, response competition, and task set to Stroop interference. Journal of Experimental Psychology: General, 132(1), 47-70.

Kashani, J., \& Sherman, D. (1988). Childhood depression: Epidemiology, etiological models, and treatment implications. Integrative Psychiatry, 6(1), 1-21.

Kastner, S., \& Ungerleider, L. (2001). The neural basis of biased competition in human visual cortex. Neuropsychologia, 39(12), 1263-1276.

Katz, L., \& Gottman, J. (1991). Marital discord and child outcomes: A social psychophysiological approach. The development of emotion regulation and 
dysregulation (pp. 129-155). New York, NY, US: Cambridge University Press.

Kaufman, J., Birmaher, B., Brent, D., et al. (1997), Schedule for Affective Disorders and Schizophrenia for School-Age Children-Present and Lifetime Version (KSADS-PL): initial reliability and validity data. Journal of the American Academy of Child \& Adolescent Psychiatry, 36, 980-988.

Kazdin, A. (1989b). Childhood depression. Journal of Child and Psychology and Psychiatry, 31, 121-160.

Kazdin, A. (1990). Childhood depression. Journal of Child Psychology and Psychiatry, 31(1), 121-160.

Kazdin, A.E., French, N.H., Unis, A.S., Esveldt-Dawson, K., \& Sherick, R.B. (1983). Hopelessness, depression, and suicidal intent among psychiatrically disturbed inpatient children. Journal of Consulting and Clinical Psychology, 51, 504510.

Keenan, K. (2000). Emotion dysregulation as a risk factor for child psychopathology. Clinical Psychology: Science and Practice, 7(4), 418-434.

Keenan-Miller, Danielle; Hammen, Constance L.; Brennan, Patricia A. (2007). Health outcomes related to early adolescent depression. Journal of Adolescent Health, 41(3), 256-262.

Kenny, D.A. (2010). "Mediation". http://davidakenny.net/cm/mediate.htm. 
Kessler, R. (2002). Epidemiology of depression. Handbook of depression (pp. 23-42). New York, NY US: Guilford Press.

Kessler, R., Avenevoli, S., \& Merikangas, K. (2001). Mood disorders in children and adolescents: An epidemiologic perspective. Biological Psychiatry, 49(12), 1002-1014.

Kim, K., Conger, R., Elder, G., \& Lorenz, F. (2003). Reciprocal influences between stressful life events and adolescent internalizing and externalizing problems. Child Development, 74(1), 127-143.

Klein, R., \& Mannuzza, S. (1991). Long-term outcome of hyperactive children: A review. Journal of the American Academy of Child \& Adolescent Psychiatry, $30(3), 383-387$.

Kopp, C. (1989). Regulation of distress and negative emotions: A developmental view. Developmental Psychology, 25(3), 343-354.

Kovacs, M. (1992) Children's Depression Inventory manual. North Tonawanda, NY: Multi-Health Systems.

Kovacs, M. (1996). Presentation and course of major depressive disorder during childhood and later years of the life span. Journal of the American Academy of Child \& Adolescent Psychiatry, 35(6), 705-715.

Kovacs, M., \& Beck, A. T. (1977). An empirical-clinical approach toward a definition of childhood depression. In J. G. Schulterbrandt \& A. Raskin (Eds.), Depression in childhood (pp. 1-25). New York: Raven Press. 
Kovacs, M., \& Goldston, D. (1991). Cognitive and social cognitive development of depressed children and adolescents. Journal of the American Academy of Child \& Adolescent Psychiatry, 30(3), 388-392.

Kovacs, M., Sherrill, J., George, C., Pollock, M., Tumuluru, R., \& Ho, V. (2006). Contextual Emotion-Regulation Therapy for Childhood Depression: Description and Pilot Testing of a New Intervention. Journal of the American Academy of Child \& Adolescent Psychiatry, 45(8), 892-903.

Ladouceur, C., Dahl, R., Williamson, D., Birmaher, B., Ryan, N., \& Casey, B. (2005). Altered Emotional Processing in Pediatric Anxiety, Depression, and Comorbid Anxiety-Depression. Journal of Abnormal Child Psychology: An official publication of the International Society for Research in Child and Adolescent Psychopathology, 33(2), 165-177.

Lahey, B.B., Chronis, A.M., Lee, S., Loney, J., Pelham, W.E., \& Hartung. C.M. (2007). Are There Sex Differences in the Predictive Validity of DSM-IV ADHD Among Younger Children? Journal of Clinical Child and Adolescent Psychology.

Lansbergen, M., Kenemans, J., \& van Engeland, H. (2007). Stroop interference and attention-deficit/hyperactivity disorder: A review and meta-analysis. Neuropsychology, 21(2), 251-262. 
Larson, R., Raffaelli, M., Richards, M., Ham, M., \& Jewell, L. (1990). Ecology of depression in late childhood and early adolescence: A profile of daily states and activities. Journal of Abnormal Psychology, 99(1), 92-102.

Laurent, J., Catanzaro, S., Joiner, T., Rudolph, K., Potter, K., Lambert, S., et al. (1999). A measure of positive and negative affect for children: Scale development and preliminary validation. Psychological Assessment, 11(3), 326-338.

Lavigne, J., LeBailly, S., Hopkins, J., Gouze, K., \& Binns, H. (2009). The prevalence of ADHD, ODD, depression, and anxiety in a community sample of 4-yearolds. Journal of Clinical Child and Adolescent Psychology, 38(3), 315-328.

Lawrence, V., Houghton, S., Tannock, R., Douglas, G., Durkin, K., \& Whiting, K. (2002). ADHD outside the laboratory: Boys' executive function performance on tasks in videogame play and on a visit to the zoo. Journal of Abnormal Child Psychology, 30(5), 447-462.

Lee, S., Lahey, B., Owens, E., \& Hinshaw, S. (2008). Few preschool boys and girls with ADHD are well-adjusted during adolescence. Journal of Abnormal Child Psychology: An official publication of the International Society for Research in Child and Adolescent Psychopathology, 36(3), 373-383.

Lejuez, C.W., Kahler, C.W., \& Brown, R.A. (2003). A modified computer version of the Paced Auditory Serial Addition Task (PASAT) as a laboratory-based stressor. The Behavior Therapist, 26(4), 290-293. 
Lewinsohn, P. M., Rohde, P., \& Seeley, J. R. (1993). Psychosocial characteristics of adolescents with a history of suicide attempt. Journal of the American Academy of Child and Adolescent Psychiatry, 32, 60-68.

Lewinsohn, P.M., Hops, H., Roberts, R.E., Seeley, J.R., \& Andrews, J.A. (1993). Adolescent psychopathology: I. Prevalence, and incidence of depression and other DSM-III-R disorders in high school students. Journal of Abnormal Psychology, 102, 133-244.

Lewinsohn, P.M., Rohde, P., Seeley, J.R., \& Baldwin, C.L. (2001). Gender differences in suicide attempts from adolescence to young adulthood. Journal of the American Academy of Child and Adolescent Psychology, 40 (4), $427-$ 434.

Lijffijt, M., Kenemans, J., Verbaten, M., \& van Engeland, H. (2005). A MetaAnalytic Review of Stopping Performance in Attention-Deficit/Hyperactivity Disorder: Deficient Inhibitory Motor Control?. Journal of Abnormal Psychology, 114(2), 216-222.

Lilienfeld, S. (2003). Comorbidity Between and Within Childhood Externalizing and Internalizing Disorders: Reflections and Directions. Journal of Abnormal Child Psychology, 31(3), 285-291.

Linehan, M. (1993). Skills training manual for treating borderline personality disorder. New York, NY US: Guilford Press.

Little, T., Card, N., Bovaird, J., Preacher, K., \& Crandall, C. (2007). Structural equation modeling of mediation and moderation with contextual factors. 
Modeling contextual effects in longitudinal studies (pp. 207-230). Mahwah, NJ US: Lawrence Erlbaum Associates Publishers.

Losier, B., McGrath, P., \& Klein, R. (1996). Error patterns of the Continuous Performance Test in non-medicated and medicated samples of children with and without ADHD: A meta-analytic review. Journal of Child Psychology and Psychiatry, 37(8), 971-987.

Maedgen, J., \& Carlson, C. (2000). Social functioning and emotional regulation in the attention deficit hyperactivity disorder subtypes. Journal of Clinical Child Psychology, 29(1), 30-42.

Mannuzza, S. \& Gittelman, R. (1984). The adolescent outcome of hyperactive girls. Psychiatry Research, 13, 19-29.

Mannuzza, S., Klein, R., Bessler, A., Malloy, P., \& LaPadula, M. (1998). Adult psychiatric status of hyperactive boys grown up. The American Journal of Psychiatry, 155(4), 493-498.

Melnick, S.M. \& Hinshaw, S.P. (2000). Emotion regulation and parenting in AD/HD and comparison boys: Linkages with social behaviors and peer preference. Journal of Abnormal Child Psychology, 28, 73-86.

Mendelson, W., Johnson, N., \& Stewart, M. (1971). Hyperactive children as teenagers: A follow-up study. Journal of Nervous and Mental Disease, 153(4), 273-279. 
Mennin, D., Heimberg, R., Turk, C., \& Fresco, D. (2005). Preliminary evidence for an emotion dysregulation model of generalized anxiety disorder. Behaviour Research and Therapy, 43(10), 1281-1310.

Milberger, S., Biederman, J., Faraone, S., \& Murphy, J. (1995). Attention deficit hyperactivity disorder and comorbid disorder: Issues of overlapping symptoms. American Journal of Psychiatry, 152(12), 1793-1799.

Neumann, A., van Lier, P. A. C., Gratz, K. L., \& Koot, H. M. (in press). Multidimensional assessment of emotion regulation difficulties in adolescents using the Difficulties in Emotion Regulation Scale. Assessment.

Nigg, J. T., \& Hinshaw, S. P. (1998). Parental personality and psychopathology associated with antisocial behaviors in childhood attention-deficit hyperactivity disorder. Journal of Child Psychology and Psychiatry, 39, 145159.

Nigg, J.T. (2000). On inhibition/disinhibition in developmental psychopathology: Views from cognitive and personality psychology and a working inhibition taxonomy. Psychological Bulletin, 126, 220-246.

Norvilitis, J., Casey, R., Brooklier, K., \& Bonello, P. (2000). Emotion appraisal in children with attention-deficit/hyperactivity disorder and their parents. Journal of Attention Disorders, 4(1), 15-26.

Oosterlaan, J., Logan, G., \& Sergeant, J. (1998). Response inhibition in CD, anxious, and control children: A meta-analysis of studies with the stop task. Journal of Child Psychology and Psychiatry, 39(3), 411-425. 
Ostrander, R., \& Herman, K. (2006). Potential Cognitive, Parenting, and Developmental Mediators of the Relationship Between ADHD and Depression. Journal of Consulting and Clinical Psychology, 74(1), 89-98.

Patterson, G., \& Stoolmiller, M. (1991). Replications of a dual failure model for boys' depressed mood. Journal of Consulting and Clinical Psychology, 59(4), 491498.

Pelham, W. E., Gnagy, E. M., Greenslade, K. E., \& Milich, R. (1992). Teacher ratings of DSM-III-R symptoms for the disruptive behavior disorders. Journal of the American Academy of Child and Adolescent Psychiatry, 31, 210-218.

Pelham, W., \& Bender, M. (1982). Peer relationships in hyperactive children:

Description and treatment. Advances in Learning \& Behavioral Disabilities, 1, $365-436$.

Pérez-Edgar, K., \& Fox, N. A. (2000, July). The Impact of Frontal Asymmetry and Attentional Control on Social Reticence. Poster presented at the International Conference on Infant Studies, Brighton, England.

Piacentini, J. C., Cohen, P., \& Cohen, J. (1992). Combining discrepant diagnostic information from multiple sources: Are complex algorithms better than simple ones? Journal of_Abnormal Child Psychology, 20, 51-63.

Piacentini, J. C., Cohen, P., \& Cohen, J. (1992). Combining discrepant diagnostic information from multiple sources: Are complex algorithms better than simple ones? Journal of_Abnormal Child Psychology, 20, 51-63.

Plutick, R. (1980). Emotions: A psychoevolutionary synthesis, New York: NY. Harper \& Row. 
Quinn, E., Brandon, T., \& Copeland, A. (1996). Is task persistence related to smoking and substance abuse? The application of learned industriousness theory to addictive behaviors. Experimental and Clinical Psychopharmacology, 4(2), 186-190.

Reynolds, C. R., \& Kamphaus, R. W. (2004). Behavior Assessment System for Children, Second Edition (BASC-2). Circle Pines, MN: American Guidance Service.

Rice, F., Lifford, K.J., Thomas, H.V. \& Thapar, A. (2007). Mental health and $\underline{\text { functional outcomes of maternal and adolescent reports of adolescent }}$ depressive symptoms, Journal of the American Academy of Child \& Adolescent Psychiatry, 46(9), 1162-1170.

Rohde, P., Lewinsohn, P., \& Seeley, J. (1994). Response of depressed adolescents to cognitive-behavioral treatment: Do differences in initial severity clarify the comparison of treatments?. Journal of Consulting and Clinical Psychology, $62(4), 851-854$.

Rohde, P., Lewinsohn, P.M., \& Seeley, J.R. (1991). Comorbidity of unipolar depression: II. Comorbidity with other mental disorders in adolescents and adults. Journal of Abnormal Psychology, 100, 214-222.

Rosenbaum, M., \& Baker, E. (1984). Self-control behavior in hyperactive and nonhyperactive children. Journal of Abnormal Child Psychology, 12(2), 303317. 
Rothbart, M., Ahadi, S., Hersey, K., \& Fisher, P. (2001). Investigations of temperament at three to seven years: The Children's Behavior Questionnaire. Child Development, 72(5), 1394-1408.

Rothbart, M., Posner, M., \& Boylan, A. (1990). Regulatory mechanisms in infant development. The development of attention: Research and theory (pp. 47-66). Oxford, England: North-Holland.

Rothbart, M.K. (1989). Temperament and development. In G.A. Kohnstamm, J.E. Bates \& M.K. Rothbart (Eds.), Temperament in childhood (pp. 187-247). Chichester, England: Wiley.

Rothbart, M.K., \& Posner, M. (1985). Temperament and the development of selfregulation. In Hartlafe, L.C., \& Telzrow, C.F. (Eds.), The neuropsychology of individual differences: A developmental perspective (pp. 93-123). New York: Plenum.

Rude, S.S., McCarthy, C.J. (2003). Emotion regulation in depressed and depression vulnerable college students. Cognition and Emotion, 17(5), 799-806.

Saylor, C.F., Finch, A.J., Baskin, C.H., Furey, W. \& Kelly, M.M. (1984). Construct validity for measures of childhood depression: Application of multitraitmultimethod methodology. Journal of Consulting and Clinical Psychology, $52,977-985$.

Scheres, A., Oosterlaan, J., Geurts, H., Morein-Zamir, S., Meiran, N., Schut, H., et al. (2004). Executive functioning in boys with ADHD: Primarily an inhibition deficit?. Archives of Clinical Neuropsychology, 19(4), 569-594. 
Schmeichel, B., Volokhov, R., \& Demaree, H. (2008). Working memory capacity and the self-regulation of emotional expression and experience. Journal of Personality and Social Psychology, 95(6), 1526-1540.

Schumacker, R. E., \& Lomax, R. G. (2004). A beginner's guide to structural equation modeling. Mahwah, NJ: Lawrence Erlbaum.

Schwartz, K., \& Verhaeghen, P. (2008). ADHD and Stroop interference from age 9 to age 41 years: A meta-analysis of developmental effects. Psychological Medicine: A Journal of Research in Psychiatry and the Allied Sciences, $38(11), 1607-1616$.

Scime, M., \& Norvilitis, J. (2006). Task performance and response to frustration in children with attention deficit hyperactivity disorder. Psychology in the Schools, 43(3), 377-386.

Shaffer, D., Fisher, P., Dulcan, M., \& Davies, M. (1996). The NIMH Diagnostic Interview Schedule for Children Version 2.3 (DISC-2.3): Description, acceptability, prevalence rates, and performance in the MECA study. Journal of the American Academy of Child \& Adolescent Psychiatry, 35(7), 865-877.

Shaw, D., \& Winslow, E. (1997). Precursors and correlates of antisocial behavior from infancy to preschool. Handbook of antisocial behavior (pp. 148-158). Hoboken, NJ US: John Wiley \& Sons Inc. 
Shields, A. M., \& Cicchetti, D. (1997). Emotion regulation in school-age children: The development of a new criterion Q-sort scale. Developmental Psychology, $33,906-916$.

Shiner, R., \& Caspi, A. (2003). Personality differences in childhood and adolescence: Measurement, development, and consequences. Journal of Child Psychology and Psychiatry, 44(1), 2-32.

Silk, J., Steinberg, L., \& Morris, A. (2003). Adolescents' emotion regulation in daily fife: Links to depressive symptoms and problem behavior. Child Development, 74(6), 1869-1880.

Singh, S., Ellis, C., Winton, A., Singh, N., Leung, J., \& Oswald, D. (1998). Recognition of facial expressions of emotion by children with attention-deficit hyperactivity disorder. Behavior Modification, 22(2), 128-142.

Sonuga-Barke, E., Dalen, L., Daley, D., \& Remington, B. (2002). Are planning, working memory, and inhibition associated with individual differences in preschool ADHD symptoms?. Developmental Neuropsychology, 21(3), 255272.

Souza, I., Pinheiro, M., Denardin, D., Mattos, P., \& Rohde, L. (2004). AttentionDeficit/Hyperactivity Disorder and comorbidity in Brazil: Comparisons between two referred samples. European Child \& Adolescent Psychiatry, $13(4), 243-248$. 
Spreen, O., \& Strauss, E. (1998). A compendium of neuropsychological tests: Administration, norms, and commentary (2nd ed.). New York, NY US: Oxford University Press.

Stage, F., Carter, H., \& Nora, A. (2004). Path Analysis: An Introduction and Analysis of a Decade of Research. Journal of Educational Research, 98(1), 5-12.

Stolberg, R., Clark, D., \& Bongar, B. (2002). Epidemiology, assessment, and management of suicide in depressed patients. Handbook of depression (pp. 581-601). New York, NY, US: Guilford Press.

Strong, D.R., Lejuez, C.W., Daughters, S., Marinello, M., Kahler, C.W., \& Brown, R.A. (2003). The Computerized Mirror Tracing Task, Version 1. Unpublished manual.

Stroop, J.R. (1935). Studies of interference in serial verbal reactions. Journal of Experimental Psychology, 28, 643-662.

Tabachnick, B. G., \& Fidell, L. S. (2001). Using Multivariate Statistics (4th ed.). Needham Heights, MA: Allyn and Bacon.

Tabachnick, B., \& Fidell, L. (2007). Using multivariate statistics (5th ed.). Boston, MA: Allyn \& Bacon/Pearson Education.

Thoits, P. (1985). Self-labeling processes in mental illness: The role of emotional deviance. American Journal of Sociology, 91(2), 221-249.

Thompson, R. (1994). Emotion regulation: A theme in search of definition. Monographs of the Society for Research in Child Development, 59(2), 25. 
van Mourik, R., Oosterlaan, J., \& Sergeant, J. (2005). The Stroop revisited: A metaanalysis of interference control in AD/HD. Journal of Child Psychology and Psychiatry, 46(2), 150-165.

Verstraeten, K., Vasey, M., Raes, F., \& Bijttebier, P. (2009). Temperament and risk for depressive symptoms in adolescence: Mediation by rumination and moderation by effortful control. Journal of Abnormal Child Psychology: An official publication of the International Society for Research in Child and Adolescent Psychopathology, 37(3), 349-361.

Walcott, C., \& Landau, S. (2004). The Relation Between Disinhibition and Emotion Regulation in Boys with Attention Deficit Hyperactivity Disorder. Journal of Clinical Child and Adolescent Psychology, 33(4), 772-782.

Waller, G., Corstorphine, E., \& Mountford, V. (2007). The role of emotional abuse in the eating disorders: Implications for treatment. Eating Disorders: The Journal of Treatment \& Prevention, 15(4), 317-331.

Watson, D., Clark, L., \& Tellegen, A. (1988). Development and validation of brief measures of positive and negative affect: The PANAS scales. Journal of Personality and Social Psychology, 54(6), 1063-1070.

Watson, D., Kotov, R., \& Gamez, W. (in press). Basic dimensions of temperament in relation to personality and psychopathology. In R.F. Krueger \& J. Tackett (Eds.), Personality and psychopathology. New York: Guilford Press.

Wechsler, D. (1991). Wechsler Intelligence Scale for Children - Third Edition: Manual. San Antonio: The Psychological Corporation. 
Weis, R., \& Smenner, L. (2007). Construct validity of the Behavioral Assessment System for Children (BASC) Self-report of personality. Journal of Psychoeducational Assessment, 25(2), 111-126.

Weissman, M., Wolk, S., Wickramaratne, P., Goldstein, R., Adams, P., Greenwald, S., et al. (1999). Children with prepubertal-onset major depressive disorder and anxiety grown up. Archives of General Psychiatry, 56(9), 794-801.

Weller, E.B., Weller, R.A., \& Svadjian, H. (1996). Mood disorders. In: Lewis, M., (Ed). Child and Adolescent Psychiatry: A comprehensive textbook. Baltimore: Williams \& Wilkins, pp. 650-5.

Zeman, J., Shipman, K., \& Suveg, C. (2002). Anger and sadness regulation: Predictions to internalizing and externalizing symptoms in children. Journal of Clinical Child and Adolescent Psychology, 31(3), 393-398. 